ANL-99/14

\author{
ARGONNE NATIONAL LABORATORY \\ 9700 South Cass Avenue \\ Argonne, IL 60439-4837
}

EVALUATION OF AN ALKALINE-SIDE SOLVENT EXTRACTION PROCESS FOR CESIUM REMOVAL FROM SRS TANK WASTE USING LABORATORYSCALE CENTRIFUGAL CONTACTORS

by

R. A. Leonard, C. Conner, M. W. Liberatore, J. Sedlet, S. B. Aase, and G. F. Vandegrift

Chemical Technology Division

August 1999 


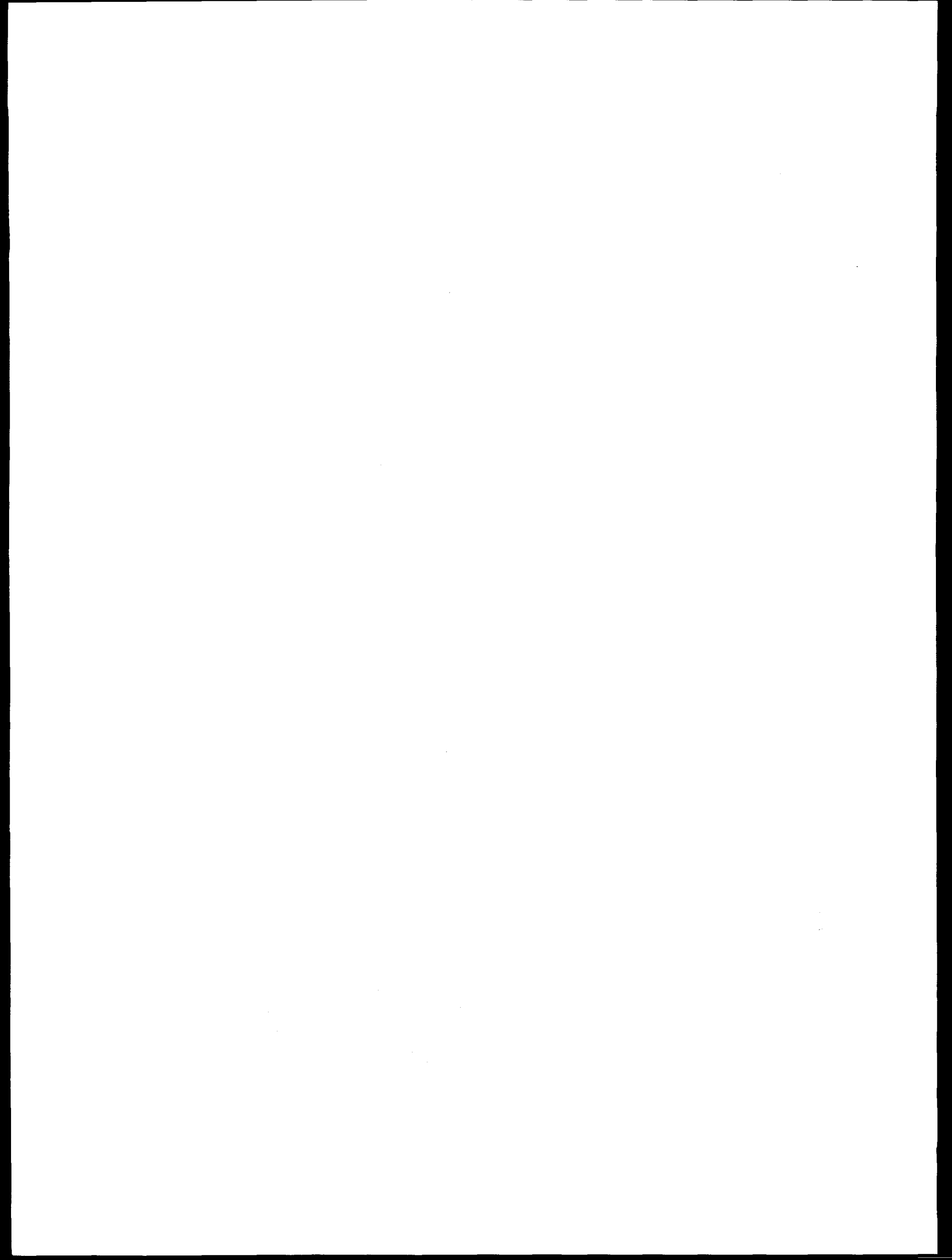




\section{DISCLAIMER}

This report was prepared as an account of work sponsored by an agency of the United States Government. Neither the United States Government nor any agency thereof, nor any of their employees, make any warranty, express or implied, or assumes any legal liability or responsibility for the accuracy, completeness, or usefulness of any information, apparatus, product, or process disclosed, or represents that its use would not infringe privately owned rights. Reference herein to any specific commercial product, process, or service by trade name, trademark, manufacturer, or otherwise does not necessarily constitute or imply its endorsement, recommendation, or favoring by the United States Government or any agency thereof. The views and opinions of authors expressed herein do not necessarily state or reflect those of the United States Government or any agency thereof. 


\section{DISCLAIMER}

Portions of this document may be illegible in electronic image products. Images are produced from the best available original document. 


\section{TABLE OF CONTENTS}

$\underline{\text { Page }}$

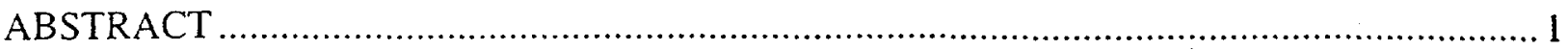

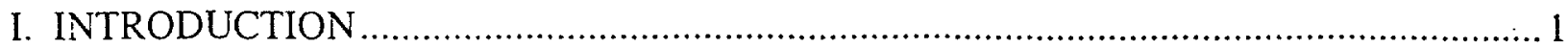

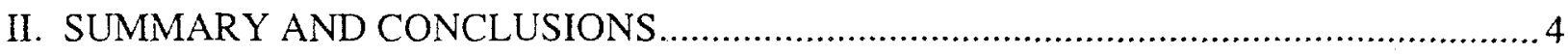

III. PRELIMINARY TEST WITH MULTISTAGE CONTACTOR .................................. 5

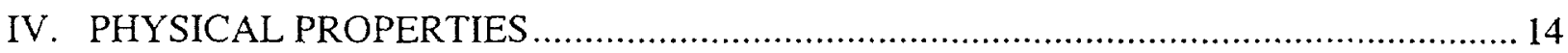

A. Density and Viscosity .................................................................. 14

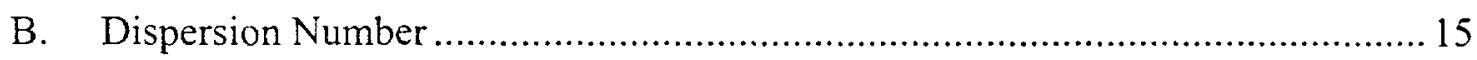

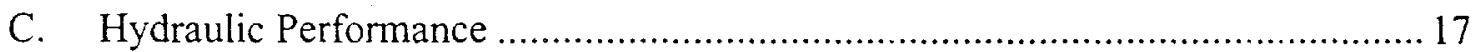

V. TESTS WITH SINGLE AND MULTISTAGE CONTACTORS ................................. 19

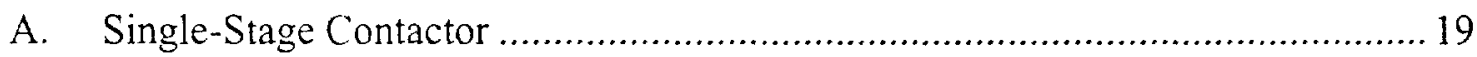

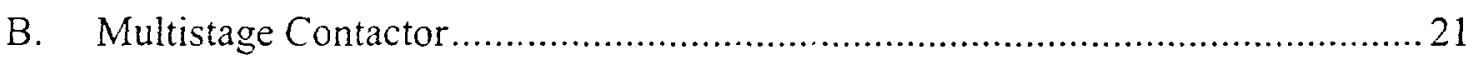

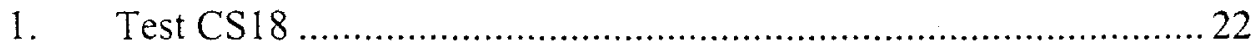

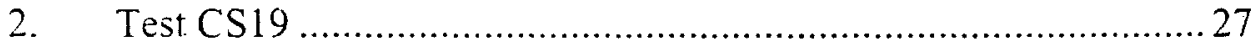

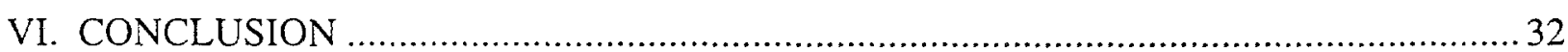

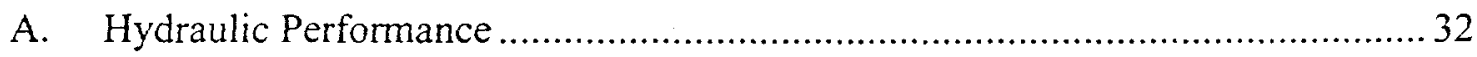

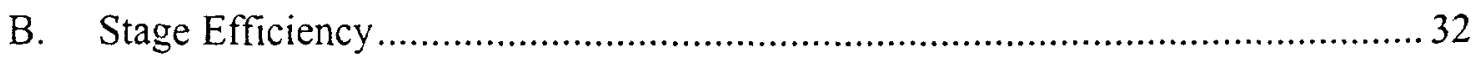

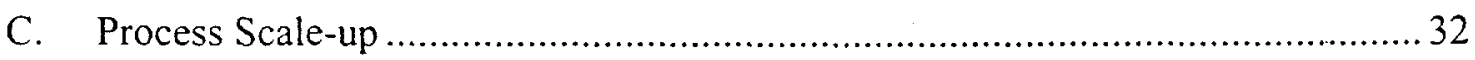

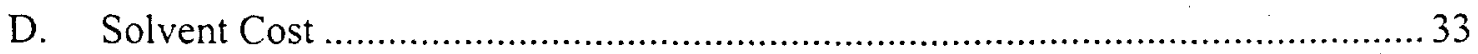

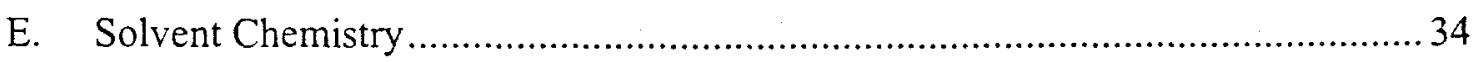

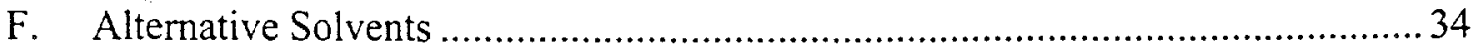

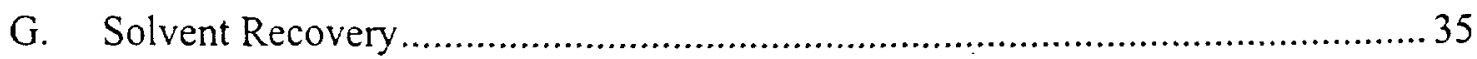

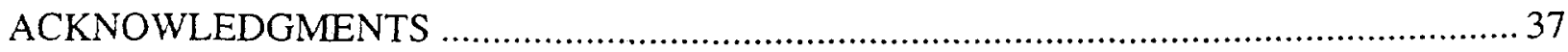


TABLE OF CONTENTS (contd)

$\underline{\text { Page }}$

APPENDIX A. Discussion of Cesium Distribution Ratio Data Measured at ANL ..................... 38

APPENDIX B. Cesium Distribution Ratios Measured at ANL ………………………….......4

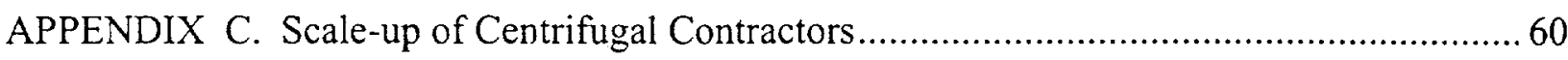

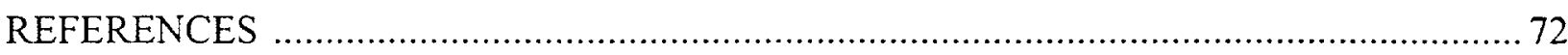




\section{LIST OF FIGURES}

No.

Title

Page

1. Multistage 2-cm Contactor Used for the Alkaline-Side CSEX Tests. 2

2. Structure of the BoBCalixC6 Extractant. 3

3. Structure of the Cs-3 Modifier 3

4. Flowsheet for Test CS2 6

5. Cesium Concentration in Aqueous (DW) Raffinate as a Function of Time for Test CS2 ...... 10

6. Cesium Concentration in Aqueous (EW) Strip as a Function of Time for Test CS2 11

7. Cesium Concentration in Organic (EP) Product as a Function of Time for Test CS2 11

8. Concentration Profile for Cs in Test CS2 12

9. Cesium Distribution Ratio for Each Stage at the End of Test CS2 13

10. Flowsheet for Tests CS18 and CS19 21

11. Cesium Concentration in Aqueous (DW) Raffinate as a Function of Time for Test $\mathrm{CS} 18$ 23

12. Cesium Concentration in Aqueous (EW) Strip as a Function of Time for Test CS18..........23

13. Cesium Concentration in Organic (EP) Product as a Function of Time for Test CS18.........24

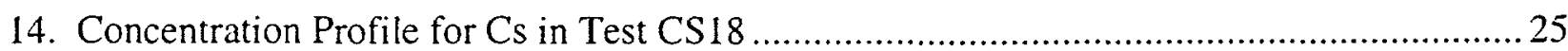

15. Cesium Distribution Ratios for Each Stage at the End of Test CS18 .............................26

16. Cesium Concentration in Aqueous (DW) Raffinate as a Function of Time for Test $\operatorname{CS} 19$

17. Cesium Concentration in Aqueous (EW) Strip as a Function of Time for Test CS19.......... 28

18. Cesium Concentration in Aqueous (FW) Rinse as a Function of Time for Test CS19 ........29

19. Cesium Concentration in Organic (EP) Product as a Function of Time for Test CS19 ........29 
No.

20. Concentration Profile for Cs in Test CS19 30

21. Cesium Distribution Ratios for Each Stage at the End of Test CS19. 31

A-1. Effect of Temperature on $\mathrm{D}_{\mathrm{Cs}}$ for CSEX Solvent and in Aqueous Phase of $1 \underline{\mathrm{M}}$ $\mathrm{NaNO}_{3}$ and $0.02 \underline{\mathrm{M} \mathrm{NaOH}}$.

A-2. Effect of Temperature on $\mathrm{D}_{\mathrm{Cs}}$ for CSEX Solvent under Stripping Conditions of $0.0005 \underline{\mathrm{M}} \mathrm{HNO}_{3}$ and $0.0001 \underline{\mathrm{M} C s N O}{ }_{3}$. 40

C-1. Correlation of Extraction Efficiency with O/A Flow Ratio in Single-Stage 2-cm Contactors 64

C-2. Correlation of Extraction Efficiency with O/A Flow Ratio in Multistage 2-cm Contactors. 68 


\section{LIST OF TABLES}

No.

Title

Page

1. SRS\#2 Simulant Composition for the DF Feed of Test CS2 …................................ 7

2. Cesium Distribution Ratios for Various Sections of Multistage Tests ............................. 8

3. Flow Rates for Feeds and Effluents in Multistage Tests ........................................

4. Steady-State Cs Concentrations in Effluents of Multistage Tests .................................. 10

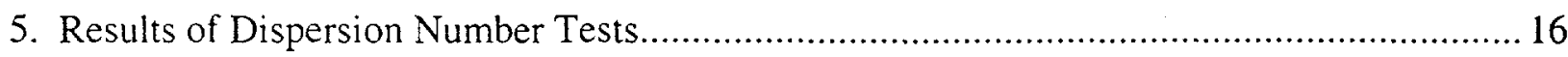

6. Results of Hydraulic Performance Tests in Single-Stage 2-cm Contactor ...................... 18

7. Results of Single-Stage Extraction Efficiency Tests ............................................. 20

8. Composition of SRS\#4 Simulant for the DF Feed in Tests CS 18 and CS $19 \ldots \ldots \ldots \ldots \ldots \ldots . . . . . . .22$

B-1. Cesium Distribution Ratio between CSEX Solvent and $1 \underline{\mathrm{M}} \mathrm{NaNO}_{3} \ldots \ldots \ldots \ldots \ldots \ldots \ldots . \ldots 43$

B-2. Cesium Distribution Ratio between CSEX Solvent and Dilute Acid or Base............. 44

B-3. Cesium Distribution Ratio between CSEX Solvent and $1 \underline{\mathrm{M}} \mathrm{NaNO}_{3}$ with $0.01 \underline{\mathrm{M}} \mathrm{HNO}_{3}$

B-4. Cesium Distribution Ratio between CSEX Solvent and $1 \underline{\mathrm{M}} \mathrm{NaNO}_{3}$ with $0.01 \mathrm{M} \mathrm{NaOH}$.

B-5. Effect of Temperature on $\mathrm{D}_{\mathrm{Cs}}$ between CSEX Solvent and Salt Solutions ................47

B-6. Effect of Temperature on $\mathrm{D}_{\mathrm{Cs}}$ between CSEX Solvent and Dilute Acid or Base ......... 47

B-7. Cesium Distribution Ratio for CSEX Solvent Used in Test CS2 ........................... 48

B-8. Cesium Distribution Ratio for CSEX Solvent Used in Tests CS18 and CS19............. 48

B-9. Cesium Distribution Ratio for CSEX Solvent Prepared at ORNL ........................ 49

B-10. Cesium Distribution Ratio for CSEX Solvent and 0.001 $\underline{\mathrm{M} \mathrm{NaOH}}$........................49

B-11. Cesium Distribution Ratio for CSEX Solvent and 0.001 $\underline{\mathrm{M}} \mathrm{HNO}_{3} \ldots \ldots \ldots \ldots \ldots \ldots \ldots . . . . . . . . . .50$ 


\section{LIST OF TABLES (contd)}

No.

B-12. Cesium Distribution Ratio for Consecutive Contacts of Fresh Solvent at $19^{\circ} \mathrm{C}$

B-13. Cesium Distribution Ratio for Consecutive Contacts of Fresh Solvent at $25^{\circ} \mathrm{C}$ with O/A Volume Ratio of 1.0

B-14. Cesium Distribution Ratio for Consecutive Contacts of Fresh Solvent at $25^{\circ} \mathrm{C}$ with Typical O/A Volume Ratios

B-15. Cesium Distribution Ratio for Consecutive Contacts of Fresh Solvent at $25^{\circ} \mathrm{C}$ at $\mathrm{O} / \mathrm{A}=1.0$ Using Contact with Stainless Steel

B-16. Cesium Distribution Ratio for Consecutive Contacts of Fresh Solvent at $25^{\circ} \mathrm{C}$ at $\mathrm{O} / \mathrm{A}=1.0$ Using Contact with Teflon PFA Tubing

B-17. Cesium Distribution Ratio for Consecutive Contacts of Fresh Solvent at Selected Temperatures

B-18. Cesium Distribution Ratio for Consecutive Contacts of Fresh Solvent with 0.001 M Triisooctyl Amine

B-19. Cesium Distribution Ratio for Consecutive Contacts of Fresh Solvent with 0.0001 M Triisooctyl Amine 58

B-20. Effect of Temperature and Scrub Solution on $\mathrm{D}_{\mathrm{Cs}}$ for Extraction 59

C-1. Summary of Extraction Efficiency in Single-Stage Centrifugal Contactor Tests 61

C-2. Effect of O/A Flow Ratio on Extraction Efficiency in Single-Stage 2-cm Contactors

C-3. Summary of Extraction Efficiency in Multistage Centrifugal Contactors .65

C-4. Effect of O/A Flow Ratio on Extraction Efficiency in Multistage 2-cm Contactors 67

C-5. Estimate of Weber Number for Interstage Flow in Various Centrifugal Contactors 70 


\title{
EVALUATION OF AN ALKALINE-SIDE SOLVENT EXTRACTION PROCESS FOR CESIUM REMOVAL FROM SRS TANK WASTE USING LABORATORY- SCALE CENTRIFUGAL CONTACTORS
}

\author{
by
}

\author{
R. A. Leonard, C. Conner, M. W. Liberatore, J. Sedlet, S. B. Aase, and G. F. Vandegrift
}

\begin{abstract}
An alkaline-side solvent extraction process for cesium removal from Savannah River Site (SRS) tank waste was evaluated experimentally using a laboratory-scale centrifugal contactor. Single-stage and multistage tests were conducted with this contactor to determine hydraulic performance, stage efficiency, and general operability of the process flowsheet. The results and conclusions of these tests are reported along with those from various supporting tests. Also discussed is the ability to scale-up from laboratory- to plant-scale operation when centrifugal contactors are used to carry out the solvent extraction process. While some problems were encountered, a promising solution for each problem has been identified. Overall, this alkaline-side cesium extraction process appears to be an excellent candidate for removing cesium from SRS tank waste.
\end{abstract}

\section{INTRODUCTION}

The Savannah River Site (SRS) currently has a large quantity of high-level waste solutions stored in underground tanks. An alkaline-side solvent extraction process for cesium removal from this waste was developed at Oak Ridge National Laboratory (ORNL). The cesium in the SRS waste is about $30 \%{ }^{137} \mathrm{Cs}$. The process can separate and concentrate the cesium from the waste and has the potential to replace the existing in-tank precipitation (ITP) process. At Argonne National Laboratory (ANL), we have worked closely with ORNL and SRS personnel to take this alkaline-side cesium extraction (CSEX) process from the test-tube stage to a plant-scale process. The key to scale up is first developing and testing process flowsheets in a multistage $2-\mathrm{cm}$ centrifugal contactor. The 2-cm contactor used has been described earlier [LEONARD-1997]. Multistage tests using radioactive ${ }^{137} \mathrm{Cs}$ were completed in the glovebox shown in Fig. 1. Further information about centrifugal contactors and the advantages that they bring to solvent extraction processes can be found in [BEBBINGTON, BERNSTEIN-1973A, BERNSTEIN-1973B, LEONARD-1980, WEBSTER]. 


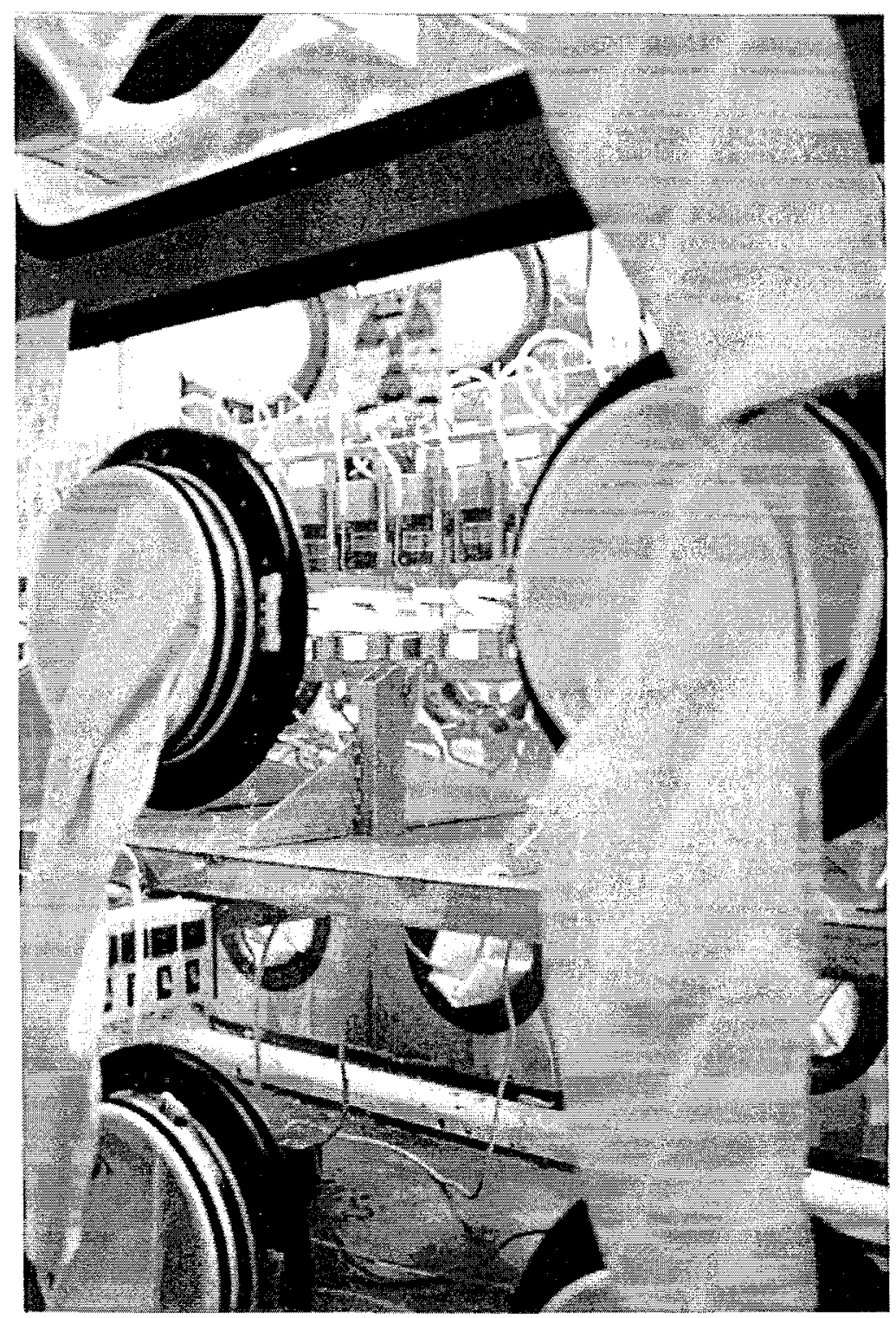

Fig. 1. Multistage 2-cm Contactor Used for the Alkaline-Side CSEX Tests

The extractant for the alkaline-side CSEX solvent is a calixarene crown, calix[4]arenebis(tert-octylbenzo-crown-6) designated BoBCalixC6 or Calix. The structure of BoBCalixC6, which has a molecular weight of $1149.52 \mathrm{~g} / \mathrm{mol}$, is shown in Fig. 2. The BoBCalixC6 was manufactured by IBC Advanced Technologies, Inc. (American Fork, UT) using a procedure developed at ORNL. Its purity is $>95 \%$. The solvent modifier is 1-(1,1,2,2-tetrafluoroethoxy)-3[4-(t-octyl)phenoxy]-2-propanol, designated Cs-3, an alkyl aryl polyether. The structure of Cs-3, which has a molecular weight of $380.43 \mathrm{~g} / \mathrm{mol}$, is shown in Fig. 3. The Cs-3 was developed and 
synthesized at ORNL. Its purity is $>98 \%$. The diluent, Isopar ${ }^{\circledR} \mathrm{L}$, is manufactured by Exxon Corp. (Houston, TX). It is composed largely of saturated paraffins with highly branched molecular structures that have an approximate boiling range from 188 to $207^{\circ} \mathrm{C}$. The CSEX

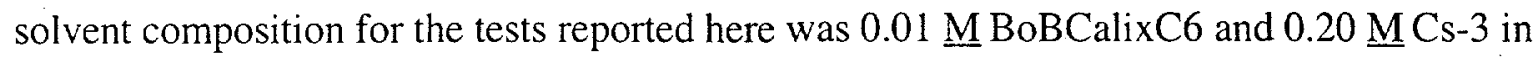
Isopar ${ }^{\circledR} \mathrm{L}$.

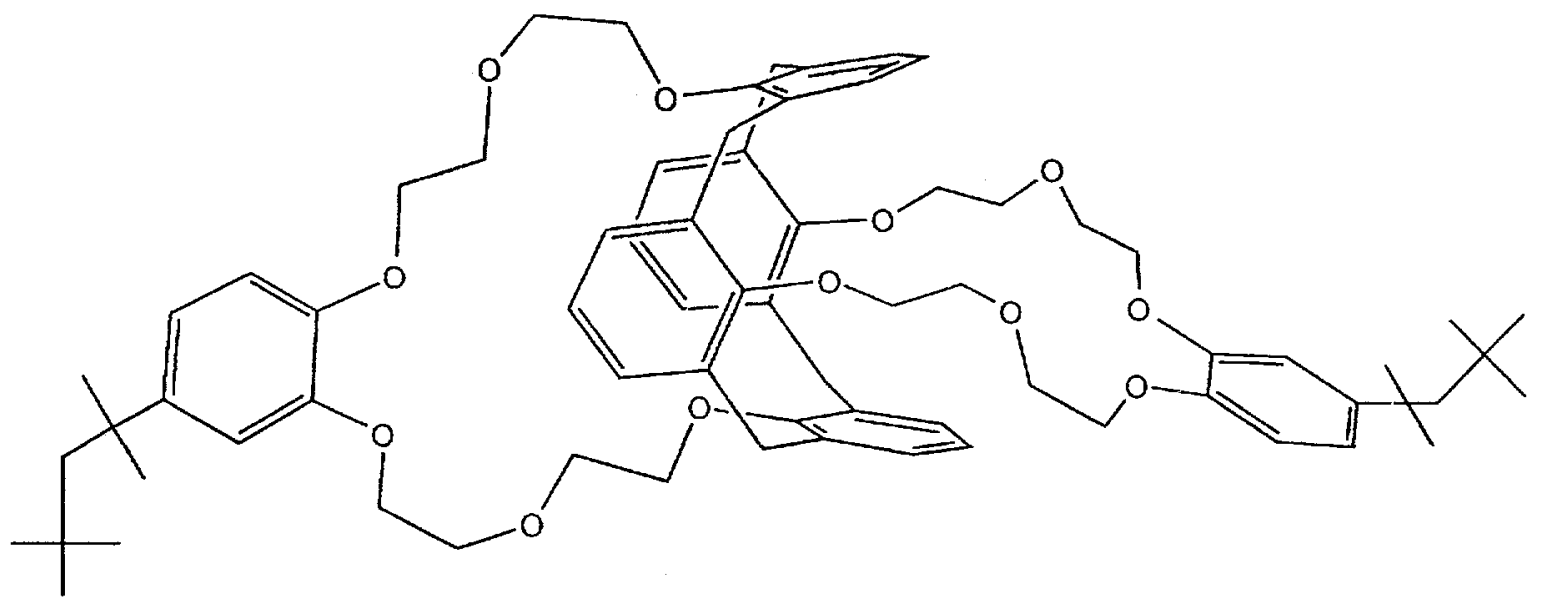

Fig. 2. Structure of the BoBCalixC6 Extractant

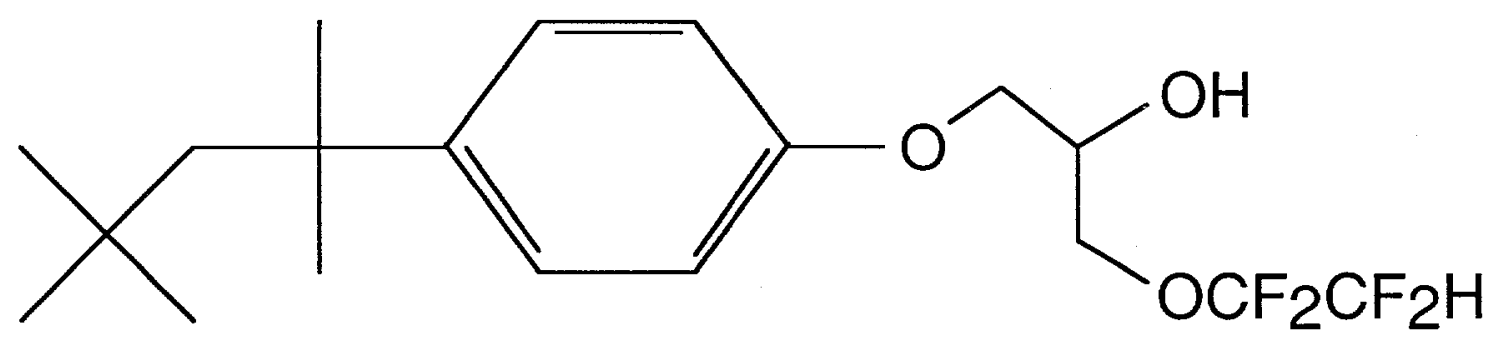

Fig. 3. Structure of the Cs-3 Modifier

The structure of this report follows roughly the sequence used to evaluate this alkaline-side CSEX process. First, based on test-tube results at ORNL, a flowsheet was designed and run in an 18-stage contactor (test CS2). This test showed that the process had potential but raised a number of questions regarding both the chemistry of the process and the operation of the contactor. The questions regarding process chemistry are discussed in detail elsewhere [BONNESEN]. However, questions regarding contactor operation are addressed in this report. Initial testing was done by (1) measuring selected physical properties of the liquids, (2) obtaining the dispersion number for the various sections of the process, (3) conducting single-stage contactor tests of hydraulic performance, and (4) carrying out single-stage contactor tests of extraction efficiency. Following this work, further testing was done using a 24-stage contactor. The first such test, CS18, had no solvent recycle. The second test, CS19, was identical to test CS18 except that it ran with full solvent recycle starting with the used solvent from test CS18. Finally, the results of the overall process evaluation were reviewed, including solvent recovery and ways to improve cesium 
removal from the solvent in the strip section of the alkaline-side CSEX process. Appendices $A$ and $B$ present and discuss the cesium distribution ratios $\left(D_{C s}\right)$ measured at $A N L$.

One of the features that makes the centrifugal contactor easy to use and to scale up is the rule-of-thumb that each stage can be designed to have essentially $100 \%$ stage efficiency whether it is used alone or in a multistage operation. A corollary rule-of-thumb is that each stage has the same hydraulic performance whether it is used alone or in a multistage operation. In Appendix C, this rule-of-thumb for stage efficiency is validated by analyzing the results from many single-stage and multistage extraction efficiency tests. The general validity of the corollary rule-of-thumb for hydraulic performance is also reviewed and confirmed.

\section{SUMMARY AND CONCLUSIONS}

Single-stage and multistage tests with the $2-\mathrm{cm}$ contactor were used to evaluate an alkalineside solvent extraction process for cesium removal from SRS tank waste. The results and conclusions can be summarized as follows.

1. Hydraulic performance of the alkaline-side cesium extraction (CSEX) process will be very good when it is carried out in multistage plant-scale $(25-\mathrm{cm})$ centrifugal contactors. Hydraulic problems seen during the tests reported here are related to the small size of the contactors used to make the laboratory tests and should not occur in larger units.

2. Extractive separation of cesium from the rest of the SRS tank waste performed about as expected based on (1) the characteristics of the $2-\mathrm{cm}$ contactor used in the test, $(2)$ a $\mathrm{D}_{\mathrm{Cs}}$ value of 8 for the extraction section, and (3) a $D_{C_{s}}$ value of 0.2 for the strip section. Thus, these $\mathrm{D}_{\mathrm{Cs}}$ values can be used as the basis for a plant-scale process. As noted in the discussion, work is being done at ORNL to achieve an even lower $\mathrm{D}_{\mathrm{Cs}}$ value for the strip section, in the range of 0.02 . No credit was taken for this potential solvent improvement in the plant-scale design reported here.

3. Based on the $D_{C S}$ values from these laboratory-scale tests, a plant-scale contactor would require 17 extraction stages and 17 strip stages to achieve a decontamination factor of 40,000 for the cesium. In this design, we used the SRS process requirements that (1) the feed flow rate from the SRS waste tanks will be $17.5 \mathrm{gpm}(66 \mathrm{~L} / \mathrm{min})$, and (2) the flow rate for the aqueous phase in the strip section will be $1.5 \mathrm{gpm}(5.7 \mathrm{~L} / \mathrm{min})$ so that the cesium is concentrated by a factor of 11.7 . When the aqueous strip effluent is $1.56 \mathrm{gpm}(5.9 \mathrm{~L} / \mathrm{min})$ or less, this cesium stream can go directly to the glass-plant melter. Thus, no evaporator will be required between the solvent extraction unit and the melter. Note that the cesium feed to the melter will be essentially free of the other components, which simplifies glass plant operation. With two additional stages for these two sections (for a conservative design), two scrub stages, two solvent recovery stages for the aqueous raffinate, two solvent recovery stages for the strip effluent, and 
two stages each for solvent cleanup and rinse (the need for these last few stages is still not certain), the plant-scale process would require 42 to 46 stages. For the process flow rates required at $S R S$, the rotor size of the plant-scale contactor would be $25 \mathrm{~cm}$.

4. The strip section of the multistage test performed as expected based on batch $\mathrm{D}_{\mathrm{Cs}}$ values measured at ANL. When the liquid from the strip stages was collected at the end of each multistage test and equilibrated, the $\mathrm{D}_{\mathrm{Cs}}$ values were found to be higher than expected based on the batch tests. In addition, the concentration of cesium in the organic effluent from the strip section of the multistage tests indicated a lower average $\mathrm{D}_{\mathrm{Cs}}$ value in the stripping section than was seen when the two liquids from the individual strip stages were equilibrated after the test. However, this apparent lower $\mathrm{D}_{\mathrm{Cs}}$ value for the overall operation of the stripping section during the multistage tests was still higher that the strip $D_{C s}$ values seen at ORNL. Continuing work at ORNL has now identified the reason for this discrepancy [MOYER] and, in addition, has found a solvent additive that will keep the $\mathrm{D}_{\mathrm{Cs}}$ value in the strip section low, in the range of 0.02 [BONNESEN].

5. The solvent can be recycled. In the tests reported here, the solvent continued to function well after being recycled four times.

6. Stage efficiencies in multistage plant-scale $(25-\mathrm{cm})$ contactors required for this process will be excellent, essentially $100 \%$. This will make process scale-up easy as each contactor stage will be one theoretical stage.

Overall, the design $\mathrm{D}_{\mathrm{Cs}}$ values of 8 for the extraction section and 0.2 for the strip section seem to be realistic. As the process temperature rises or falls, these values will go up or down together. Since it is planned to have the same number of extraction and scrub stages, and since the tank-waste feed (DF) and the strip feed (EF) flow rates will be kept constant, the solvent flow rate (DX) will be adjusted, either down (if the temperature rises) or up (if the temperature falls), to maintain an appropriate balance between the decontamination factor for the extraction and the stripping factor for the strip section. To reach the design decontamination factor of 40,000 , the process will need 17 extraction stages and 17 strip stages. If the $\mathrm{D}_{\mathrm{Cs}}$ value in the strip section can be reduced as suggested by the continuing work at ORNL [BONNESEN, MOYER], then the number of extraction and strip stages can also be reduced.

\section{PRELIMINARY TEST WITH MULTISTAGE CONTACTOR}

The first test with the multistage 2-cm centrifugal contactor (CS2), which was done on July 21,1998 , employed a configuration that also could be used in the 18-stage 25 -cm contactor that has been operating in F canyon at SRS since 1964. In this contactor, aqueous feed streams can enter at any stage, aqueous effluents can only be taken at the end of each bank of six contactors, that is, at stages 1,7 , and 13. The organic feed enters at stage 1 and exits at stage 18 . The actual feed points and the planned flow rates for this test are shown in Fig. 4. The DF feed 
was the SRS\#2 simulant, whose composition is given in Table 1, and reflects an estimate of the average composition for the alkaline-side tank waste at SRS. To this simulant ${ }^{137} \mathrm{Cs}$ was added as a radioactive tracer. In this way the concentration of Cs from the DF feed could be measured throughout the process. Since the small amount of Cs in the strip (EF) feed is natural (cold) cesium, it was not measured by this radiotracer technique. The Cs in the strip feed helped to strip the hot $\mathrm{Cs}$ in the solvent into the strip (EW) effluent. A discussion of the theory behind this coldcesium technique is given in [BONNESEN].

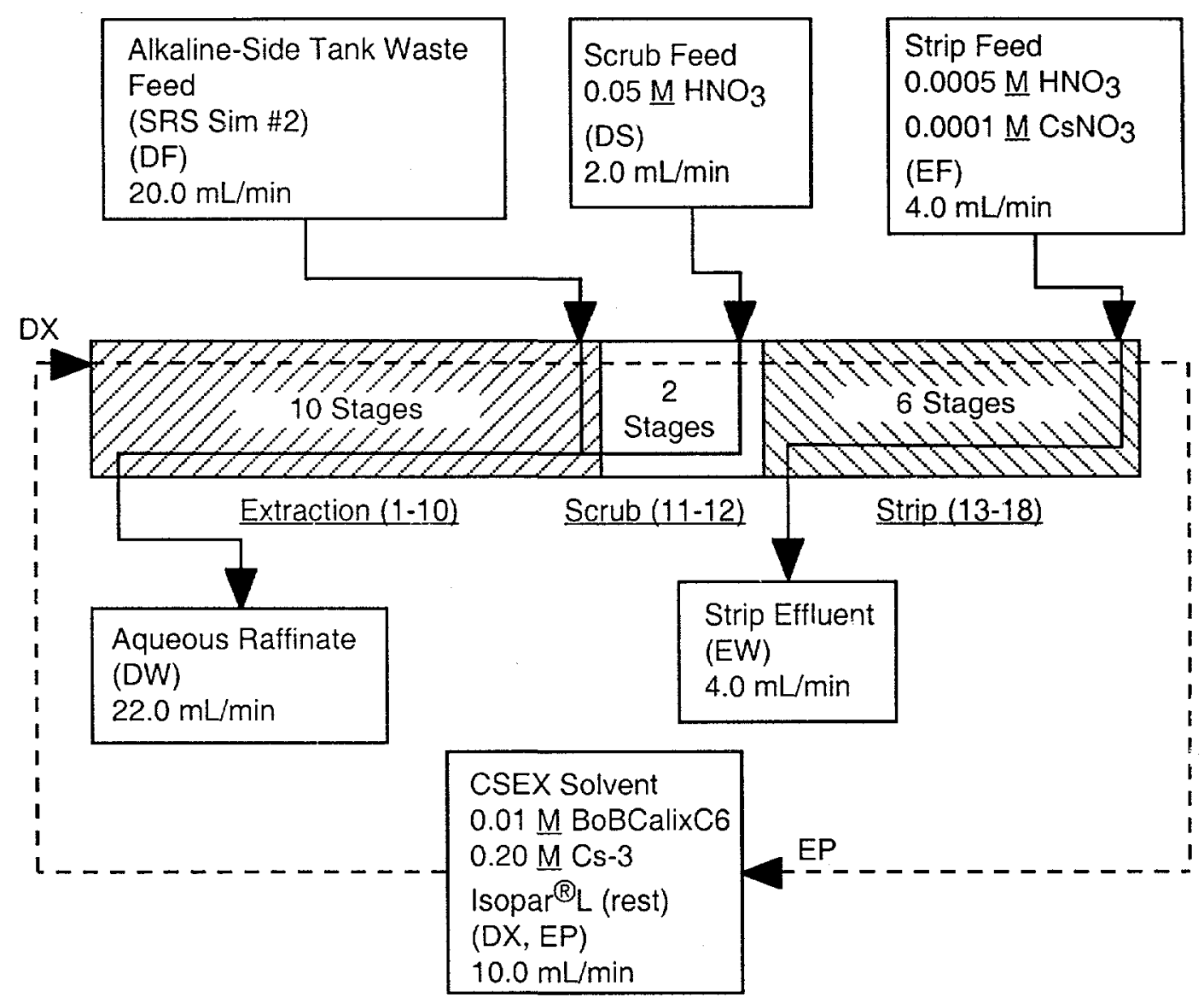

Fig. 4. Flowsheet for Test CS2

Using a simple model that assumes $100 \%$ stage efficiency and a constant distribution ratio for cesium $\left(D_{C s}\right)$ for each section of the process [LEONARD-1999A], the desired decontamination factor (D.F.) of 40,000 for cesium can be reached with the flows shown in Fig. 4 if $D_{C s}$ is 6.07 for the extraction section, $>0.2$ for the scrub section (to prevent $\mathrm{Cs}$ pinching there), and 0.071 for the strip section. Based on test-tube data from ORNL [BONNESEN], the expected $\mathrm{D}_{\mathrm{Cs}}$ value was 9.9 for the extraction section and 1.44 for the scrub section. As these $\mathrm{D}_{\mathrm{Cs}}$ values are higher than the $\mathrm{D}_{\mathrm{Cs}}$ values needed, the process D.F. can be achieved even if stage efficiencies are somewhat less than $100 \%$. The ORNL values for the strip section caused more concern. Without $\mathrm{CsNO}_{3}$ in the strip (EF) feed, the first three batch strips gave $D_{C s}$ values of $0.034,0.182$, and 1.06 . When $0.0001 \mathrm{M} \mathrm{CsNO}_{3}$ was added to the strip (EF) feed, the next two batch strips gave $\mathrm{D}_{\mathrm{Cs}}$ values of 
0.038 and 0.088 . Further batch strips could not be carried out because the ${ }^{137} \mathrm{Cs}$ concentration was too low to be measured. If the $\mathrm{D}_{\mathrm{Cs}}$ values in the contactor stages are in the range of the two low ones seen at ORNL, the process will work well. However, if the $\mathrm{D}_{\mathrm{Cs}}$ values in the contactor stages increase with each successive strip, as is also suggested by the ORNL data, the strip section will not work well. As these batch tests were not full countercurrent tests, we did not have an exact duplication of the contactor test. Thus, to be sure that we could separate the effects in the extraction section from those in the strip section, the process solvent was not recycled as shown in Fig 4.

Table 1. SRS\#2 Simulant Composition for the DF Feed of Test CS2

\begin{tabular}{|c|c|c|}
\hline Ionic Species & Conc, $\underline{\mathrm{M}}$ & Notes \\
\hline $\mathrm{Na}^{+}$ & 7 & \\
\hline $\mathrm{Al}^{3+}$ & 0.40 & \\
\hline $\mathrm{K}^{+}$ & 0.02 & \\
\hline $\mathrm{Cs}^{+}$ & 0.0007 & Cold Cs \\
\hline $\mathrm{Cs}^{+}-137$ & $4 \mathrm{E}-08$ & Approximate conc. \\
\hline $\mathrm{OH}^{-}$(total) & 3.5 & $\mathrm{OH}^{-}$added \\
\hline $\mathrm{OH}^{-}(\mathrm{free})$ & 1.9 & $\mathrm{OH}^{-}$unreacted \\
\hline $\mathrm{NO}_{3}^{-}$ & 2.7 & \\
\hline $\mathrm{NO}_{2}^{-}$ & 1 & \\
\hline $\mathrm{SO}_{4}{ }^{2-}$ & 0.22 & \\
\hline $\mathrm{CO}_{3}^{2-}$ & 0.20 & \\
\hline $\mathrm{Cl}^{-}$ & 0.10 & \\
\hline $\mathrm{F}^{-}$ & 0.05 & \\
\hline $\mathrm{CrO}_{+}^{2-}$ & 0.015 & \\
\hline
\end{tabular}

After test CS2, batch tests were performed to determine $\mathrm{D}_{\mathrm{Cs}}$ in the extraction, scrub, and strip sections during the test. These results, given in Table 2 , were obtained at $25^{\circ} \mathrm{C}$. The temperature of each section of multistage test CS2 is also shown in this table. To convert each batch $\mathrm{D}_{\mathrm{Cs}}$ value to its value at the test temperature, the effect of temperature on the $\mathrm{D}_{\mathrm{Cs}}$ was determined. The results show that the change in $\mathrm{D}_{\mathrm{Cs}}$ with temperature can be calculated using

$$
\mathrm{D}_{2}=\mathrm{D}_{1} \operatorname{EXP}\left\{\mathrm{a}\left(\mathrm{T}_{2}-\mathrm{T}_{1}\right) /\left[\left(\mathrm{T}_{2}+\mathrm{b}\right)\left(\mathrm{T}_{1}+\mathrm{b}\right)\right]\right\}
$$

where $\mathrm{D}_{1}$ is $\mathrm{D}_{\mathrm{Cs}}$ at temperature $\mathrm{T}_{1}, \mathrm{D}_{2}$ is $\mathrm{D}_{\mathrm{Cs}}$ at temperature $\mathrm{T}_{2}$, $\mathrm{a}$ is $10,200 \mathrm{~K}$, and $\mathrm{b}$ is the constant, 273.15 , that converts temperatures $T_{1}$ and $T_{2}$ from ${ }^{\circ} \mathrm{C}$ to $\mathrm{K}$. This equation is used to calculate the batch $\mathrm{D}_{\mathrm{Cs}}$ values at the test temperature for each section. From these results, we concluded that $\mathrm{D}_{\mathrm{Cs}}$ was (1) about as expected for the extraction section, (2) lower than expected for the scrub section but still much higher than required, and (3) too high for the required operation of the strip section (given the flow conditions of the test and the desired D.F. for the extraction section). 
Table 2. Cesium Distribution Ratios for Various Sections of Multistage Tests

\begin{tabular}{|c|c|c|c|c|c|c|}
\hline Test No. & Section & $\begin{array}{c}\text { Temp. } T_{1} \text { Used } \\
\text { to Measure } D_{C} \\
\text { in Batch Tests, } \\
{ }^{\circ} \mathrm{C}\end{array}$ & $\begin{array}{c}\mathrm{D}_{\mathrm{Cs}} \text { Measured } \\
\text { in Batch Tests } \\
\text { at Temp. } \mathrm{T}_{1}\end{array}$ & $\begin{array}{l}\text { Temp. } \mathrm{T}_{2} \text { of } \\
\text { Section during } \\
\text { Multistage } \\
\text { Tests, }{ }^{\circ} \mathrm{C}\end{array}$ & $\begin{array}{l}\mathrm{D}_{\mathrm{Cs}} \text { Calc'd for Section } \\
\text { during Multistage Test } \\
\text { Based on Section Temp. } \\
\text { and Batch Test Value }\end{array}$ & Notes \\
\hline $\mathrm{CS} 2$ & Extraction & 25 & 8.8 & 23.5 & 10.49 & \\
\hline$"$ & Scrub & 25 & 0.70 & 21.4 & 1.07 & \\
\hline$"$ & Strip & 25 & 0.22 & 21.7 & 0.32 & \\
\hline CS 18 & Extraction & 19 & 16.5 & 22.1 & 11.45 & \\
\hline$"$ & Scrub & 19 & 1.3 & 21.7 & 0.94 & \\
\hline$"$ & Strip & 19 & 0.32 & 20.6 & 0.27 & \\
\hline CS 19 & Extraction & 19 & 16.5 & 24.9 & 8.24 & \\
\hline$n$ & Scrub & 19 & 1.3 & 21.2 & 1.00 & \\
\hline$"$ & Strip & 19 & 0.32 & 21.8 & 0.23 & $a$ \\
\hline
\end{tabular}

a. Used the same increase in the strip section temperature over the lab temperature as was used for test CS18, $1.7^{\circ} \mathrm{C}$. We could not determine the effluent temperature from the solvent in the effluent container, as it was heated to $22^{\circ} \mathrm{C}$ above the lab temperature. The solvent was heated by the stirring energy used to mix the solvent before being recycled it back to stage 1 .

The planned flow rates for each feed and effluent are shown in Fig. 4. The actual flow rates are given in Table 3 along with the measurement error, the actual organic-to-aqueous $(\mathrm{O} / \mathrm{A})$ flow ratio, and the material balance for the cesium. Also shown in Table 3 is the expected fractional stage efficiency, which was calculated using the $\mathrm{O} / \mathrm{A}$ flow ratio and a correlation for multistage 2-cm contactors given in Appendix C. As discussed there, this correlation is valid only for $2-\mathrm{cm}$ contactors that have liquid flows below 50 to $100 \mathrm{~mL} / \mathrm{min}$. For larger centrifugal contactors, which will have much higher flow rates, stage efficiencies will be higher, very close to $1.0(100 \%)$, so that no correlation of stage efficiency with $\mathrm{O} / \mathrm{A}$ flow ratio will be required. 
Table 3. Flow Rates for Feeds and Effluents in Multistage Tests

\begin{tabular}{|c|c|c|c|c|c|c|c|}
\hline Test & $\begin{array}{c}\text { Feed or } \\
\text { Effluent }\end{array}$ & $\begin{array}{c}\text { Measured } \\
\text { Flow Rate, } \\
\text { mL/min }\end{array}$ & $\begin{array}{c}\text { Flow Rate } \\
\text { Error, } \\
\mathrm{mL} / \mathrm{min}\end{array}$ & $\begin{array}{c}\text { Flow Rate } \\
\text { Error, \% }\end{array}$ & $\begin{array}{c}\text { Measured } \\
\text { O/A Flow } \\
\text { Ratio }\end{array}$ & $\begin{array}{c}\text { Fract. Stage } \\
\text { Effic. Based on } \\
\text { O/A Flow Ratio }\end{array}$ & $\begin{array}{c}\text { Amt of Entering } \\
\text { Cs Recovered for } \\
\text { each Test, \% }\end{array}$ \\
\hline CS2 & DF & 19.7 & 1.7 & 9 & - & - & 106 \\
\hline$"$ & DS & 2.3 & 0.4 & 17 & 4.13 & 0.716 & \\
\hline$"$ & DW & 22.0 & 1.7 & 8 & 0.432 & 0.750 & \\
\hline$"$ & EF,EW & 3.6 & 0.4 & 11 & 2.64 & 0.743 & \\
\hline$"$ & DX,EP & 9.5 & 0.6 & 6 & - & - & \\
\hline CS18 & DF & 25.34 & 2.5 & 10 & - & - & 118 \\
\hline$"$ & DS & 1.35 & 0.3 & 22 & 3.85 & 0.720 & \\
\hline$"$ & DW & 26.69 & 1.6 & 6 & 0.195 & 0.703 & \\
\hline$"$ & EF,EW & 2.2 & 0.3 & 14 & 2.36 & 0.749 & \\
\hline$"$ & DX,EP & 5.2 & 0.6 & 12 & - & - & \\
\hline CS19 & DF & 25.65 & 1.50 & 6 & - & - & 83 \\
\hline$"$ & DS & 1.40 & 0.25 & 18 & 4.93 & 0.706 & \\
\hline$"$ & DW & 27.05 & 2.69 & 10 & 0.255 & 0.719 & \\
\hline$"$ & EF,EW & 2.52 & 0.25 & 10 & 2.74 & 0.741 & \\
\hline$"$ & FF,FW & 7.06 & 0.08 & 1 & 0.977 & 0.799 & \\
\hline$"$ & DX,EP & 6.90 & 0.49 & 7 & -- & -- & \\
\hline
\end{tabular}

The steady-state cesium concentration for each effluent stream is given in Table 4. The cesium concentration is only that in the DF feed, which contains a ${ }^{137} \mathrm{Cs}$ tracer. The cesium from the EF strip feed has no ${ }^{137} \mathrm{Cs}$ tracer and, so, cannot be tracked by the ${ }^{137} \mathrm{Cs}$ tracer method. This table shows that (1) the cesium concentration in the DW raffinate was 1840 times less than that in the DF feed, and (2) the cesium concentration in the EP product is 46 times less than that in the DF feed. Figures 5, 6, and 7 show the cesium concentration in three effluents, DW, EW, and EP, respectively, over time. Figure 5 shows that DW was essentially at steady state. Fig. 6 shows that EW was also at steady state. Figure 7 shows that EP was not completely at steady state; the cesium concentration was still dropping. This finding means that, with respect to solvent stripping, process operation was continuing to improve even at the end of the test. 
Table 4. Steady-State Cs Concentrations in Effluents of Multistage Tests

\begin{tabular}{|c|c|c|c|c|c|c|}
\hline Test & Feed or Effluent & {$[\mathrm{Cs}], \underline{\mathrm{M}}$} & $\begin{array}{c}\text { Data } \\
\text { Points } \\
\text { Used }\end{array}$ & $\begin{array}{c}{[\mathrm{Cs} \text { in DF]/ }} \\
\text { [Cs in } \\
\text { Effluent }]\end{array}$ & $\begin{array}{c}{[\mathrm{Cs} \text { in }} \\
\text { Effluent }] / \mathrm{Cs} \\
\text { in DF }]\end{array}$ & Notes \\
\hline $\mathrm{CS} 2$ & $\mathrm{DF}$ & $7.00 \mathrm{E}-04$ & 1 & Not appl. & Not appl. & \\
\hline$"$ & DW & $3.80 \mathrm{E}-07$ & 1 & 1842 & $5.43 \mathrm{E}-04$ & \\
\hline$"$ & EW & $4.00 \mathrm{E}-03$ & 3 & 0.175 & 5.7 & $\mathrm{a}$ \\
\hline$"$ & $\mathrm{EP}$ & $1.53 \mathrm{E}-05$ & 2 & 45.8 & $2.19 \mathrm{E}-02$ & $a, b$ \\
\hline $\operatorname{CS} 18$ & DF & $2.70 \mathrm{E}-04$ & 1 & Not appl. & Not appl. & \\
\hline$"$ & DW & $9.73 \mathrm{E}-07$ & 1 & 277 & $3.60 \mathrm{E}-03$ & $b$ \\
\hline$"$ & EW & $3.52 \mathrm{E}-03$ & 3 & 0.077 & 13.0 & $\mathrm{a}$ \\
\hline$"$ & EP & $5.45 \mathrm{E}-05$ & 2 & 5.0 & $2.02 \mathrm{E}-01$ & $a, c$ \\
\hline $\operatorname{CS} 19$ & DF & $2.70 \mathrm{E}-04$ & 1 & Not appl. & Not appl. & \\
\hline$"$ & DW & $1.14 E-05$ & 1 & 24 & $4.22 \mathrm{E}-02$ & $a, d$ \\
\hline$"$ & EW & $2.03 E-03$ & $i$ & 0.133 & 7.5 & $a, b$ \\
\hline$"$ & $\mathrm{FW}$ & $2.05 \mathrm{E}-06$ & 1 & 131.7 & $7.59 \mathrm{E}-03$ & $a, d$ \\
\hline$"$ & $\mathrm{EP}$ & $4.36 \mathrm{E}-05$ & 4 & 6.2 & $1.61 \mathrm{E}-01$ & $\mathrm{a}$ \\
\hline
\end{tabular}

a. Concentration of $\mathrm{Cs}$ in this effluent is only that from the DF feed. The Cs from the EF strip feed is not tracked by the ${ }^{137} \mathrm{Cs}$ analysis used to measure Cs concentration.

b. Concentration still decreasing.

c. Concentration may still be increasing slightly.

d Concentration stili rising.

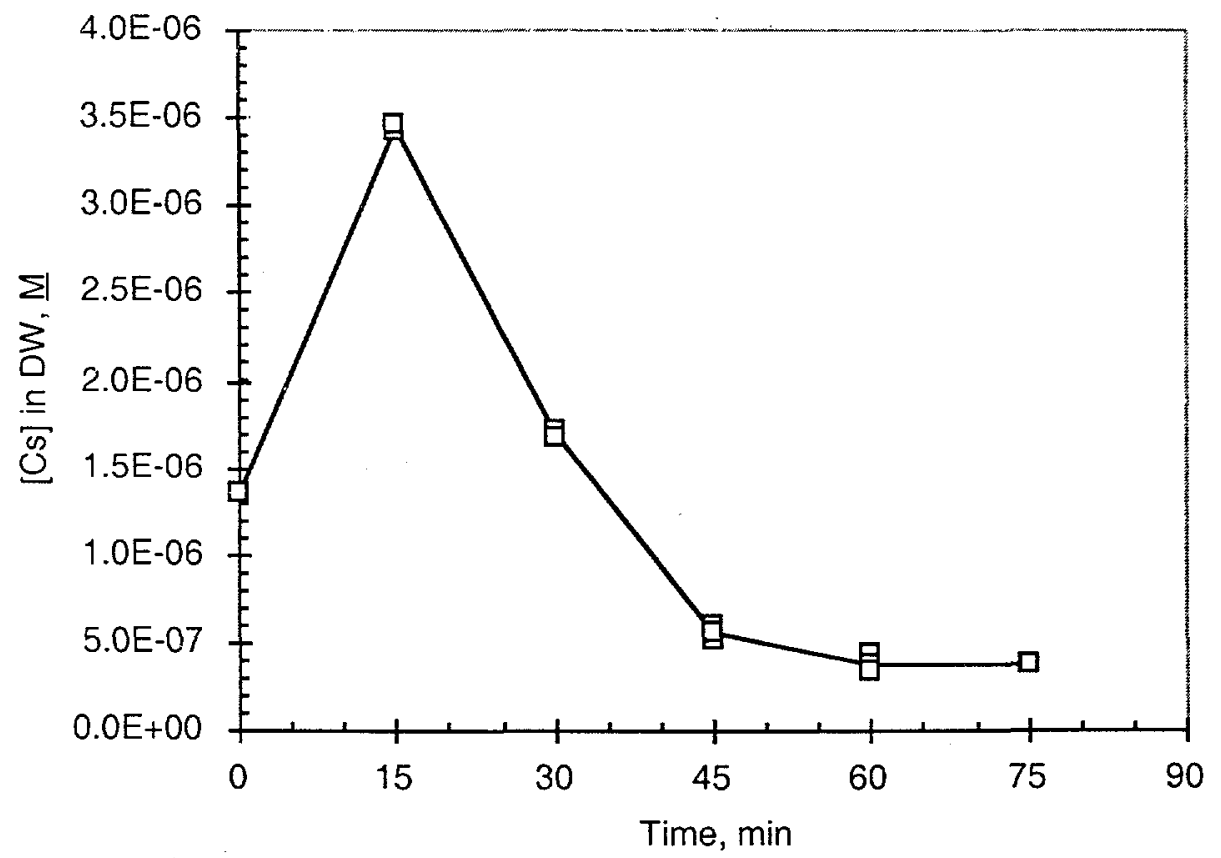

Fig. 5. Cesium Concentration in Aqueous (DW) Raffinate as a Function of Time for Test CS2 


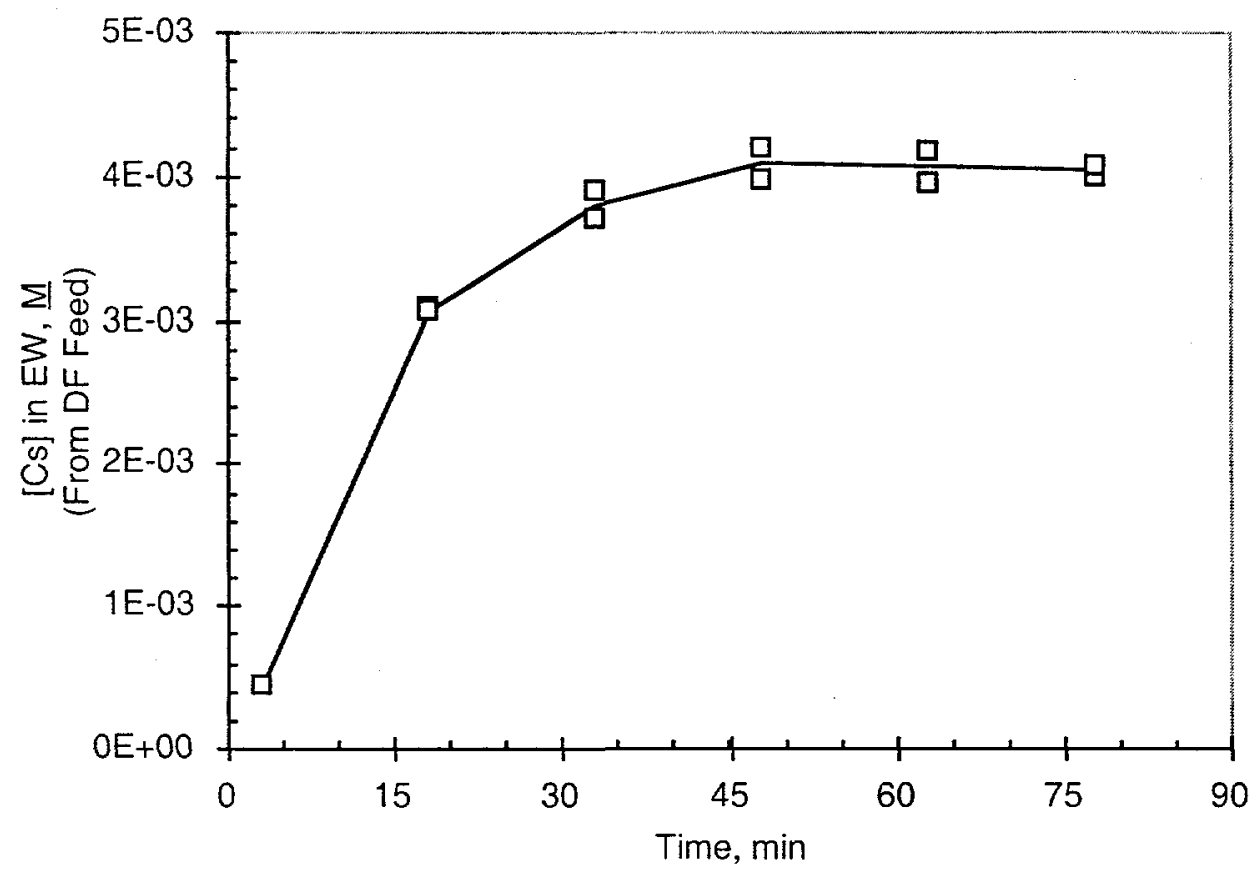

Fig. 6. Cesium Concentration in Aqueous (EW) Strip as a Function of Time for Test CS2

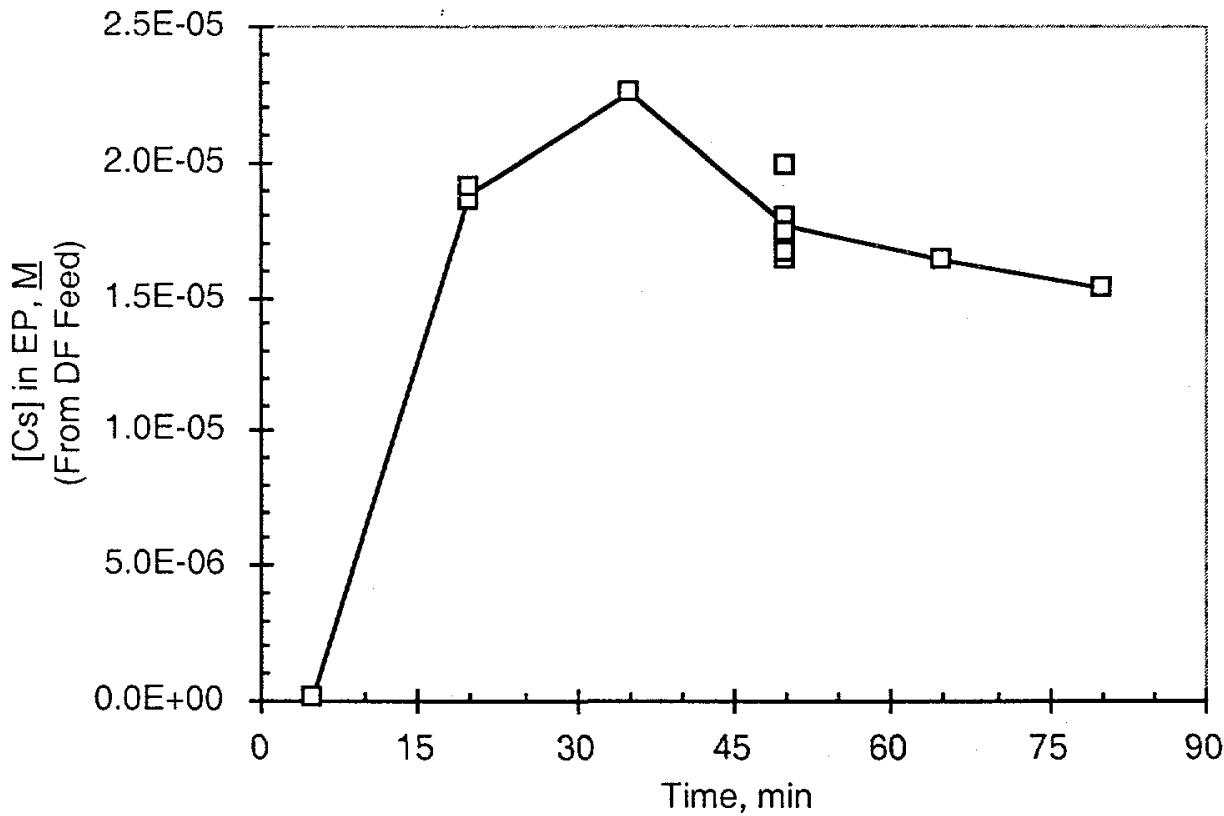

Fig. 7. Cesium Concentration in Organic (EP) Product as a Function of Time for Test CS2

The flowsheet for test CS2 was evaluated using the SASSE spreadsheet developed at ANL for modeling solvent extraction processes [LEONARD-1994]. To compare test CS2 with the calculations, both the model calculations (lines) and the experimental data (points) are plotted in Fig. 8. The solid experimental points are for effluent samples taken during the run and represent operating conditions that existed during the run. The open experimental points are for stage 
samples taken after the test and equilibrated and will not necessarily match the model exactly. If the fractional stage efficiency is decreased from the correlation value of 0.750 (see Table 3 ) to 0.707 , the model curve matches the observed DW raffinate concentration. The model curve shown in the extraction section of Fig. 8 is for a fractional stage efficiency in the extraction section of 0.707 . If the stage efficiency was 1.0 , the appropriate $\mathrm{D}_{\mathrm{Cs}}$ for the extraction section would have been 4.86. This is a very low value that is not supported by any batch test data at either ANL or ORNL or by the equilibrated stage samples after the test. Thus, the stage efficiency in the extraction section must have been significantly less than 1.0 and, in fact, close to the value predicted by the correlation in Appendix C.

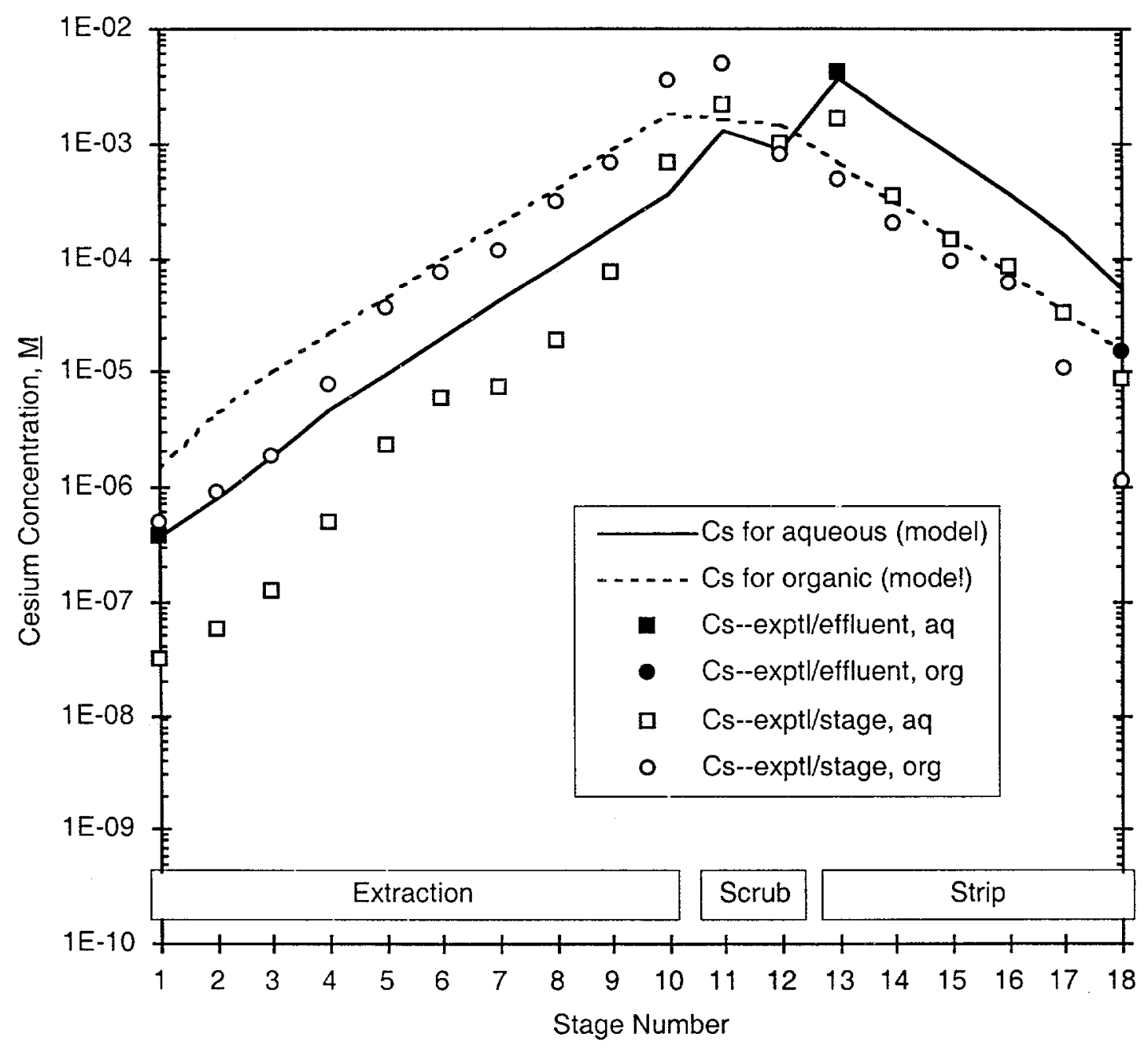

Fig. 8. Concentration Profile for Cs in Test CS2

Estimating the stage efficiency for the strip section from the experimental data is difficult because of the uncertainty in the $\mathrm{D}_{\mathrm{Cs}}$ value for the strip section. Using the correlation value of 0.743 for the fractional stage efficiency in the strip section (see Table 3 ), a $\mathrm{D}_{\mathrm{Cs}}$ value of 0.0878 is required to match the model curve with the EP effluent concentration. This is the model curve shown in the strip section of Fig. 8 . If the stage efficiency were 1.0 , the $\mathrm{D}_{\mathrm{Cs}}$ value required to 
match the EP effluent concentration would be higher, 0.1334 . This $\mathrm{D}_{\mathrm{Cs}}$ value is still lower than the 0.32 value expected based on the batch test results shown in Table 2. Thus, the operation of the stripping section during test CS2 was better than expected based on ANL batch tests. However, $\mathrm{D}_{\mathrm{Cs}}$ is more than expected based on ORNL batch tests with $\mathrm{Cs}$ in the strip feed, which gave $\mathrm{D}_{\mathrm{Cs}}$ values in batch stripping of 0.038 and 0.088 . When the two liquid phases in each stage were drained at the end of test CS2 and the phases equilibrated, the $\mathrm{D}_{\mathrm{Cs}}$ values in the strip section ranged from 0.13 to 0.6 (Fig. 9). These $\mathrm{D}_{\mathrm{Cs}}$ values are much higher than must have existed during test CS2. Because of these results, additional work was done at ORNL to understand the factors that control the $\mathrm{D}_{C s}$ value in the strip section [BONNESEN].

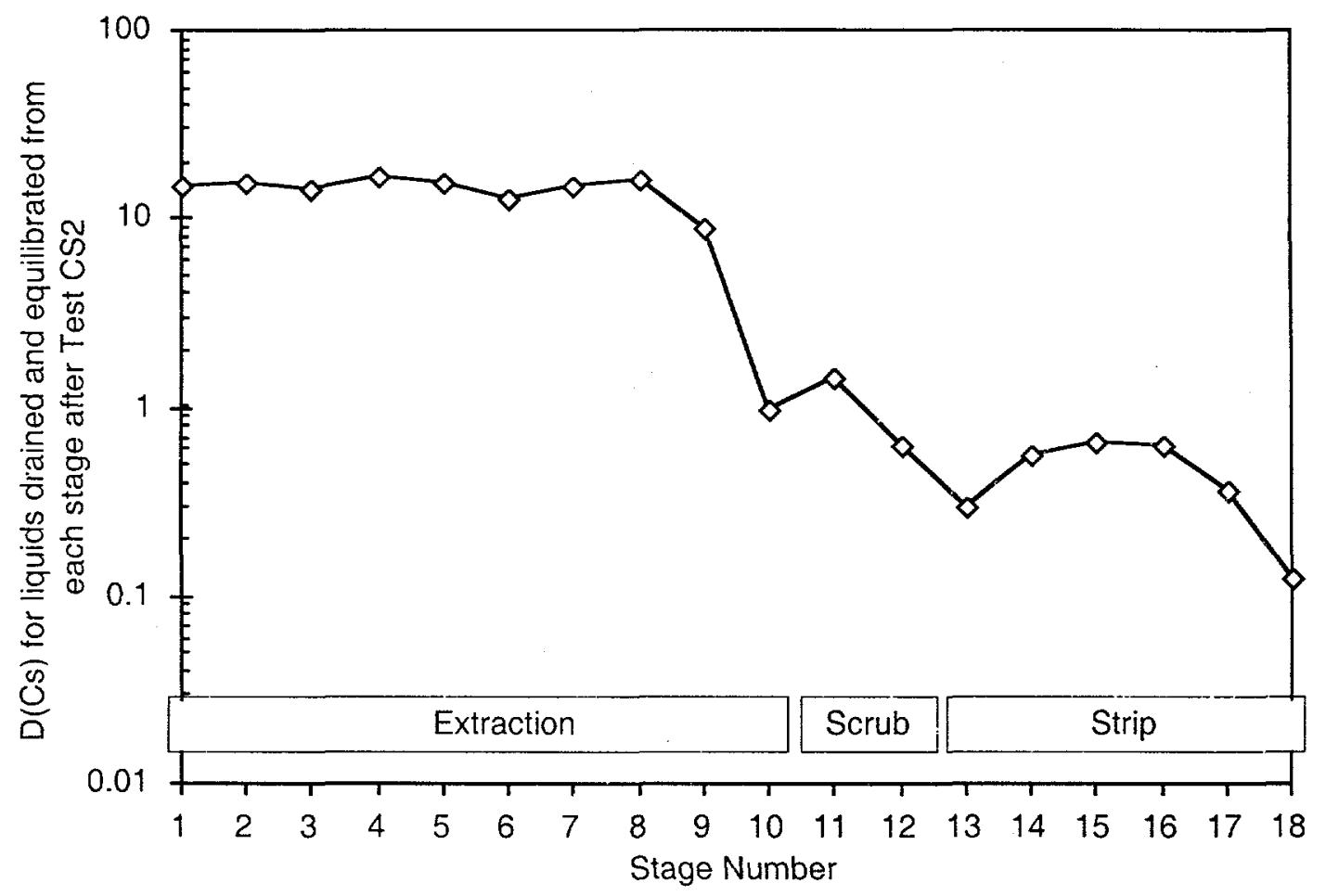

Fig. 9. Cesium Distribution Ratio for Each Stage at the End of Test CS2

Three hardware problems and one hydraulic-performance problem were observed during test CS2. The first hardware problem was with the rotor in stage 6 . As the contactor was being filled with aqueous phase, we observed the aqueous phase backing up into the interstage line to stage 6 ; as a result, we discovered rotor 6 was not turning. This rotor/motor assembly was replaced with the motor/rotor assembly from stage 21 , which was not being used. This problem did not affect the quality of the test. The second hardware problem was with the aqueous (DF) pump. It seized up just when organic phase, which was started after all aqueous flows were fully established and their effluents seen, had reached stage 13. The contactor was shut down, the pump was replaced, and the test resumed. The hydraulic-performance problem appeared when we were restarting the test. At that point, the interstage lines to stage 3 filled up, and some organic phase overflowed the standpipe at stage 1. This appeared to be a phase inversion problem, as is discussed below. Turning off the organic pump for a while seemed to solve the problem. 
However, we continued to see significant amount of aqueous phase flowing in organic interstage lines from stages 1-3 throughout the test. Thus, the operation of the extraction section is suspect. For the third hardware problem, the replacement DF pump quit sometime after the 75-min samples were taken. The test was stopped as soon as this problem was discovered. While we do not know exactly how long the pump was out of service, it could not have been any longer than 10 min. Thus, the stage-to-stage concentration profile in Fig. 9 is somewhat in doubt. It is probable that the $D_{C s}$ values in stages 9 and 10 , the two stages closest to the DF feed, are lower than the other extraction stages because of this pump failure.

After the test, a small amount of crud was observed, mainly in the liquid drained from stages 6 and 8 . X-ray diffraction (XRD) analysis indicates that this crud was amorphous. The crud was also analyzed by inductively coupled plasma-atomic emission spectroscopy (ICP-AES) and found not to contain any metals. When the crud was mixed with fresh DX and DF, $\mathrm{D}_{\mathrm{Cs}}$ for the extraction section appeared to increase slightly, from about 9.8 to 11.1. No crud or precipitate was found inside the stages when the rotors were removed.

Because of this crud, each of the 24 contactor stages was cleaned after test CS2. This included rinsing each rotor and each housing with first 2-ethyl hexanol, then ethanol, and finally water. In addition, the inlet and outlines lines to each housing and the liquid-level tubes for each stage were brushed out mechanically. While the contactor had been in use since 1993 and the stages had been cleaned by flushing with various liquids, the contactor had never been cleaned this thoroughly. Some crud was found in many tubes. The most crud was found in liquid-level (standpipe) tubes. Finally, all of the PFA Teflon interstage tubing lines were replaced.

To determine the source of these cruds, the contactor tests between 1993 and 1998 were reviewed. The results show that the following extractants, modifiers, and stripping agents have been used in some or all of the contactor stages: BoBCalixC6 (max. conc. of $0.01 \mathrm{M}$ ), Cs-3 (max. conc. of $0.20 \underline{\mathrm{M}}$ ), octyl(phenyl)-N,N-diisobutylcarbamoylmethyl phosphine oxide (CMPO, $\max$. conc. of $0.20 \underline{\mathrm{M}}$ ), bis-4,4'(5')[(tert-butyl)cyclohexano]-18-crown-6 (CE, max. conc. of $0.20 \underline{\mathrm{M}}$ ), diamyl amylphosphonate (DAAP, very limited use, max. conc. of $1.2 \mathrm{M}$ ), tributyl phosphate (TBP, max. conc. of $1.2 \mathrm{M}$ ), and lauryl nitrate ( $\mathrm{LN}$, very limited use, max. conc. of 5 vol\%). In addition, two diluents, Isopar ${ }^{\circledR} \mathrm{L}$ and 1-octanol (very limited use), have been used in the solvents.

\section{PHYSICAL PROPERTIES}

\section{A. Density and Viscosity}

Since the operation of the centrifugal contactor depends on the density of the two phases, the density of selected liquids was measured by weighing each liquid in a 100 - to $1000-\mathrm{mL}$ volumetric flask at a known temperature. The density was found to be $788.4 \pm 0.7 \mathrm{~g} / \mathrm{L}$ at $24^{\circ} \mathrm{C}$ for the solvent and $758 \pm 1 \mathrm{~g} / \mathrm{L}$ at $25^{\circ} \mathrm{C}$ for the Isopar ${ }^{\circledR} \mathrm{L}$ diluent. The closeness in the density of the solvent and the diluent reflects the relatively small concentrations of extractant and modifier in the solvent. This solvent has the lowest density of any that has ever been run in the contactor. Since the solvent density is near the lower design limit for the 2 -cm contactor, the design calculations 
were rechecked. The calculations show that, when the total throughput exceeds the contactor capacity, the mode of failure will be significant aqueous phase in the organic effluent $(>1 \% \mathrm{~A}$ in $\mathrm{O}$ ). This mode of failure will occur at all O/A flow ratios since the more-dense (aqueous) phase has a density of $1000 \mathrm{~g} / \mathrm{L}$ or higher. The SRS\#2 simulant, which is the aqueous (DF) feed, has a density of $1310 \pm 1 \mathrm{~g} / \mathrm{L}$ at $24.5^{\circ} \mathrm{C}$. This DF feed is near the high end of aqueous-phase densities run in the 2 -cm contactor.

Since a higher organic-phase viscosity will generally lead to poorer separation of the two immiscible phases [LEONARD-1995], the solvent viscosity was measured using a Brookfield Synchro-Lectric viscometer with an ultra-low adapter. The alkaline-side CSEX solvent was found to have a viscosity of $2.09 \pm 0.01 \mathrm{mPa} \cdot \mathrm{s}$ at $25^{\circ} \mathrm{C}$. The Isopar ${ }^{\circledR} \mathrm{L}$ diluent used to prepare the alkaline-side CSEX solvent was found to have a viscosity of $1.56 \pm 0.02 \mathrm{mPa} \cdot \mathrm{s}$ at $25^{\circ} \mathrm{C}$. To determine the contribution of Cs-3 modifier to the solvent viscosity, a solvent was prepared which

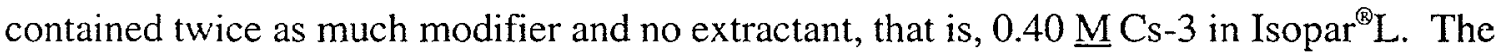
viscosity of this solvent was found to be $2.46 \pm 0.06 \mathrm{mPa} \cdot \mathrm{s}$ at $25^{\circ} \mathrm{C}$. Assuming that this viscosity increase is proportional to the modifier concentration, the viscosity of $0.20 \mathrm{M} \mathrm{Cs}-3$ in Isopar ${ }^{\circledR} \mathrm{L}$ would be $2.01 \mathrm{mPa} \cdot \mathrm{s}$. Since this solvent with $0.01 \mathrm{M}$ BoBCalixC6 added has a viscosity of 2.09 $\mathrm{mPa} \cdot \mathrm{s}$, most of the viscosity increase in the test solvent relative to the diluent must come from the modifier rather than the extractant.

The closeness in the viscosity of the alkaline-side CSEX solvent to its diluent indicates that the small concentrations of extractant and modifier in the solvent are more important than the large size of these molecules. Compared with other organic solvents we have used in the centrifugal contactor, this solvent has one of the lowest viscosities. Thus, phase separation should not be hindered by high solvent viscosity.

\section{B . Dispersion Number}

To evaluate the general ability of a two-phase dispersion to separate quickly and yield a good solvent extraction process, dispersion numbers were determined with the solvent $(0.01 \underline{\mathrm{M}}$ BoBCalix 6 and $0.20 \underline{\mathrm{M} C s-3}$ in Isopar ${ }^{\circledR} \mathrm{L}$ ) and the various aqueous phases that appear in the different sections of the alkaline-side CSEX process. The procedure for the dispersion number test is described in [LEONARD-1995]. The tests were done at room temperature $\left(23.2 \pm 1.4^{\circ} \mathrm{C}\right)$. Because of warming caused by shaking the two-phase mixture in a graduated cylinder and from this cylinder having been held in the experimenter's hands, the solution temperature for the test was slightly higher $\left(24.6 \pm 1.8^{\circ} \mathrm{C}\right)$. The dispersion numbers, $\mathrm{N}(\mathrm{Di})$, for the various aqueous phases and $\mathrm{O} / \mathrm{A}$ ratios are given in Table 5. 
Table 5. Results of Dispersion Number Tests

\begin{tabular}{|c|c|c|c|c|c|c|c|}
\hline \multirow[b]{2}{*}{ Aqueous Phase } & \multirow[b]{2}{*}{$\mathrm{O} / \mathrm{A}$} & \multirow[b]{2}{*}{$\begin{array}{l}\text { Avg. } \\
\text { N(Di) }\end{array}$} & \multirow[b]{2}{*}{$\begin{array}{c}\text { Performance } \\
\text { Rating }\end{array}$} & \multirow[b]{2}{*}{$\begin{array}{c}\text { Dispersed } \\
\text { Phase }\end{array}$} & \multicolumn{2}{|c|}{ Appearance } & \multirow[b]{2}{*}{ Notes } \\
\hline & & & & & $\mathrm{A}$ & $\mathrm{O}$ & \\
\hline SRS\#2 Simulant (DF) & 0.33 & $1.1 \mathrm{E}-03$ & VG & $\mathrm{O}$ & V Cldy & SI CIdy & \\
\hline$"$ & 1 & $1.4 \mathrm{E}-03$ & VG & $\mathrm{A}$ & $\mathrm{Clr}$ & Cldy & \\
\hline$"$ & 3 & $1.9 \mathrm{E}-03$ & E & $\mathrm{A}$ & $\mathrm{Clr}$ & Cldy & a \\
\hline 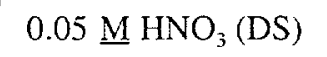 & 0.33 & $1.4 \mathrm{E}-03$ & VG & $\mathrm{O}$ & Cldy & V Cldy & b \\
\hline$"$ & 1 & $1.2 \mathrm{E}-03$ & VG & $\mathrm{A}$ & Crys Clr & V Cldy & \\
\hline$"$ & 3 & 1.1E-03 & $\mathrm{VG}$ & $\mathrm{A}$ & Crys Clr & V Cldy & \\
\hline $\begin{array}{c}0.0005 \underline{\mathrm{M} \mathrm{HNO}_{3} \text { and }} \\
0.0001 \underline{\mathrm{M} \mathrm{CsNO}_{3}} \\
(\mathrm{EF})\end{array}$ & 0.33 & $1.8 \mathrm{E}-04$ & $\mathrm{P}$ & $\mathrm{O}$ & Cldy & Sl Cldy & c \\
\hline$"$ & 1 & $7.3 \mathrm{E}-04$ & G & A & Crys $\mathrm{Clr}$ & V Cldy & \\
\hline$"$ & 3 & $1.1 \mathrm{E}-03$ & $\mathrm{VG}$ & $\mathrm{A}$ & $\mathrm{V} \mathrm{Clr}$ & V Cldy & \\
\hline $0.5 \underline{\mathrm{M} \mathrm{NaOH}}(\mathrm{FF})$ & 0.33 & $2.2 \mathrm{E}-03$ & $\mathrm{E}$ & A & Cldy & Cldy & \\
\hline 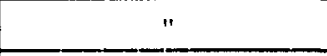 & 1 & $8.6 \mathrm{E}-04$ & $\mathrm{VG}$ & $\mathrm{A}$ & $\mathrm{Clr}$ & V Cldy & a \\
\hline 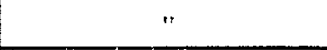 & 3 & $1.0 \mathrm{E}-03$ & $\mathrm{VG}$ & $\mathrm{A}$ & $\mathrm{Clr}$ & V Cldy & $\mathrm{a}$ \\
\hline
\end{tabular}

a. The N(Di) is based on disappearance of the dispersion band. Some dispersed A liquid was still moving through the $O$ phase. The movement of this dispersed liquid should be much faster in the centrifugal contactor so that the $\mathrm{N}$ (Di) shown here should appiy to contactor operation.

b. The N(Di) is based on disappaarance of the dispersion band. Some dispersed O liquid was still moving through the $\mathrm{A}$ phase. The movement of this dispersed liquid should be much faster in the centrifugal contactor so that the N(Di) shown here should apply to contactor operation.

c. The N(Di) is based on movement of the interface as there was no dispersion band. Since throughput is limited by the movement of these finely dispersed liquid droplets, whose movement increases as the first power of the acceleration, not to the $1 / 2$ power, as is the case with the dispersion band, the $\mathrm{N}(\mathrm{Di})$ in the centrifugal contactor should be higher than that in these gravity-settling batch tests. Thus, in a centrifugal contactor, the performance rating should be good or very good.

The performance ratings in Table 5 give the expected performance for each case. The correspondence of the rating with the dispersion number $\left\{\mathrm{N}_{\mathrm{Di}}\right.$ or $\left.\mathrm{N}(\mathrm{Di})\right\}$ is as follows. Excellent (E) is for $N_{D_{1}}>16 \times 10^{-4}$. Very good (VG) is for $N_{D i}$ from 8 to $16 \times 10^{-4}$. Fair (F) is for $N_{D_{1}}$ from 2 to $4 \times 10^{-4}$. Poor $(\mathrm{P})$ is for $\mathrm{N}_{\mathrm{Di}}$ from 0.2 to $2 \times 10^{-4}$. Very poor (VP) is for $\mathrm{N}_{\mathrm{Di}}<0.2 \times 10^{-4}$. As Table 5 shows, most of these tests were rated $\mathrm{E}$ or VG. Further discussion of solvent evaluation using the dispersion number is given in [LEONARD-1995].

Based on the dispersion number being $8 \times 10^{-4}$ or greater for all but two cases, we expect generally good performance for this alkaline-side CSEX process. The lowest dispersion number (rated P) occurred with $0.0005 \underline{\mathrm{M}} \mathrm{HNO}_{3}$ and $0.0001 \underline{\mathrm{M}} \mathrm{CsNO}_{3}$ at an $\mathrm{O} / \mathrm{A}$ of 0.33 . However, as no dispersion band formed in this case, phase separation is controlled by the movement of the 
other-phase droplets. Since the movement of other-phase droplets will be to the first power under the accelerational forces in the centrifugal contactor, not to the $1 / 2$ power as is the case for the dispersion number, this case should not be a problem in the centrifugal contactor. The hydraulic performance tests reported below show this to be the case. Overall, the dispersion number tests predict that the alkaline-side CSEX process should work well in the centrifugal contactor.

\section{Hydraulic Performance}

While the dispersion number test is a quick test indicating how a solvent pair will perform in solvent extraction equipment, some of the performance is specific to the equipment. To get this additional information, hydraulic performance tests must be done in the type of equipment that will be used for solvent extraction processing. Since centrifugal contactors are to be used in carrying out the alkaline-side CSEX process, hydraulic performance was determined in a one-stage $2-\mathrm{cm}$ centrifugal contactor using the organic phase $\left(0.01 \underline{\mathrm{M}}\right.$ BoBCalixC6 and $0.20 \underline{\mathrm{M} C s-3}$ in Isopar $\left.{ }^{(0)} \mathrm{L}\right)$ along with the various aqueous phases that appears in the different sections of the process. The tests were done at room temperature $\left(24.6 \pm 0.9^{\circ} \mathrm{C}\right)$. Because solutions were warmed by each pass through the contactor with both phases under full recycle, the solution temperatures for the tests were slightly higher $\left(26.8 \pm 1.8^{\circ} \mathrm{C}\right)$. The results of the hydraulic performance tests are summarized in Table 6. The rating for the hydraulic-performance results in Table 6 corresponds to the following code. Excellent (E) is for no problems. Very good (VG) is for no problems, but at least one phase was very cloudy. If any other-phase carryover was observed, it was less than $1 \%$. Borderline (B) is for 1 to $2 \%$ other-phase carryover. Unacceptable (U) is for $>2 \%$ other-phase carryover. If noted, it may also indicate a phase-inversion problem. 
Table 6. Results of Hydraulic Performance Tests in Single-Stage 2-cm Contactor

\begin{tabular}{|c|c|c|c|c|c|c|c|c|c|}
\hline \multirow{2}{*}{ Aqueous Phase } & \multirow{2}{*}{$\begin{array}{l}\text { O/A } \\
\text { Flow } \\
\text { Ratio }\end{array}$} & \multirow{2}{*}{$\begin{array}{c}\text { Flow (both } \\
\text { phases) } \\
\text { mL/min }\end{array}$} & \multirow{2}{*}{$\begin{array}{l}\text { Initial } \\
\text { Cont. } \\
\text { Phase }\end{array}$} & \multicolumn{2}{|c|}{$\begin{array}{l}\text { Other-Phase } \\
\text { Carryover. \% }\end{array}$} & \multicolumn{2}{|c|}{ Appearance } & \multirow[b]{2}{*}{ Rating } & \multirow[b]{2}{*}{ Notes } \\
\hline & & & & $\mathrm{O}$ in $\mathrm{A}$ & $\mathrm{A}$ in $\mathrm{O}$ & A & $\mathrm{O}$ & & \\
\hline SRS\#2 Simulant & 0.20 & 30 & $\mathrm{~A}$ & 0.0 & 0.0 & Hazy & Crys Clr & $E$ & \\
\hline " & $"$ & 36 & $\mathrm{~A}$ & 0.0 & 1.5 & $\mathrm{Hazy}$ & Crys Clr & $\mathrm{B}$ & \\
\hline$"$ & $"$ & 42 & $\mathrm{~A}$ & 0.0 & 0.4 & Hazy & Crys Clr & $\mathrm{VG}$ & \\
\hline$"$ & 0.33 & 40 & $\mathrm{~A}$ & 0.0 & 0.0 & V SI Cldy & Clr to Crys Clr & $\mathrm{E}$ & \\
\hline$"$ & $"$ & 40 & $\mathrm{O}$ & 0.0 & 0.9 & V Clr & Sl Cldy & VG & $\mathrm{a}$ \\
\hline$"$ & 0.45 & 32 & $\mathrm{~A}$ & 0.0 & 0.0 & $\mathrm{Clr}$ & Crys Clr & $\mathrm{E}$ & $b, c$ \\
\hline$"$ & $"$ & 32 & $\mathrm{~A}$ & 0.0 & 0.0 & Clr & Crys Clr & $E$ & $c, d$ \\
\hline$"$ & 1 & 40 & $\mathrm{~A}$ & 0.0 & 0.0 & $\begin{array}{c}\text { Clr to Crys } \\
\mathrm{Clr} \\
\end{array}$ & $\begin{array}{l}\text { V Sl Cldy to } \\
\text { Crys Clr } \\
\end{array}$ & $\mathrm{E}$ & \\
\hline$"$ & $"$ & 40 & $\mathrm{O}$ & 0.0 & 0.9 & $\mathrm{Clr}$ & V Sl Cldy & $\mathrm{VG}$ & \\
\hline$"$ & 3 & 12 & $\mathrm{O}$ & 0.0 & 15.3 & $\mathrm{Cl}_{\Gamma}$ & Cldy & $\mathrm{U}$ & \\
\hline$"$ & $"$ & 20 & $\bar{A}$ & 0.0 & 12.5 & Crys Clr & Cldy & $\mathrm{U}$ & \\
\hline$"$ & $"$ & 20 & $\mathrm{~A}$ & 0.0 & 13.3 & Cldy & SI Cldy & $\mathrm{U}$ & $\mathrm{e}$ \\
\hline$"$ & $1 "$ & 20 & $\mathrm{O}$ & 0.0 & 0.0 & $\mathrm{VClr}$ & $\mathrm{V} \mathrm{Clr}$ & $E$ & \\
\hline$"$ & $"$ & 30 & A & N.M. & N.M. & N.M. & N.M. & $\mathrm{U}$ & $\mathrm{e}$ \\
\hline$"$ & $"$ & 30 & $\mathrm{O}$ & 0.0 & 20.1 & Sl Cldy & Cldy & $\mathrm{U}$ & \\
\hline$"$ & $"$ & 30 & 0 & 0.0 & 0.0 & $\mathrm{Clr}$ & S! Cldy & $E$ & \\
\hline$"$ & $"$ & 40 & A & $0.0^{\circ}$ & 16.5 & $\mathrm{Clr}$ & Cldy & $\mathrm{U}$ & \\
\hline$"$ & $"$ & 40 & $\mathrm{O}$ & N.M. & (yes) & N.M & N.M. & $\mathrm{U}$ & \\
\hline $0.05 \mathrm{M} \mathrm{HNO}_{3}$ & 0.33 & 40 & A & 0.0 & 0.0 & $\mathrm{Clr}$ & V Cldy & VG & \\
\hline " & $"$ & 40 & 0 & 0.0 & 0.0 & $\mathrm{Clr}$ & V Cldy & $\mathrm{VG}$ & \\
\hline$"$ & 1 & 40 & $\mathrm{~A}$ & 0.0 & 0.0 & $\mathrm{VClr}$ & V Cldy & VG & \\
\hline$"$ & $"$ & 40 & $\mathrm{O}$ & 0.0 & 0.0 & V Clr & V Cldy & $\mathrm{VG}$ & \\
\hline$"$ & 3 & 40 & $\mathrm{~A}$ & 0.0 & 0.0 & $\mathrm{~V} \mathrm{Clr}$ & V Cldy & $\mathrm{VG}$ & \\
\hline$"$ & $"$ & 40 & $\mathrm{O}$ & 0.0 & 0.0 & $\mathrm{VClr}$ & V Cldy & VG & \\
\hline $\begin{array}{l}0.0005 \mathrm{M} \mathrm{HNO}_{3} \\
0.0001 \mathrm{M} \mathrm{CsNO}_{3}\end{array}$ & 0.33 & 40 & $\mathrm{~A}$ & 0.0 & 0.0 & $\mathrm{Clr}$ & V Cldy & VG & \\
\hline$"$ & $"$ & 40 & $\mathrm{O}$ & 0.0 & 0.0 & $\mathrm{Clr}$ & Cldy & $\mathrm{E}$ & \\
\hline$"$ & 1 & 40 & $\mathrm{~A}$ & 0.0 & 0.0 & $\mathrm{~V} \mathrm{Clr}$ & V Cldy & $\mathrm{VG}$ & \\
\hline$"$ & $"$ & 40 & $\mathrm{O}$ & 0.0 & 0.0 & $\mathrm{VClr}$ & V Cldy & VG & \\
\hline$"$ & 3 & 40 & $\mathrm{~A}$ & 0.0 & 0.0 & $\mathrm{VClr}$ & V Cldy & $\mathrm{VG}$ & \\
\hline$"$ & $"$ & 40 & $\mathrm{O}$ & 0.0 & 0.0 & $\mathrm{~V} \mathrm{Clr}$ & V Cldy & VG & \\
\hline $0.5 \underline{\mathrm{M} \mathrm{NaOH}}$ & 0.33 & 40 & A & 0.0 & 0.0 & Crys Clr & Hazy & $\mathrm{E}$ & \\
\hline$"$ & $"$ & 40 & 0 & 0.0 & 0.0 & Crys Clr & Hazy & $\mathrm{E}$ & $\mathrm{f}$ \\
\hline$"$ & 1 & 40 & $\mathrm{~A}$ & 0.0 & 0.0 & Crys Clr & Hazy & $\mathrm{E}$ & . \\
\hline$"$ & $"$ & 40 & $\mathrm{O}$ & 0.0 & 0.0 & Crys Clr & Hazy & $\mathrm{E}$ & \\
\hline$"$ & 3 & 40 & $\mathrm{~A}$ & 0.0 & 0.0 & Crys Clr & Cldy & $\mathrm{E}$ & \\
\hline$"$ & $"$ & 40 & $\mathrm{O}$ & 0.0 & 0.0 & Hazy & SI Cldy & $E$ & \\
\hline
\end{tabular}

a. Hard to get to $\mathrm{O}$ continuous. When first turn on O-only flow with some A phase in stage, get $\mathrm{O}$ overflowing the standpipe. Turn off $\mathrm{O}$. Repeat process with same result. Turn off rotor. Turn on O. Works okay.

b. Used pristine solvent for this test.

c. Same flow rates as in extraction section of Test CS2.

d. Recycled solvent used here and for all other tests except where noted.

e. Some $O$ phase exiting from top of liquid level tube (standpipe). Fails to go from A- to O-continuous operation.

f. Hard to get to $O$ continuous. With O-only flow, get $O$ rising to top of the standpipe. Tum off rotor for 10 sec. Restart. Works okay. 
The hydraulic performance for the scrub $\left(0.05 \mathrm{M} \mathrm{HNO}_{3}\right)$ and strip $\left(0.0005 \underline{\mathrm{MNO}_{3}}\right.$ and $0.0001 \mathrm{M} \mathrm{CsNO}_{3}$ ) sections reported in Table 6 confirms the above dispersion number results. Note that the hydraulic performance is good at all O/A flow ratios. In particular, stripping performance is good at low $\mathrm{O} / \mathrm{A}$ flow ratios even though the dispersion number was low there.

Hydraulic performance in the extraction section (SRS\#2 simulant) was also very good at low (0.33) and medium (1.0) O/A flow ratios. At high (3.0) O/A flow ratios, the 2-cm contactor had phase inversion problems. The dispersion would not convert easily from aqueous- to organiccontinuous operation. This made the dispersion very viscous so that it could not flow into the rotor. Instead, the dispersion would back up in the mixing zone, and liquid would be seen at the top of the liquid level tube (standpipe) and sometimes overflowing this tube. In addition, we often found greater than $1 \%$ aqueous phase in the organic effluent in this operational region.

Performance was very dependent on the process path. If the path was right and the flow rate not too high, good process operation could be found even at high O/A flow ratios. This is not satisfactory process operation and the 2-cm contactor should not be operated in this region with the highly alkaline SRS\#2 simulant. Fortunately, high O/A flow ratios are not needed in the extraction section of this process. An excursion into the high O/A flow region, as happened in test CS2, can cause continuing problems even after returning to lower O/A flow ratios. However, these tests of single-stage hydraulic performance show that, if the rotor motor is turned off long enough for the rotor to stop spinning and then restarted, the phase inversion problem disappears, and the process runs smoothly.

The two problems seen in the hydraulic-performance tests are peculiar to the $2 \cdot \mathrm{cm}$ contactor and should not impact the general use of properly designed larger contactors. The first problem, other-phase carryover that is greater than $1 \%$, is related to the weir design. This 2 -cm contactor was not optimized for very low-density $(0.79 \mathrm{~g} / \mathrm{mL})$ solvent with very high-density $(1.31 \mathrm{~g} / \mathrm{mL})$ SRS\#2 simulant. Instead, it was designed to include process phases where the ratio of the lessdense phase over the more-dense phase was as high as 0.9. Thus, with respect to the rotor weir diameters, we were operating the 2 -cm contactors at the edge of the design envelope in the extraction section. Any unit for the alkaline-side CSEX process would be designed so that it is optimized for this process; so, this will not be a problem for a plant-scale unit. The second problem, the resistance to phase inversion, is related to the small size of the contactor. As discussed in Appendix C, this problem has only been seen in the smallest $(2-\mathrm{cm})$ centrifugal contactors. It has never been seen in larger contactors $(4-25 \mathrm{~cm})$. Therefore, phase inversion is not a serious contactor problem. In particular, based on the dispersion number tests and our previous experience with the PUREX process, the hydraulic performance of this alkaline-side CSEX process should be acceptable in larger centrifugal contactors at all O/A flow ratios.

\section{TESTS WITH SINGLE AND MULTISTAGE CONTACTORS}

\section{A. Single-Stage Contactor}

The 2-cm centrifugal contactors were designed to have an extraction efficiency of $98 \%$ at each stage. To evaluate actual efficiency, tests were done in a one-stage $2-\mathrm{cm}$ centrifugal contactor 


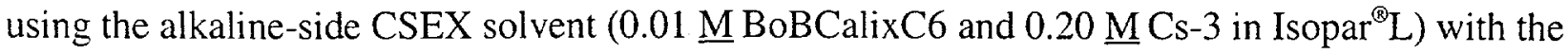
various aqueous phases. The results, given in Table 7 , cover the range of operations in the different sections of the alkaline-side CSEX process. While fresh solvent was used for the extraction section, the solvent was reused for the other sections, just as is the case for the actual process. The aqueous phase solutions were always fresh.

Table 7. Results of Single-Stage Extraction Efficiency Tests

\begin{tabular}{|c|c|c|c|c|c|c|c|}
\hline $\begin{array}{l}\text { Test } \\
\text { Code } \\
\end{array}$ & $\begin{array}{c}\text { Total Flow } \\
\text { Rate, } \\
\mathrm{mL} / \mathrm{min} \\
\end{array}$ & $\mathrm{O} / \mathrm{A}$ & $\begin{array}{c}\text { Source of } \\
\text { Organic Phase } \\
\end{array}$ & $\begin{array}{c}\text { Operating } \\
\text { (Apparent) } \mathrm{D}_{\mathrm{Cs}}\end{array}$ & \begin{tabular}{|c|} 
Equilibrium \\
$D_{\mathrm{Cs}}$ \\
\end{tabular} & Stage Efficiency & $\begin{array}{c}\text { Stage } \\
\text { Efficiency } \\
\text { Error } \\
\end{array}$ \\
\hline \multicolumn{8}{|c|}{ Extraction (SRS\#2 simulant) } \\
\hline $\mathrm{CS} 3$ & 32 & 0.45 & Fresh & 8.9 & 9.3 & $99.4 \%$ & $0.9 \%$ \\
\hline $\mathrm{CS} 4$ & 42 & 0.17 & $"$ & 5.9 & 7.7 & $88.4 \%$ & $2.4 \%$ \\
\hline CS5 & 40 & 0.33 & $"$ & 7.8 & 8.2 & $99.4 \%$ & $1.6 \%$ \\
\hline CS6 & 40 & 0.6 & $"$ & 8.3 & 9.2 & $98.7 \%$ & $0.7 \%$ \\
\hline CS7 & 40 & 1 & $"$ & 9.3 & 9.7 & $99.5 \%$ & $0.8 \%$ \\
\hline \multicolumn{6}{|r|}{ Average: } & $97.1 \%$ & \\
\hline \multicolumn{6}{|c|}{ Average w/o CS4: } & $99.3 \%$ & \\
\hline \multicolumn{8}{|c|}{ Scrub $\left(0.05 \mathrm{M} \quad \mathrm{HNO}_{3}\right)$} \\
\hline CS8 & 12 & 5 & $\mathrm{CS} 3-7$ & 0.70 & 0.60 & $79.2 \%$ & $8.1 \%$ \\
\hline $\operatorname{CS} 9$ & 24 & 5 & $"$ & 0.84 & 0.63 & $82.6 \%$ & $11.5 \%$ \\
\hline \multicolumn{6}{|r|}{ Average: } & $80.9 \%$ & \\
\hline \multicolumn{8}{|c|}{ Strip $\left(0.0005 \underline{\mathrm{M}} \mathrm{HNO}_{3}, 0.0001 \underline{\mathrm{M}} \mathrm{CsNO}_{3}\right)$} \\
\hline $\operatorname{CS} 10$ & 14 & 2.5 & CS8-9 & 0.17 & 0.14 & $97.4 \%$ & $5.0 \%$ \\
\hline CS11 & 40 & 3 & $"$ & 0.14 & 0.13 & $105.8 \%$ & $10.2 \%$ \\
\hline $\mathrm{CS} 12$ & 40 & 0.33 & $"$ & 0.57 & 0.14 & $87.9 \%$ & $8.5 \%$ \\
\hline $\mathrm{CS} 13$ & 40 & 1 & $"$ & 0.17 & 0.13 & $100.8 \%$ & $5.6 \%$ \\
\hline CS14 & 40 & 1 & CS10-13 & 0.31 & 0.26 & $107.2 \%$ & $2.4 \%$ \\
\hline $\operatorname{CS} 15$ & 40 & 1 & $\mathrm{CS} 14$ & 0.34 & 0.26 & $98.8 \%$ & $6.4 \%$ \\
\hline $\operatorname{CS} 16$ & 40 & 1 & $\mathrm{CS} 15$ & 0.30 & 0.26 & $99.8 \%$ & $4.3 \%$ \\
\hline \multicolumn{6}{|r|}{ Average: } & $99.7 \%$ & \\
\hline \multicolumn{8}{|c|}{ Extraction (SRS\#4 simulant) } \\
\hline $\mathrm{CS} 17$ & 31.2 & 0.177 & CS16 & 9.8 & 10.7 & $97.7 \%$ & $0.7 \%$ \\
\hline
\end{tabular}

Except for a few cases where the O/A flow ratio was much higher or lower than 1.0 , the stage efficiency was $98 \% \pm 2 \%$. As discussed in Appendix C, lower stage efficiencies are attributed to pulsed flow into the contactor at low flow rates where surface tension can hold liquid back for a period time, for example, for a few seconds or more. When the O/A flow ratio differs from 1.0, the flow rate of one entering stream decreases and the effect of surface tension increases. In addition, a low total flow rate reduces stage efficiency by lowering the flow of both phases. Thus, the worst case (test CS8 with a stage efficiency of $79 \%$ ) occurred when the flow rate was low, only $12 \mathrm{~mL} / \mathrm{min}$, and the $\mathrm{O} / \mathrm{A}$ flow ratio was high, 5.0 . 


\section{B . Multistage Contactor}

The second multistage test with the 2-cm centrifugal contactor was done on September 22, 1998 in a 24-stage unit (Fig. 10). This test was divided into two parts: part I (test CS18) used no solvent recycle and part II (test CS19), full solvent recycle starting with the used solvent from test CS18. The composition of the alkaline-side tank waste feed, SRS\#4 simulant, is given in Table 8 . Using the batch test results, we calculated the distribution ratio for cesium in the extraction, scrub, and strip sections of test CS18; these $D_{C s}$ values are given in Table 2. The planned flow rate for each feed and effluent is shown in Fig. 10. The actual flow rates are given in Table 3 along with the measurement error, the actual O/A flow ratio, the material balance for the cesium, and the stage efficiency calculated from the O/A flow ratio as given in Appendix $\mathrm{C}$ for the 2-cm contactor.

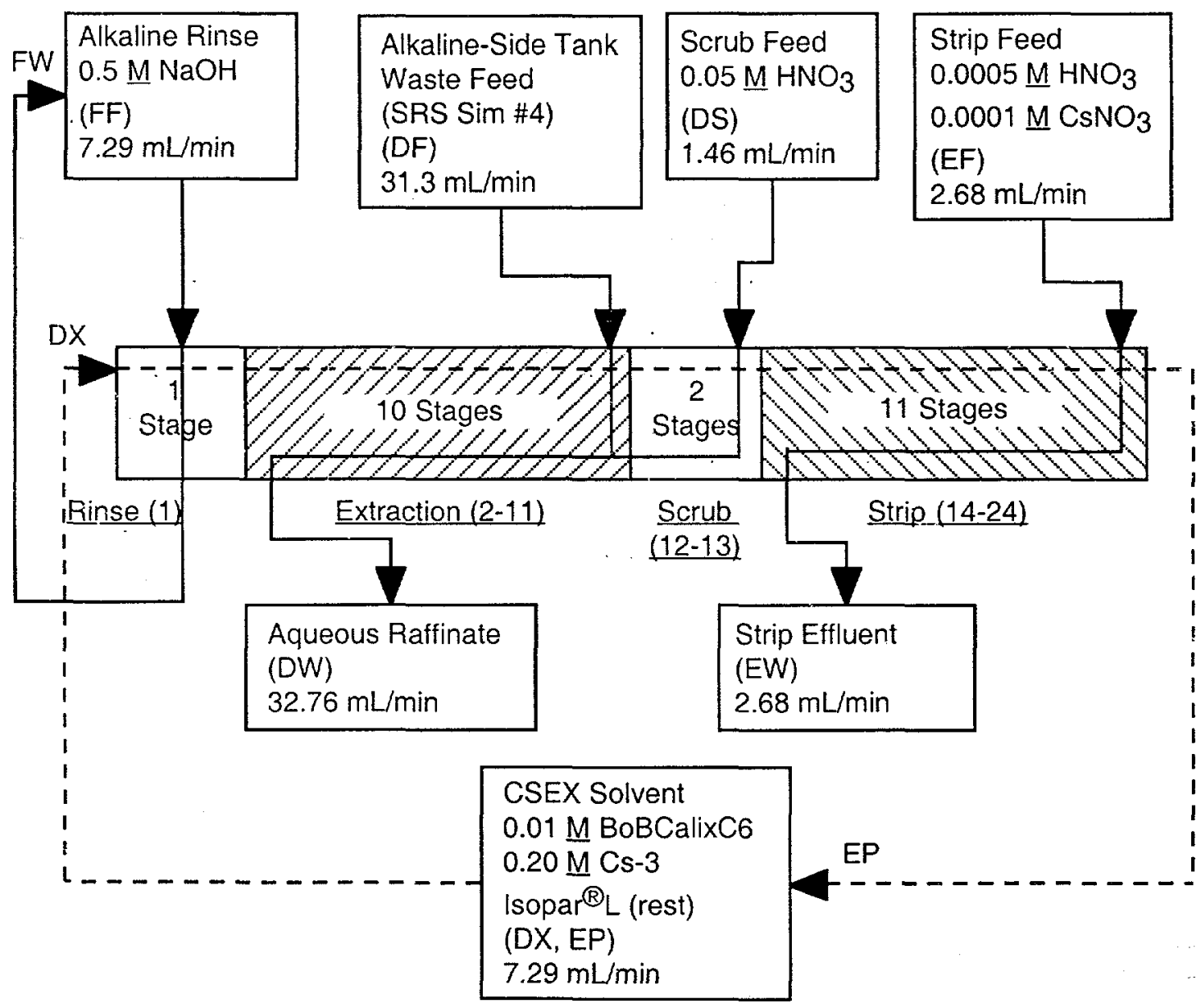

Fig. 10. Flowsheet for Tests CS18 and CS19 
Table 8. Composition of SRS\#4 Simulant for the DF Feed in Tests CS18 and CS 19

\begin{tabular}{|c|c|c|}
\hline Ionic Species & Conc, $\mathrm{M}$ & Notes \\
\hline $\mathrm{Na}^{+}$ & 6.44 & \\
\hline $\mathrm{Al}^{3+}$ & 0.44 & \\
\hline $\mathrm{K}^{+}$ & 0.017 & \\
\hline $\mathrm{Cs}^{+}$ & 0.00027 & Cold Cs \\
\hline $\mathrm{Cs}^{+}-137$ & $1 \mathrm{E}-08$ & Approximate conc. \\
\hline $\mathrm{OH}^{-}$(total) & 3.28 & OH added \\
\hline $\mathrm{OH}^{-}$(free) & 1.52 & $\mathrm{OH}^{-}$unreacted \\
\hline $\mathrm{NO}_{3}{ }^{-}$ & 2.7 & \\
\hline $\mathrm{NO}_{3}^{-}$ & 0.82 & \\
\hline $\mathrm{SO}_{4}{ }^{2-}$ & 0.20 & \\
\hline $\mathrm{CO}_{3}^{2-}$ & 0.20 & \\
\hline $\mathrm{Cl}^{-}$ & 0.10 & \\
\hline $\mathrm{F}^{-}$ & 0.05 & \\
\hline $\mathrm{CrO}_{+}^{2-}$ & 0.015 & \\
\hline
\end{tabular}

The design basis for the flowsheet used in tests CS18 and CS19 had two key points. First, the relative flow rates were the same as those for the final SRS process. Second, the decontamination factor for the extraction section was balanced with the stripping factor for the strip section. In addition, the flowsheet was not limited to 18 stages. This limit would have been imposed only if it were planned to use the existing 18 -stage $25-\mathrm{cm}$ contactor at SRS. Thus, we were able to use all 24 contactor stages in the glovebox. The $\mathrm{D}_{\mathrm{Cs}}$ value for the extraction section was to be 8; that for the strip section, 0.2 . These $\mathrm{D}_{\mathrm{Cs}}$ values and an assumed $100 \%$ stage efficiency were substituted into the model given in [LEONARD-1999A] to obtain a solvent (DX) flow rate that balances the decontamination and stripping factors. The key flow rates for the SRS process are a feed (DF) flow rate from the SRS waste tanks of $17.5 \mathrm{gpm}(66 \mathrm{~L} / \mathrm{min})$, and an aqueous effluent (EW) flow rate from the strip section of $1.5 \mathrm{gpm}(5.7 \mathrm{~L} / \mathrm{min})$. Since test CS18 had no solvent recycle, there is no interaction between the exiting solvent from the strip section and the operation of the extraction section. This allows both sections to be evaluated independently. In test CS19, we are able to evaluate the effect of solvent recycle. Test CS18 was done in the morning; test CS19, in the afternoon.

\section{Test CS18}

The steady-state cesium concentration for each effluent stream in test CS18 is given in Table 4. The cesium concentration is only that cesium coming in as part of the DF feed. Because the nonradioactive cesium in the EF strip feed contains no ${ }^{137} \mathrm{Cs}$, it is not tracked by the ${ }^{137} \mathrm{Cs}$ tracer method used to measure cesium concentration. This table shows that (1) the cesium concentration in the DW raffinate is 277 times less than that in the DF feed, and (2) the cesium concentration in the EP product is 5.0 times less than that in the DF feed. Figures 11-13 show the cesium concentration in the three effluents (DW, EW, and EP) over time. Figure 11 shows that the cesium 
concentration in DW is still dropping at the end of the test. Figure 12 shows that EW is essentially at steady state. Figure 13 shows that EP is just about at steady state. These findings indicate that the overall process was continuing to improve even at the end of the test.

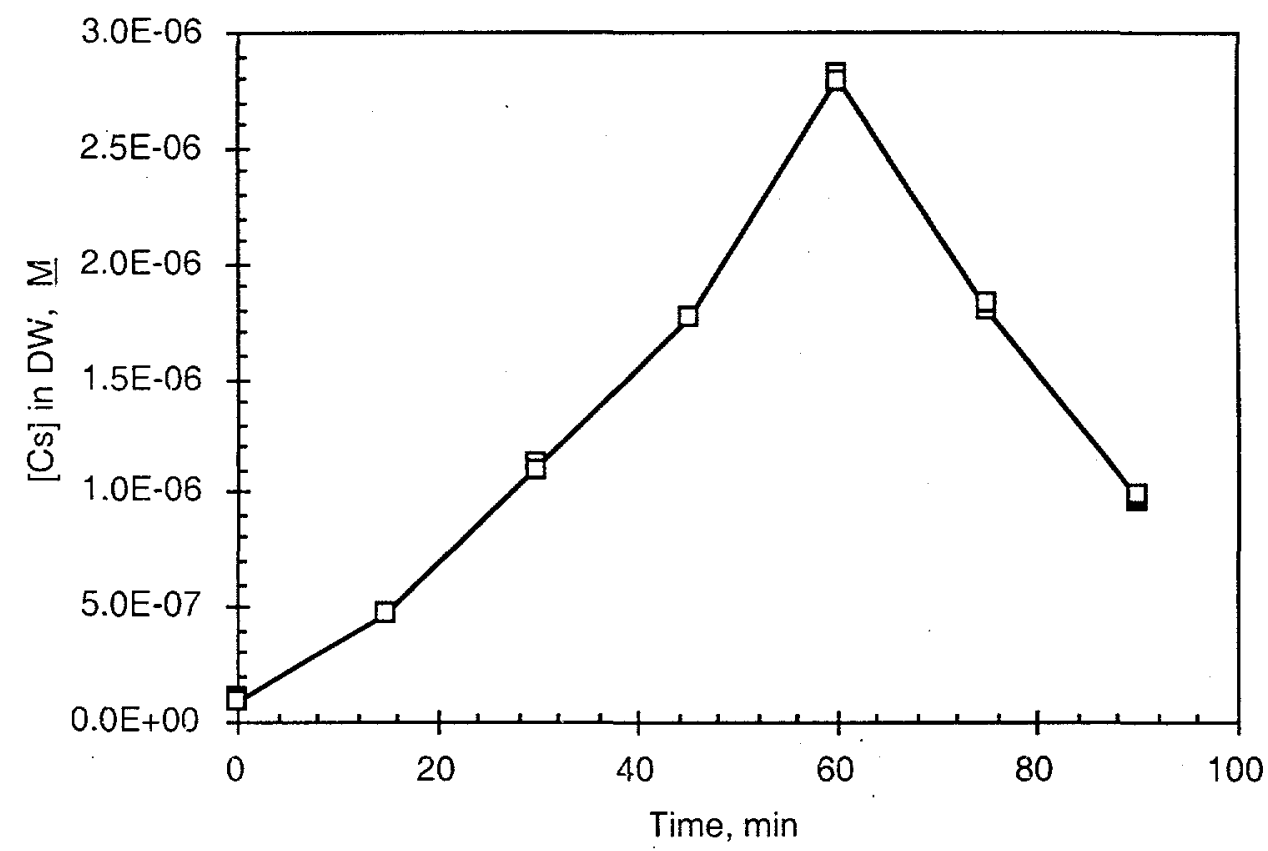

Fig. 11. Cesium Concentration in Aqueous (DW) Raffinate as a Function of Time for Test CS18

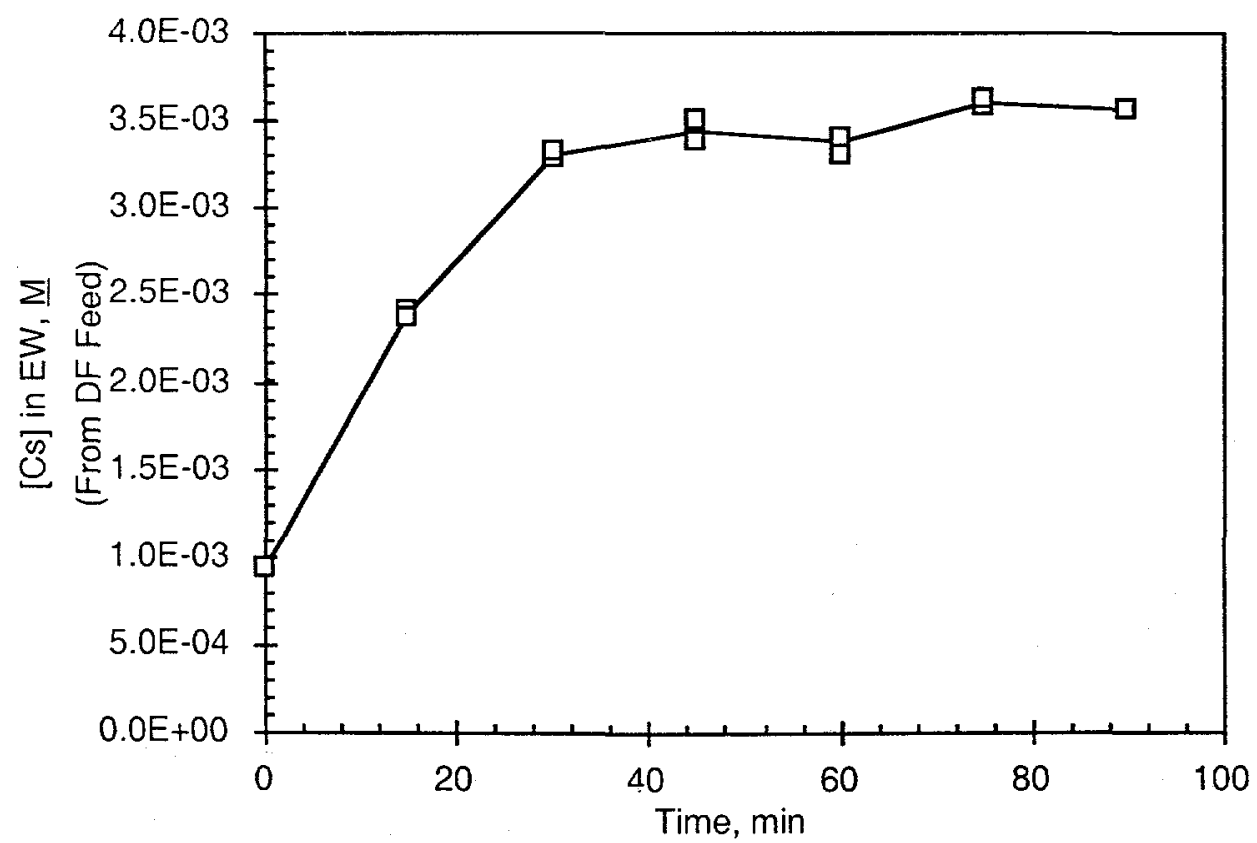

Fig. 12. Cesium Concentration in Aqueous (EW) Strip as a Function of Time for Test CS18 


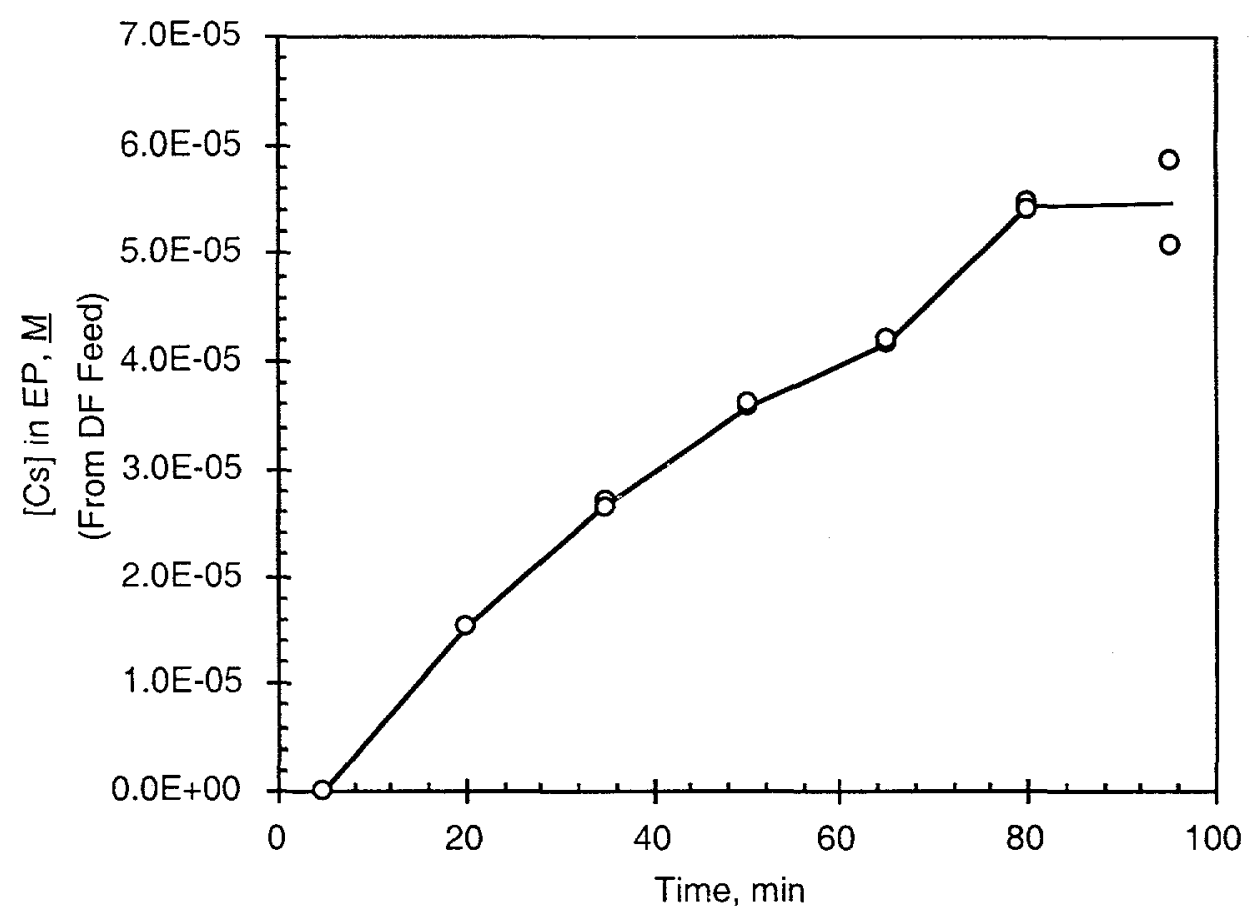

Fig. 13. Cesium Concentration in Organic (EP) Product as a Function of Time for Test CS18

Figure 14 is a plot of the stage-to-stage cesium concentrations for test CS18 calculated using the SASSE spreadsheet [LEONARD-1994]. If the fractional stage efficiency for the extraction section is increased from the correlation value of 0.703 (see Table 3 ) to 0.804 , the model curve matches the DW raffinate concentration. This is the model curve shown in the extraction section of Fig. 14. If stage efficiency had been kept at the correlation value of 0.703 , then $D_{c s}$ in the extraction section would have to be increased from the 11.45 value given in Table 2 to 14.92 to match the $\mathrm{DW}$ raffinate concentration. Based on the temperature in the extraction section, this $\mathrm{D}_{\mathrm{Cs}}$ value is too high. Thus, the stage efficiency in the extraction section was probably somewhat higher than that given by the correlation in Appendix C. However, this stage efficiency, which was calculated from the SASSE model, is not unexpected given the scatter of the data used to obtain the correlation, possible errors in estimating the process temperature, and the sensitivity of $\mathrm{D}_{\mathrm{Cs}}$ to the process temperature. 


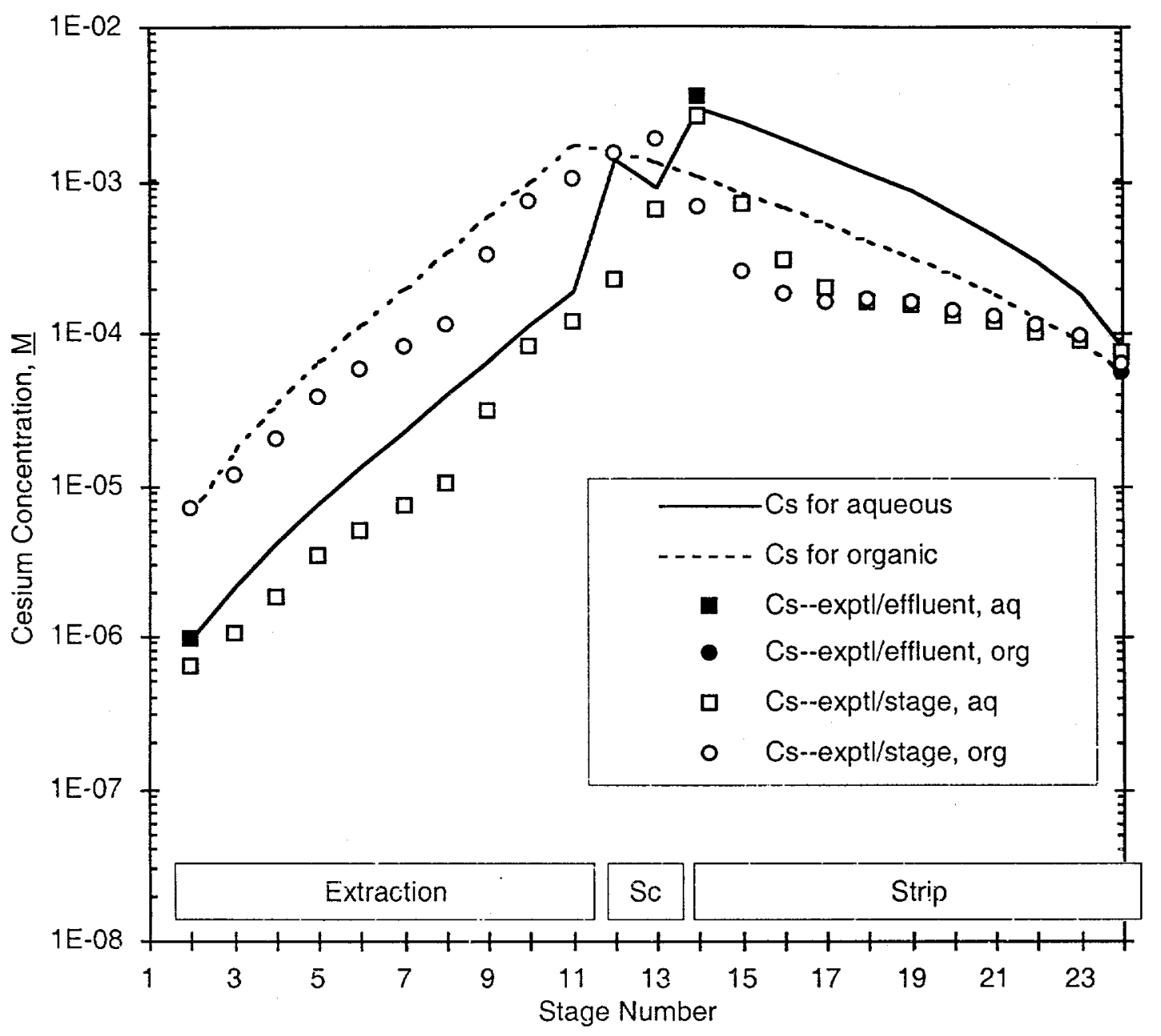

Fig. 14. Concentration Profile for Cs in Test CS18

If the stage efficiency for the strip section is decreased from the correlation value of 0.749 (see7 Table 3) to 0.627, the model curve matches the EP product concentration. This is the model curve shown in the strip section of Fig. 14. If the stage efficiency had been kept at the correlation value of 0.749 , then $\mathrm{D}_{\mathrm{Cs}}$ in the strip section would have to be increased from the 0.27 value given in Table 2 to 0.32 to match the EP product concentration. Based on the temperature in the strip section, this high $\mathrm{D}_{\mathrm{Cs}}$ value does not seem appropriate. Thus, the stage efficiency in the extraction section was probably somewhat lower than that given by the correlation in Appendix C. However, this stage efficiency, which was calculated from the SASSE model, is not unexpected given the scatter of the data used to derive the correlation, possible errors in estimating the process temperature, and the sensitivity of $\mathrm{D}_{\mathrm{Cs}}$ to the process temperature. Thus, the operation of the stripping section during test CS18 was what would be expected based on ANL batch tests done after the test.

As shown in Table 2, the average $\mathrm{D}_{\mathrm{Cs}}$ value in the extraction section was 11.45 , somewhat higher than the 8 assumed in designing the flowsheet. As also shown in Table 2, the average $\mathrm{D}_{\mathrm{Cs}}$ 
value in the strip section was 0.27 , somewhat higher than the 0.2 assumed in designing the flowsheet. As a result, and as the data show, the extraction section was more effective in extracting the cesium than the strip section was in stripping it.

At the end of the test, the process was stopped quickly, and the two liquid phases in each stage were drained and equilibrated. The $\mathrm{D}_{\mathrm{Cs}}$ values obtained are plotted in Fig. 15. The results for the strip section show that, after the first three stages, the $D_{C s}$ values all range between 0.8 and 1.2. The lowest value for the strip section, in stage 14, was 0.24 . Thus, except for the first three strip stages, the $D_{C s}$ values measured in the strip section after test CS18 are much higher than could have existed during the test. This estimate of a low $\mathrm{D}_{\mathrm{Cs}}$ value in the strip section is based on the stripping required to obtain the low cesium concentration seen in the organic (EP) effluent.

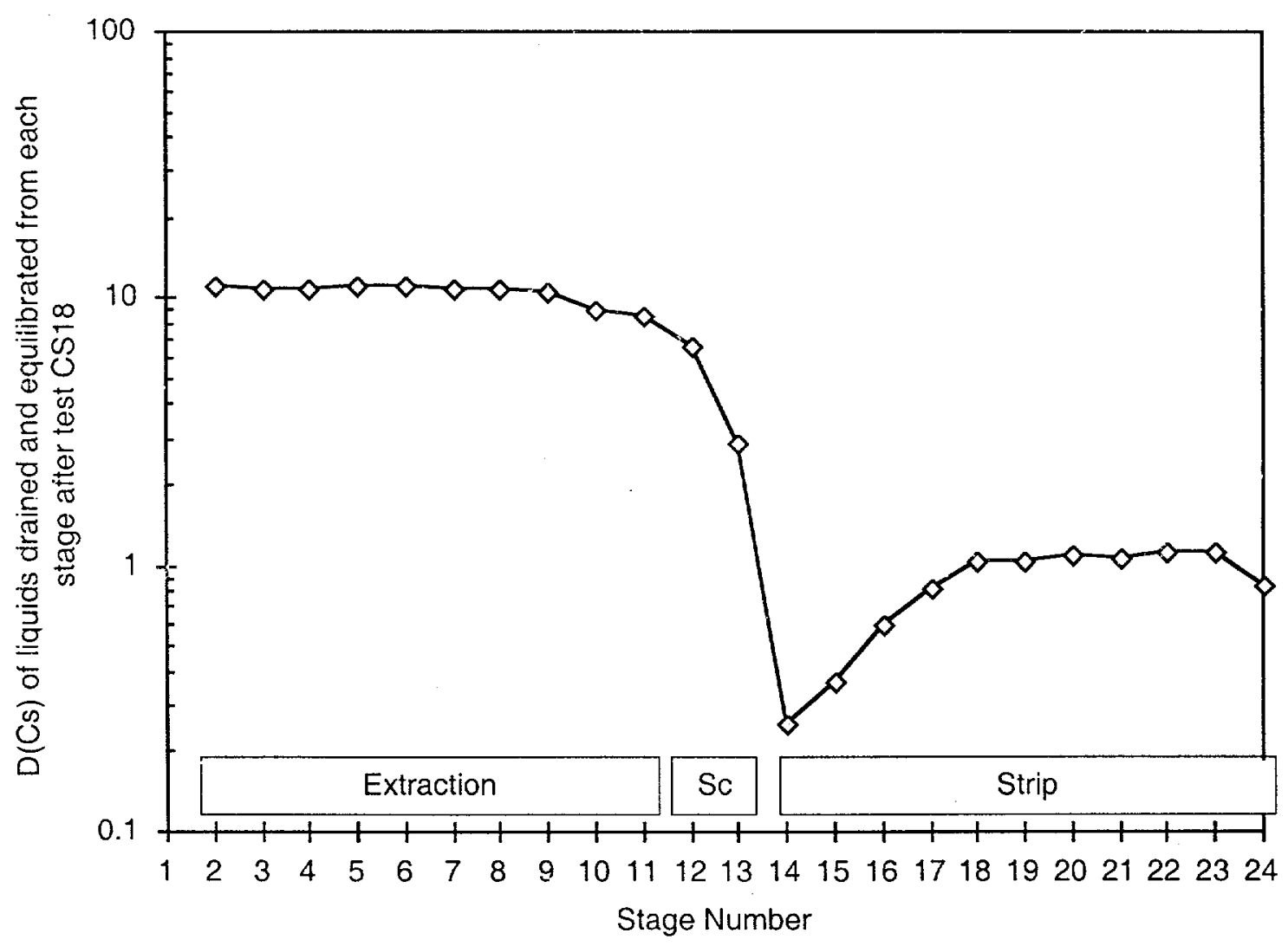

Fig. 15. Cesium Distribution Ratios for Each Stage at the End of Test CS18

An apparent problem was observed during the startup of test CS18. In one of the scrub stages, liquid was observed backing up in the aqueous interstage line. The rotor motor for that stage was turned off for several seconds so that the rotor could stop, then the motor was restarted. This operation allowed the liquid to flow out of the interstage line. This operation had to be repeated several times before the stage operated properly with the low interstage liquid level of the other lines. Other than that, test CS18 ran very smoothly. After the test, when the stage liquids were drained, the solutions were found to be very clean with no crud. This finding suggests that the contactor cleanup done after test CS2 was quite effective. 


\section{Test CS19}

To evaluate the effect of solvent recycle, test CS19 was also carried out in the 24-stage unit using the flowsheet shown in Fig. 10. This test was identical to test CS18, except that the solvent was recycled. From batch equilibrations done after test CS19, the distribution ratios for cesium in the extraction, scrub, and strip sections of test CS19 were determined and are given in Table 2. The planned flow rate for each feed and effluent is shown in Fig. 10. The actual flow rates are given in Table 3 along with the measurement error, the actual O/A flow ratio, the material balance for the cesium, and the stage efficiency calculated from the O/A flow ratio as given in Appendix $\mathrm{C}$ for the $2-\mathrm{cm}$ contactor. The initial solvent volume for this test, all of it solvent from test CS18, was only $510 \mathrm{~mL}$. After the contactor had been filled with solvent, only $320 \mathrm{~mL}$ was left in the solvent (DX) feed tank. A magnetic stir bar was turning in the bottom of the solvent feed tank so that the solvent (EP) effluent was mixed quickly with the solvent already in the tank. The solvent volume in the tank dropped slowly with time to $200 \mathrm{~mL}$ as samples of 5 to $10 \mathrm{~mL}$ were taken every 15 min during the test. By the end of the test, the solvent had been recycled through the contactor four times.

The steady-state cesium concentration for each effluent stream is given in Table 4. The cesium concentration is only that cesium in the $\mathrm{DF}$ feed. As the nonradioactive cesium in the $\mathrm{EF}$ strip feed has no ${ }^{137} \mathrm{Cs}$, it is not tracked by the ${ }^{137} \mathrm{Cs}$ tracer method used to measure cesiuin concentration. This table shows that (1) the cesium concentration in the DW raffinate is 24 times less than that in the DF feed, and (2) the cesium concentration in the EP product is 6.2 times less than that in the DF feed. Figures 16-19 show the cesium concentrations of the four effluents (DW, $\mathrm{EW}, \mathrm{FW}$, and EP) over time. Figure 16 shows that the cesium concentration in DW is still increasing with time. Figure 17 shows that $\mathrm{EW}$ is essentially at steady state and possibly even dropping some. Figure 18 shows that $\mathrm{FW}$ is steadily increasing with time. This is expected since the FW stream is operated at full recycle as shown in Fig. 10. Figure 19 shows that EP is nearly at steady state.

When the curves for the cesium concentration in FW and DW are compared (Figs. 18 and 16 , respectively), one sees that the cesium concentration in the FW effluent is 3 to 5 times greater than that for the DW effluent at any given time. The rising cesium concentration in the FW rinse system causes the cesium concentration in the solvent returning to the extraction section to rise also and, so, drives the rising cesium concentration in the DW raffinate. Because the cesium concentration in the FW rinse system is rising steadily, the overall process appears to be as close to steady state as it is possible to be for this flowsheet. In a fully operational system that reduced $\mathrm{D}_{\mathrm{Cs}}$ in the EP effluent to the desired value, the concentration of cesium in the FW effluent would increase much more slowly and, in fact, this rinse solution would be replaced at appropriate intervals to keep the cesium in the recycled DX solvent low. 


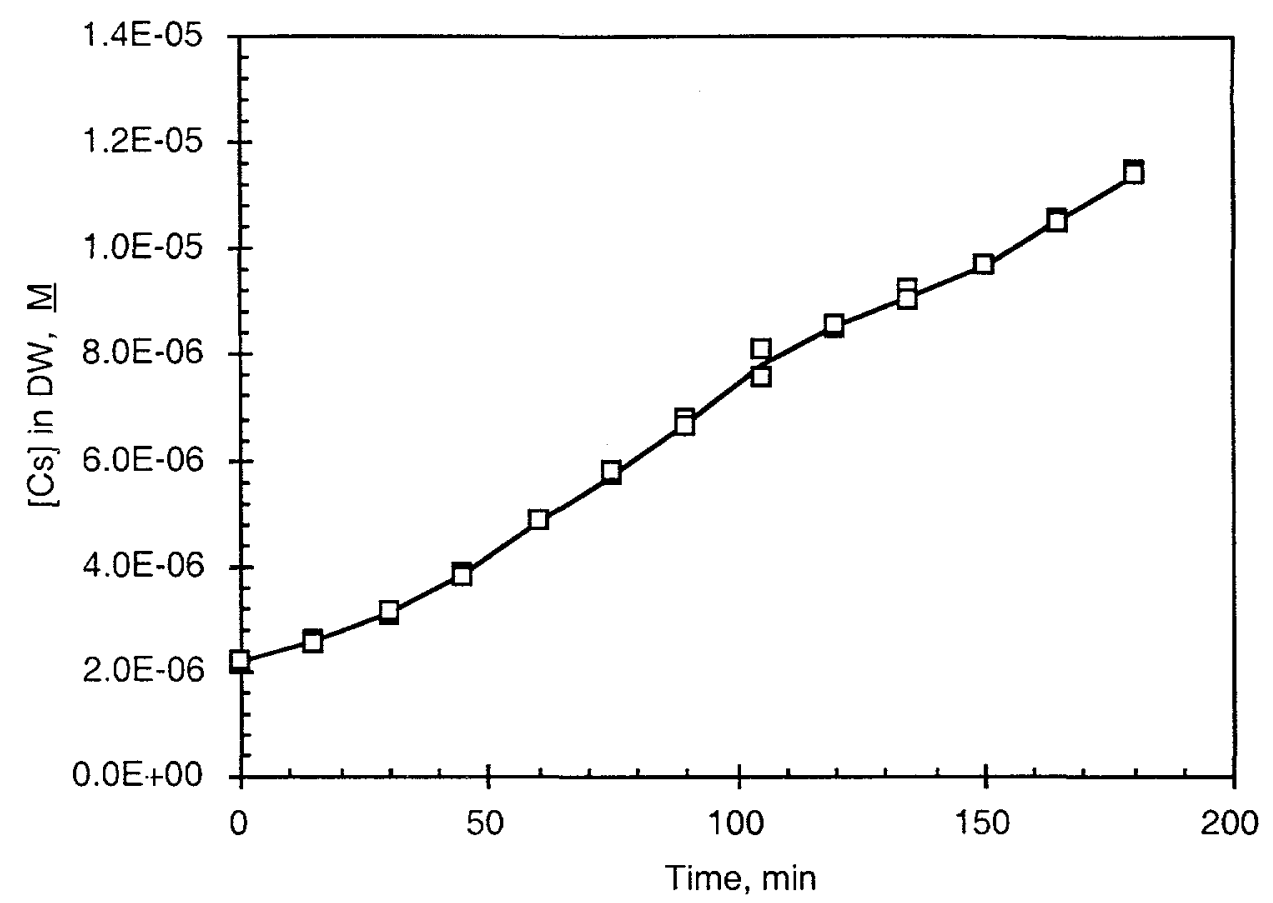

Fig. 16. Cesium Concentration in Aqueous (DW) Raffinate as a Function of Time for Test CS19

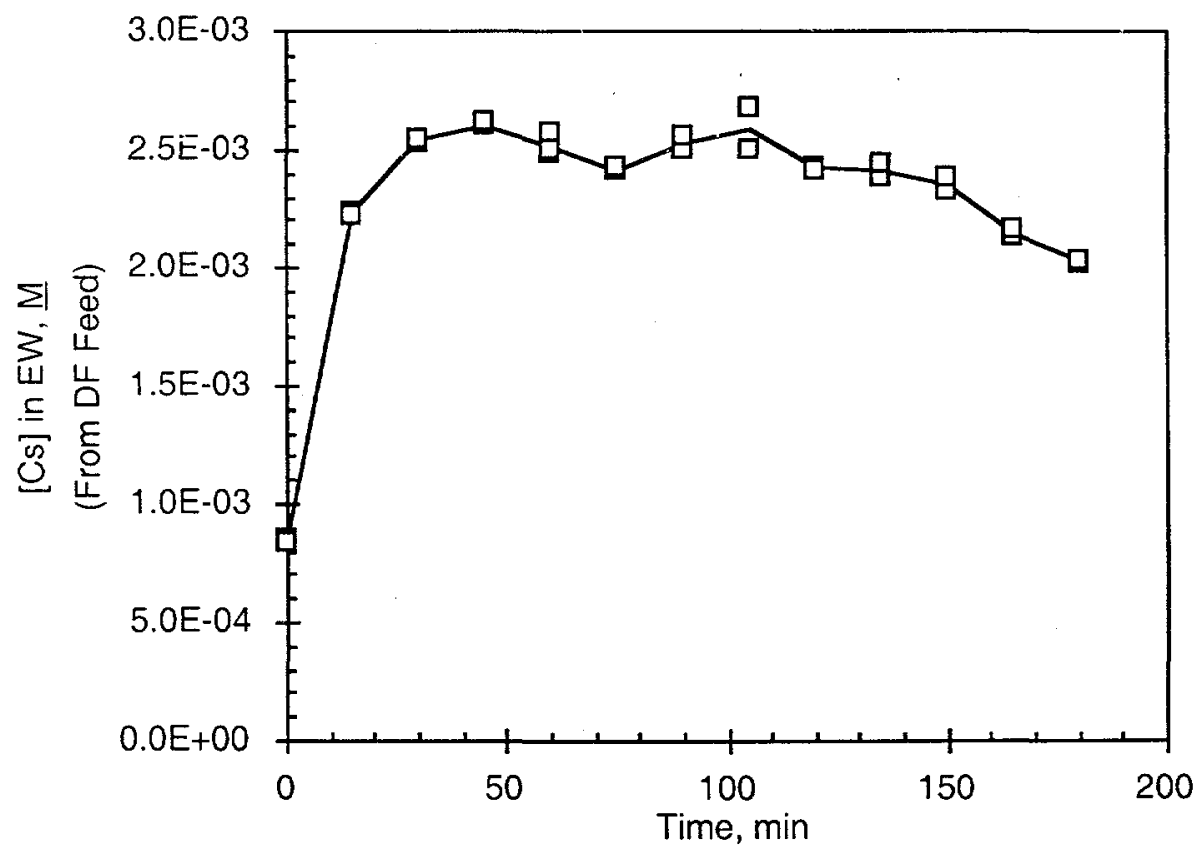

Fig. 17. Cesium Concentration in Aqueous (EW) Strip as a Function of Time for Test CS19 


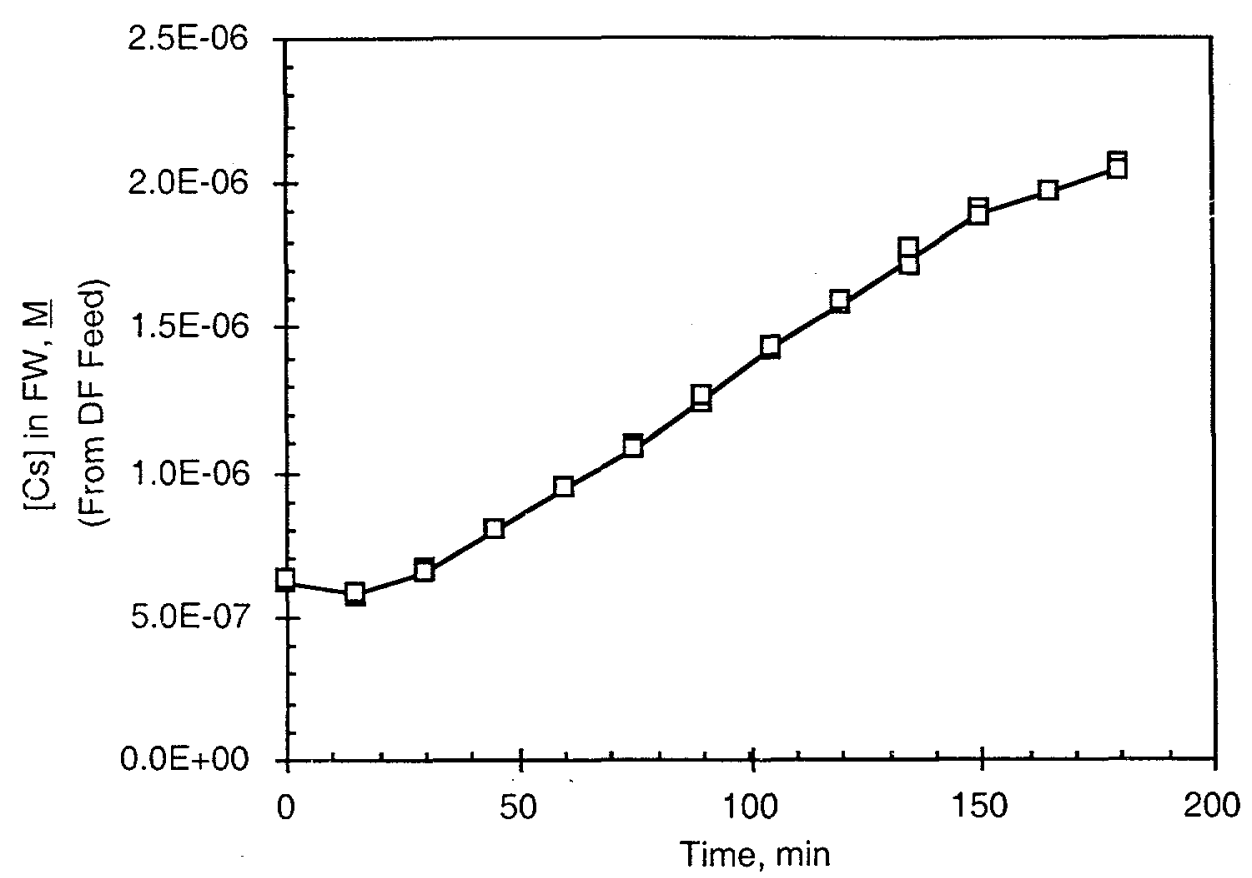

Fig. 18. Cesium Concentration in Aqueous (FW) Rinse as a Funcion of Time for Test CS19.

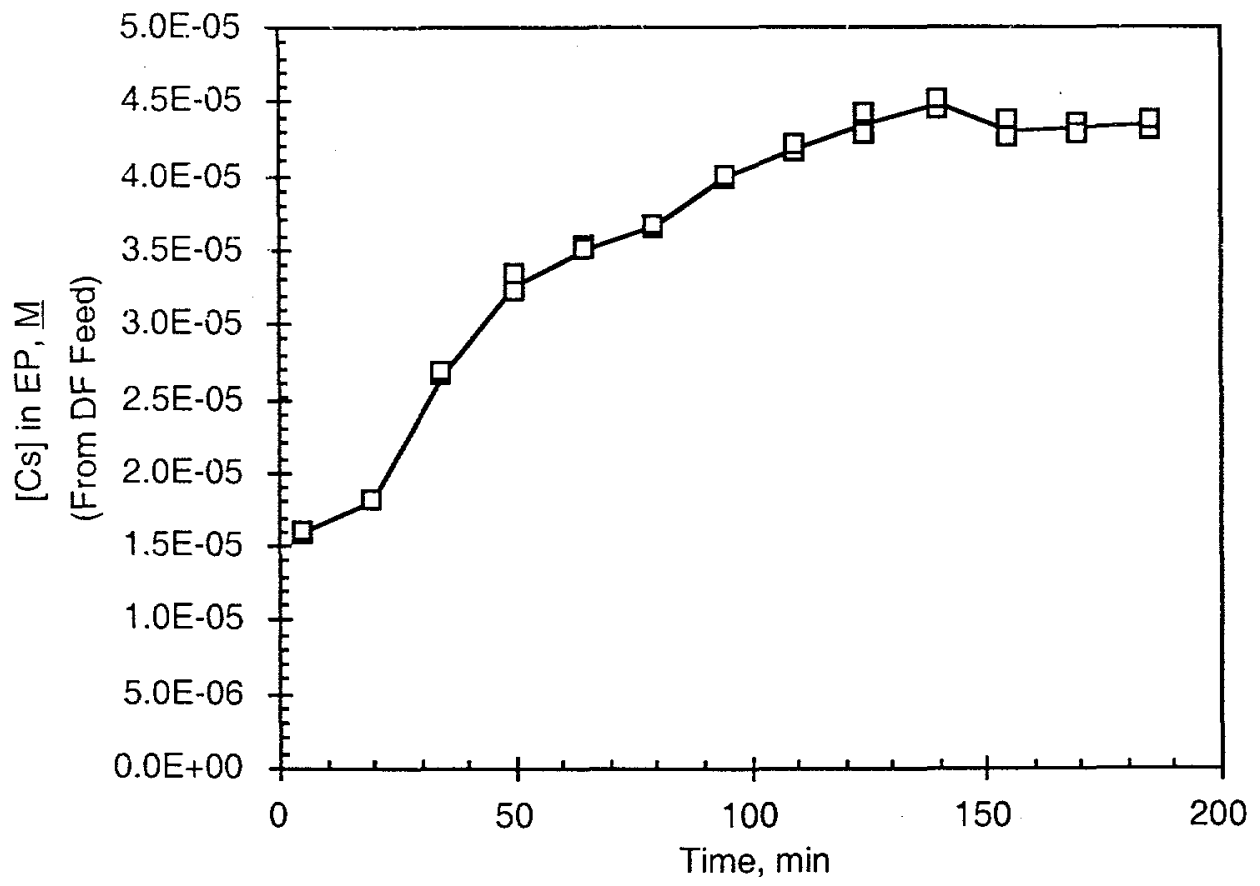

Fig. 19. Cesium Concentration in Organic (EP) Product as a Function of Time for Test CS19

Figure 20 shows the stage-to-stage cesium concentrations for test CS19 calculated using the SASSE spreadsheet [LEONARD-1994]. If the fractional stage efficiency for the extraction section is decreased from the correlation value of 0.719 (see Table 3 ) to 0.615 , while the stage 
efficiency for the strip section is decreased from the correlation value of 0.741 (see Table 3 ) to 0.610 , the model curve matches both the DW raffinate concentration and the EP product concentration. This is the model curve shown in Fig. 20. The model uses the $\mathrm{D}_{\mathrm{Cs}}$ values given in Table 2 and the flow rates given in Table 3. If these stage efficiencies had been kept at their correlation values (see Table 3 ) and the $\mathrm{D}_{\mathrm{Cs}}$ values changed from those given in Table $2, \mathrm{D}_{\mathrm{Cs}}$ for the extraction section would drop slightly, from 8.24 to 7.05 , and $\mathrm{D}_{\mathrm{Cs}}$ for the strip section would increase slightly, from 0.23 to 0.273 . Based on the temperature in the extraction and strip sections, these new $\mathrm{D}_{\mathrm{Cs}}$ values do not seem appropriate. Thus, the stage efficiency in both the extraction and strip sections was probably somewhat lower than that given by the correlation in Appendix C. However, these stage efficiencies, which were calculated from the SASSE model, are not unexpected given the scatter of the data used to derive the correlation, possible errors in estimating the process temperature, and the sensitivity of $\mathrm{D}_{\mathrm{CS}_{\mathrm{S}}}$ to the process temperature.

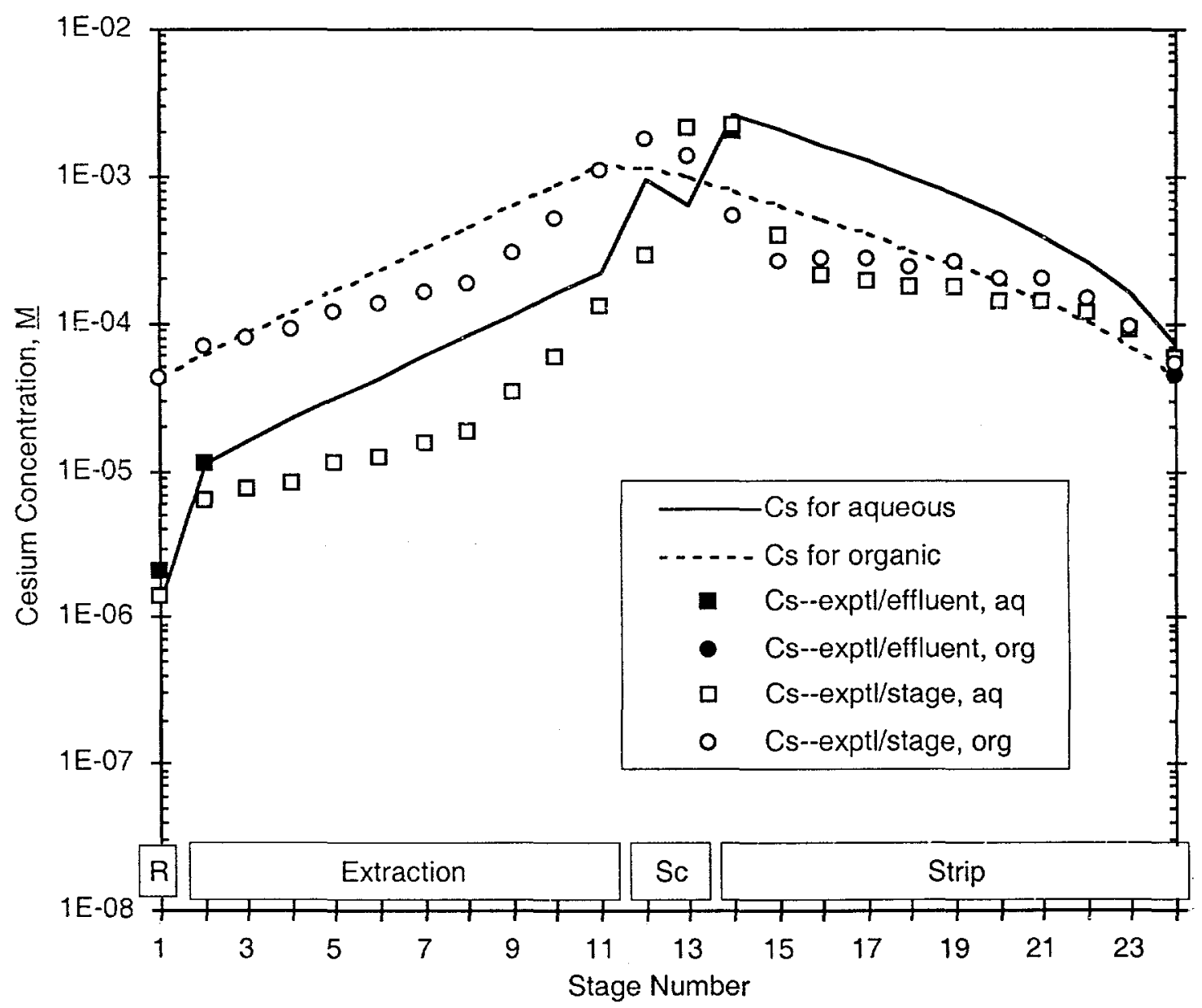

Fig. 20. Concentration Profile for Cs in Test CS19

At the end of the test, the process was stopped quickly, and the two liquid phases in each stage were drained and equilibrated. The $D_{C s}$ values obtained are plotted in Fig. 21 . The results for the strip section show that, after the first two stages, the $\mathrm{D}_{\mathrm{Cs}}$ values are high, ranging between 0.9 and 1.4. The lowest value, in stage 14 , was 0.23 . Thus, after the first two strip stages, the 
$\mathrm{D}_{\mathrm{Cs}}$ stage values measured after test CS19 are much higher than must have existed during the test. This estimate of a low $\mathrm{D}_{\mathrm{CS}}$ value in the strip section is based on the stripping required to obtain the low cesium concentration seen in the organic (EP) effluent.

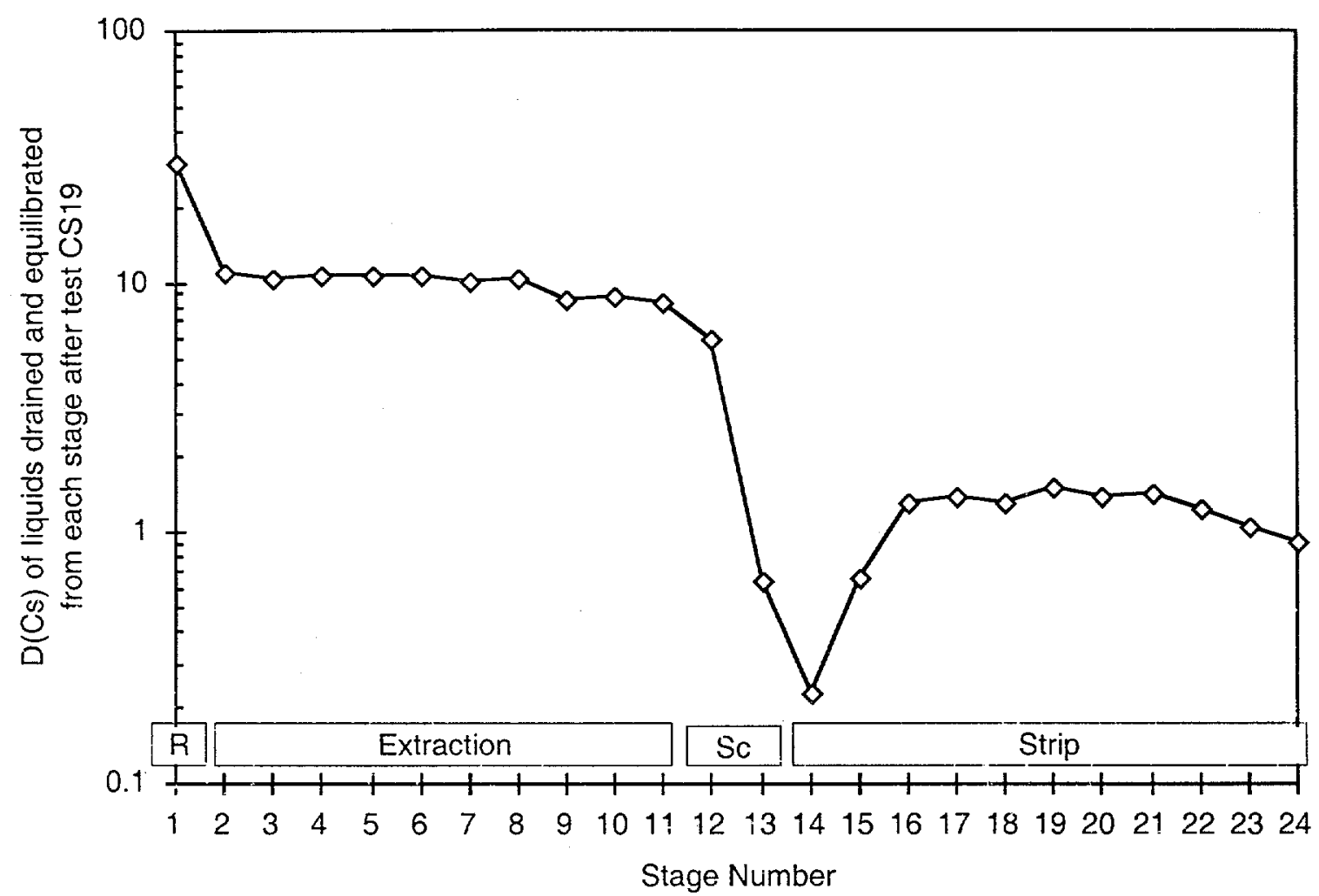

Fig. 21. Cesium Distribution Ratios for Each Stage at the End of Test CS19

In sum, the overall operation of the 24-stage 2 -cm contactor was quite good during test CS19. Hydraulic performance was good and there were no mechanical problems. One small problem was that the solvent in the solvent feed tank was gradually heated up over the 190-min test from an initial value of $25.7^{\circ} \mathrm{C}$ to a steady state value of $44 \pm 2^{\circ} \mathrm{C}$ after $115 \mathrm{~min}$. Because of the long solvent feed line to stage 1 and the cooling effect of contact with the rinse (FF) feed, the solvent would have been close to room temperature by the time it reached stage 2 , which is the first extraction stage. To check this assumption, the temperature of the extraction (DW) raffinate for test CS19 was compared with that for test CS18. It is noted that, after $100 \pm 10$ min of operation, this temperature was $27^{\circ} \mathrm{C}$, compared with $25^{\circ} \mathrm{C}$ for test CS18 at the same time. Since the DF feed and the glovebox were both $1^{\circ} \mathrm{C}$ warmer for test CS 19 , this translates to the DW effluent being an additional $11^{\circ} \mathrm{C}$ warmer for test $\mathrm{CS} 19$, because the DX feed was being warmed by the mixing in the solvent feed tank. 


\section{CONCLUSION}

An alkaline-side CSEX process for cesium removal from SRS tank waste using centrifugal contactors was evaluated in a multistage $2-\mathrm{cm}$ contactor and shown to work well. Various aspects of this evaluation are now discussed in more detail, including (1) hydraulic performance, (2) stage efficiency, (3) process scale-up, (4) solvent cost, (5) solvent chemistry, (6) alternative solvents, and (7) solvent recovery.

\section{A. Hydraulic Performance}

The overall hydraulic performance of the CSEX process was excellent. As discussed in Appendix $\mathrm{C}$, the phase inversion problems seen in the $2-\mathrm{cm}$ contactor are related to the small size of the contactors used to make the laboratory tests and should not occur in larger units. While the weir radius for the aqueous and organic phases was not optimized for the range of phase densities associated with this process, the unit still worked well. When a contactor is designed for this process, these weirs would be optimized. The dispersion number tests indicated that the phase separation would be poor in the strip section at low O/A flow ratios. However, the hydraulic performance tests in the $2-\mathrm{cm}$ contactor showed that the use of the centrifugal contactor can overcome this problem. Note that, because the cesium is concentrated in the strip effluent, the strip section will normally be operated at high O/A flow ratios where both the dispersion number and the hydraulic performance indicate good phase separation.

\section{B. Stage Efficiency}

While the $2-\mathrm{cm}$ contactors were designed to have a stage efficiency of $98 \%$, this is rarely realized because the flow in the interstage lines usually occurs as slugs of liquid rather than as a continuous flowing stream. As discussed in Appendix $\mathrm{C}$, this occurs because surface tension forces control the interstage flow at the low flow rates required for the 2 -cm contactor. At higher flow rates, that is, greater than 100 to $200 \mathrm{~mL} / \mathrm{min}$, the liquid momentum controls the interstage flow so that this flow becomes continuous. This allows the efficiency of each contactor stage to approach its design potential. Thus, a well-designed $4-\mathrm{cm}$ contactor should achieve stage efficiencies greater than $95 \%$, and $9-\mathrm{cm}$ and larger units should attain efficiencies greater than $99 \%$. In particular, the stage efficiencies in a well-designed multistage plant-scale $(25-\mathrm{cm})$ contactor required for this process will be excellent, essentially $100 \%$.

\section{Process Scale-up}

To scale up a solvent extraction process, one needs to know stage efficiency, the distribution ratios of the components (especially the key component or components) in each section of the process, the relative flow rates required, and the desired feed flow rate. With nearly $100 \%$ stage efficiency, as is the case for centrifugal contactors, process scale-up is very straightforward since each stage is equivalent to a theoretical stage. The laboratory-scale contactor tests reported here showed that the distribution ratio for cesium is well defined for the extraction and scrub sections. The $\mathrm{D}_{\mathrm{Cs}}$ value for the strip section varied in ways that we did not fully understand at the time. A fuller discussion of this problem is given below along with some ways to improve the 
solvent. Based on the 2 -cm contactor tests reported here, one should use a $D_{C s}$ value of 8 for the extraction section, a $\mathrm{D}_{\mathrm{Cs}}$ value of 1 for the scrub section, and a $\mathrm{D}_{\mathrm{Cs}}$ value of 0.2 for the strip section for the extractive separation of cesium from the rest of the SRS tank waste.

With this information from the laboratory-scale contactor tests, the simple process model [LEONARD-1999A] and the SASSE worksheet [LEONARD-1994] can be used to develop a flowsheet that meets the SRS goals. The three key SRS goals for this process are (1) a decontamination factor of 40,000 for the cesium from the other components in the DF feed, (2) a feed flow rate from the SRS waste tanks of $17.5 \mathrm{gpm}(66 \mathrm{~L} / \mathrm{min})$, and (3) a flow rate for the aqueous phase in the strip section of $1.5 \mathrm{gpm}(5.7 \mathrm{~L} / \mathrm{min})$ so that the cesium is concentrated by a factor of 11.7. When such a cesium concentration is achieved, no concentration will be required before the cesium effluent is fed to the glass plant melter. Note that the cesium feed to the melter will be essentially free of the other components in the DF feed so that glass plant operation is also simplified. To reach these design goals, a plant-scale contactor would require 17 extraction stages and 17 strip stages. With two additional stages for these two sections (for a conservative design), two scrub stages, two solvent recovery stages for the aqueous raffinate, two solvent recovery stages for the strip effluent, and two stages each for solvent cleanup and rinse (the need for these last few stages is still not certain), the plant-scale process would require a total of 42 to 46 stages. For the process flow rates required, the rotor size of the plant-scale contactor would be $25 \mathrm{~cm}$.

Assuming that all stages in the process will be run at the same temperature, the appropriate mode of operation is as follows. This operation mode is based on the fact that, as the temperature rises and falls due to seasonal variations, the $\mathrm{D}_{C s}$ values for the extraction and strip sections go down or up together. As the temperature rises, the DX flow rate would be reduced; as the temperature falls, the DX flow rate would be increased. This is done to keep an appropriate balance between the decontamination factor for the extraction section and the stripping factor for the strip section. If heating or cooling is possible, then making the extraction section cooler or the strip section hotter, or both, would further improve the process.

\section{Solvent Cost}

While BoBCalixC6 is very effective in extracting only cesium from a highly basic solution with many components, it would be a major process cost. We estimate that, at the production levels needed for this process, BoBCalixC6 would cost $\$ 150 / \mathrm{g}$. For $40 \mathrm{~g}$ of BoBCalixC6 from IBC Advanced Technologies (American Fork, UT) used in tests reported here, the cost was $\$ 500 / \mathrm{g}$. Earlier, $20 \mathrm{~g}$ of BoBCalixC6 from IBC had cost $\$ 725 / \mathrm{g}$. The production cost for the Cs3 is estimated to be $\$ 1.5 / \mathrm{g}$ based on the method that ORNL now uses to make this modifier. There is currently no commercial source for the Cs-3 modifier. The Isopar ${ }^{\circledR} \mathrm{L}$ cost will be less than $\$ 5 / \mathrm{L}$. Because a liter of solvent will cost $\$ 1844$, the estimated 1000 gal $(3800 \mathrm{~L})$ required for a plantscale process at SRS will cost $\$ 7.0 \mathrm{M}$. Note that the BoBCalixC6 is $93.5 \%$ of the solvent cost; Cs-3, 6.2\%; and Isopar ${ }^{\circledR} \mathrm{L}, 0.3 \%$ or less. The liquid volume in a $25-\mathrm{cm}$ contactor is $6.7 \mathrm{gal} / \mathrm{stage}$ ( $25 \mathrm{~L} /$ stage), so the total liquid in a 42 to 46 stage unit will be 280 to $310 \mathrm{gal}(1100$ to $1200 \mathrm{~L}$ ). Since 30 to $40 \%$ of this contactor liquid would be the solvent, 10 to $15 \%$ of the total solvent would actually be in the process at any one time. In the tests done here, the solvent was recycled four 
times and continued to function well. In the plant design, where a solvent life of one year is assumed, the solvent would be recycled many times. Thus, questions of solvent stability and solvent recovery become important. Some of these questions are discussed below.

\section{E. Solvent Chemistry}

The work done here shows that the distribution ratio for cesium is fairly sensitive to temperature. This temperature effect can be predicted by using Eq 1. Process operation that takes this temperature effect into account is discussed above.

After the initial multistage test (CS2), it appeared that precipitation of solids might be a problem. However, when the contactor was thoroughly cleaned after test CS2, we were able to operate without any solids or crud forming, even though the solvent was recycled four times

Further information on the solvent chemistry was obtained at ORNL [BONNESEN]. Their work shows that the other components listed in the SRS simulant (Tables 1 and 8) are not extracted by the BoBCalixC6. Also, the BoBCalixC6 will not extract $\mathrm{Hg}, \mathrm{Fe}, \mathrm{Pb}$, or silicate. The ORNL report gives $\mathrm{D}_{\mathrm{Cs}}$ as a function of $\mathrm{HNO}_{3}, \mathrm{NaOH}, \mathrm{Cs}^{+}, \mathrm{BoBCalixC6}$, and $\mathrm{Cs}-3$, as well as the results of initial tests to assess chemical and radiation damage. The results look encouraging. They do show that strong $(1 \underline{\mathrm{M}}) \mathrm{HNO}_{3}$ will degrade the $\mathrm{BcBC}$ alix 6 . For that reason, acid concentration in the strip feed is very low.

The use of iso-paraffins, such as Isopar ${ }^{\circledR} \mathrm{L}$, as the diluent in place of normal paraffins, such as normal dodecane (nDD), is probably not important. 'The normal paraffins have been used for many years in the Purex solvent with good success at SRS. Current work with the iso-paraffins started when crown ethers were used to extract strontium. It was found that solvents using isoparaffins were less likely to form a second organic phase than those using normal paraffins. For the current process solvent with its low concentration of both extractant and modifier, we do not anticipate a problem with either diluent. However, no tests have been done with nDD as the diluent. If nDD is used, tests should be carried out to determine whether there will be any process problems.

\section{F. Alternative Solvents}

The strip section in the multistage tests performed about as expected on the basis of batch $\mathrm{D}_{\mathrm{Cs}}$ values measured at $\mathrm{ANL}$ after each test using the feeds from the test. However, the two liquid phases from most strip stages, which were collected at the end of each multistage test and equilibrated, had higher $\mathrm{D}_{\mathrm{Cs}}$ values than expected. Our expectations were based on (1) the batch tests using the feeds from each multistage test and (2) the cesium concentration in the organic (EP) product from each multistage test. In addition, these $\mathrm{D}_{\mathrm{Cs}}$ values for the stripping section were higher than those measured at ORNL with solutions that were prepared to be identical. At ORNL, the $\mathrm{D}_{\mathrm{Cs}}$ values for the stripping section were as low as 0.02 . Further work at ORNL seems to have identified the discrepancy [MOYER]. It appears that the aqueous (DF) feed made at ANL contained two surfactants, undecyl and dodecyl sulfonic acids in their anionic form, in the $1 \mathrm{ppm}$ range. These surfactants were also present in the ORNL feed, but at a much lower concentration. 
These two surfactants, which are common ingredients for liquid detergents, were found by electrospray mass spectrometry to be present in "Joy" liquid detergent. This detergent is used for cleaning glassware at ANL. As a further test of this hypothesis, sodium dodecyl sulfonate was added to the aqueous (DF) feed at ORNL and found to cause the same stripping problems that were seen earlier with the aqueous (DF) feed prepared at ANL.

Work is being done at ORNL to improve the stripping of cesium from the solvent [BONNESEN, MOYER]. One solution has already been found to be quite effective, trioctylamine (or other suitable alkylamine extractant) at very low concentrations $\left(1 \times 10^{-5}\right.$ to $\left.1 \times 10^{-3} \underline{\mathrm{M}}\right)$ in the solvent. With this solvent additive, the $\mathrm{D}_{\mathrm{CS}}$ values in the stripping section are all about 0.02 , even for the aqueous (DF) feeds made at ANL. With this solvent additive, the number of extraction and strip stages required to meet the process goals for the SRS tank waste could be reduced.

\section{G. Solvent Recovery}

Any extractant (BoBCalixC6) and modifier (Cs-3) leaving with the aqueous raffinate and the aqueous strip effluent as dissolved or dispersed material can be recovered by contacting each effluent with two stages of the diluent (Isopar ${ }^{\mathbb{B}} \mathrm{L}$ ). The rate at which solvent is lost by dispersion and dissolution in the aqueous effluents determines the size of the solvent recovery system. The loss rate can be calculated if the concentration of the solvent dispersion and the dissolved extractant is known or can be estimated. Based on the cloudiness of the aqueous effluents, the dispersed solvent in the effluents can be estimated to be $20 \mathrm{ppm}$ (very clear) to $400 \mathrm{ppm}$ (very cloudy). The dissolution of $\mathrm{BoBCalixC6}$, which includes two crown ethers in its structure, in the effluents is estimated to be equal to or less than that of a molecule that includes only one crown ether, bis$4,4^{\prime}\left(5^{\prime}\right)$ [(tert-butyl)cyclohexano]-18-crown-6 (CE_Sr). The dissolution of CE_Sr is aqueous effluents is in the range of 7 to 15 ppm [LEONARD-1999B].

Solvent recovery would be done as follows. The aqueous effluent would be fed to two recovery stages in series. The diluent feed to each recovery stage would be operated at full recycle for just that stage and should recover $98 \%$ or more of the solvent from the aqueous phase as it passes though the stage. When the BoBCalixC6 concentration in the first-recovery-stage diluent increases so that it is 1 to $5 \%$ of its concentration in the solvent, this diluent would be sent to a vacuum distillation unit. There, Isopar ${ }^{\circledR} \mathrm{L}$ would be recovered as the overhead product since it is more volatile than either the extractant or the modifier. The extractant and modifier, now concentrated in the bottom of the vacuum distillation unit to about the same value as the working solvent, would be returned to the process. The diluent feed for the second recovery stage would be moved to the first recovery stage, and the recovered (distilled) diluent would be returned to the second recovery stage. In this way, $99.9 \%$ of the solvent in the aqueous effluents should be recovered and recycled. In addition, the recovery medium, the pure Isopar ${ }^{\circledR} \mathrm{L}$, is itself recovered and reused.

No work was done to demonstrate the effectiveness with which pure Isopar ${ }^{\circledR} \mathrm{L}$ can remove the solvent from the aqueous effluents in a centrifugal contactor stage. However, such techniques have been done on a batch basis. For example, at ORNL, concentrations of BoBCalixC6 and Cs-3 
in aqueous phases are determined by, first, contacting the aqueous phase with dichloromethane to extract these organics. Then, the dichloromethane is evaporated to dryness. The residual weight gives the total mass of solvent that was in the aqueous phase. This residue is then redissolved in hexamethyl benzene and the concentration of BoBCalixC 6 and $\mathrm{Cs}-3$ is determined by nuclear magnetic resonance. Given that centrifugal contactors have high stage efficiencies and that an organic phase is commonly used to recover organic molecules from an aqueous phase, solvent recovery from the aqueous effluents using the process diluent should be straightforward. 


\section{ACKNOWLEDGMENTS}

This work was supported by the U.S. Department of Energy through the Efficient Separations and Processing Crosscutting Program, Office of Science and Technology, Office of Environmental Management, and through the Savannah River Technical Center at the Savannah River Site under Contract W-31-109-Eng-38 with Argonne National Laboratory, managed by the University of Chicago. The authors acknowledge the co-operative working relationship with members of the Savannah River Site, especially, Reid A. Peterson, Walter Tamosaitis, Joe Carter, Kenneth Rueter, Major Thompson, and Steve Piccolo. The authors also acknowledge the continuing co-operative relationship with members of Oak Ridge National Laboratory, especially, Bruce A. Moyer and Peter V. Bonnesen. 


\section{APPENDIX A}

\section{DISCUSSION OF CESIUM DISTRIBUTION RATIO DATA MEASURED AT ANL}

\section{INTRODUCTION}

In this appendix, we discuss the ${ }^{137} \mathrm{Cs}$ distribution ratio $\left(\mathrm{D}_{\mathrm{Cs}}\right)^{1}$ data given in Appendix $\mathrm{B}$. These data were collected at ANL in support of the alkaline-side CSEX process for solvent extraction developed by Bruce Moyer and associates at ORNL [BONNESEN]. This process was developed for extracting cesium ion from alkaline tank waste solutions. We collected these data for two purposes:

7. To help in the flowsheet design to demonstrate this process in our 24-stage 2-cm minicontactor.

8. To reconcile the differences in ${ }^{137} \mathrm{Cs}$ distribution ratios measured under stripping conditions at ANL and ORNL.

We were able to use these data in the design and demonstration of the process flowsheet, but a satisfactory answer to differences between the measured distribution ratios eluded us. A discussion of these two topics follows. Note that, since this work was done, these differences have been yesolved. Further work done by Bruce Moyer and coworkers at ORNL have identified indecyl and dodecyl sulfonic acids as responsible for the discrepancy (see [BONNESEN, MOYER]). They have also shown that the addition of a trialkylamine would improve stripping performance and provide insufance against potential problems associated with organic-phasesoluble anionic impurities, such as undecyl and dodecyl sulfonates, in the aqueous feed.

\section{FLOWSHEET DESIGN}

Four important observations about this solvent extraction process are evident from studying the data in Appendix $\mathrm{B}$. They are (1) $\mathrm{D}_{\mathrm{Cs}}$ can be increased by increasing the concentration of nitrate or hydroxide anions, (2) there is a strong dependence of $\mathrm{D}_{\mathrm{Cs}}$ on temperature, (3) $\mathrm{D}_{\mathrm{Cs}}$ measured at tracer levels can be inconsistent, and (4) trialkyl amines have a positive effect on the stripping of cesium. These topics are discussed here along with their application to flowsheet design. Note that all $\mathrm{D}_{\mathrm{Cs}}$ values were determined by measuring the amount of ${ }^{137} \mathrm{Cs}$ in each phase after equilibration of the two phases.

First, $\mathrm{D}_{\mathrm{Cs}}$ can be increased by increasing the aqueous phase concentration of nitrate or hydroxide ions. This effect for the nitrate ions is due to $\mathrm{CsNO}_{3}$ being the most easily extractable aqueous-phase salt by the neutral BoBCalixC6 extractant. This is the operative mechanism specified by the ORNL developers. However, the highest $D_{C s}$ values measured at $A N L$ were from solutions containing only hydroxide anion. In tracer studies, the $\mathrm{D}_{\mathrm{Cs}}$ values from $0.001 \mathrm{M} \mathrm{NaOH}$

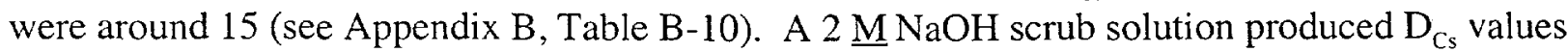

\footnotetext{
${ }^{1} \mathrm{D}_{\mathrm{Cs}}$ is the ratio of the concentrations of ${ }^{137} \mathrm{Cs}$ in the organic and aqueous solutions following equilibration of the solutions by mixing at a selected temperature.
} 
of 40 to 60 (see Appendix B, Table B-12). The reason that $\mathrm{NaOH}$ (and presumably the hydroxide anion alone) gives such a high $\mathrm{D}_{\mathrm{Cs}}$ value is not fully understood. This effect could be due to an acidic impurity or an acidic hydrogen on the BoBCalixC6 or the CS-3 modifier.

Second, the large decrease in $\mathrm{D}_{\mathrm{Cs}}$ with increasing temperature is the greatest temperature effect we have ever encountered in a solvent extraction system. Figures A-1 and A-2 show this temperature effect in the standard thermodynamic plot of $\ln \left(\mathrm{D}_{\mathrm{C}_{s}}\right)$ vs. $1 / \mathrm{T}$, where $\mathrm{T}$ is temperature in kelvin. The large negative enthalpy of this reaction ( $\Delta \mathrm{H}$ for the line is $-84 \mathrm{~kJ} / \mathrm{mol}$ for Fig. A-1 and $-85 \mathrm{~kJ} / \mathrm{mol}$ for Fig. A-2) makes process temperature an important operating parameter. For example, if the $\mathrm{D}_{\mathrm{Cs}}$ value were 10 at $25^{\circ} \mathrm{C}$, it would be 5.8 at $30^{\circ} \mathrm{C}$, and 17.7 at $20^{\circ} \mathrm{C}$. Note that, for Fig. A-1, the data are given in Table B-5 of Appendix B; the line (average) is based on the average of the data at 25 and $50^{\circ} \mathrm{C}$; the slope of the line is $10,300 \mathrm{~K}$; and $\Delta \mathrm{S}$ for the line is -0.3 $\mathrm{kJ} /$ (degree $\bullet \mathrm{mol})$. For Fig. A-2, the data are given in Tables B-12, $-13,-15,-16$, and -17 of Appendix $\mathrm{B}$ (the second and third contacts in the batch strip operation), the line (model) is based on a least-squares fit of the data at 19,25 , and $52^{\circ} \mathrm{C}$; the slope of the line is $10,160 \mathrm{~K}$; and $\Delta \mathrm{S}$ for the line is $-0.3 \mathrm{~kJ} /$ (degree $\bullet \mathrm{mol})$. Based on these data, a slope of $10,200 \mathrm{~K}$ was used for temperature coefficient a of Eq. 1 in the main body of this report.

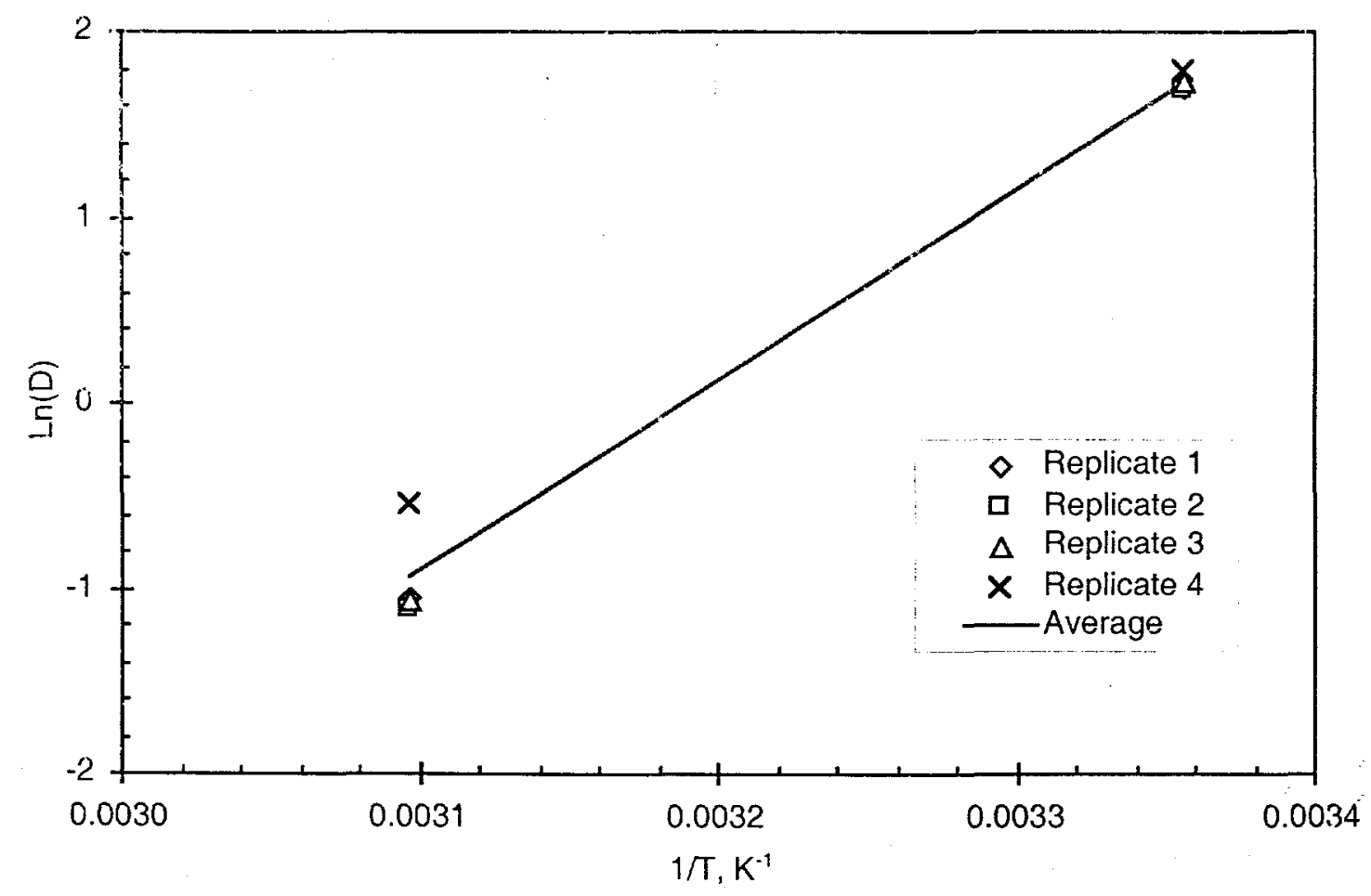

Fig. A-1. Effect of Temperature on $\mathrm{D}_{\mathrm{Cs}}$ for CSEX Solvent and in Aqueous Phase of $1 \mathrm{M} \mathrm{NaNO}_{3}$ and $0.02 \underline{\mathrm{M} \mathrm{NaOH}}$ 


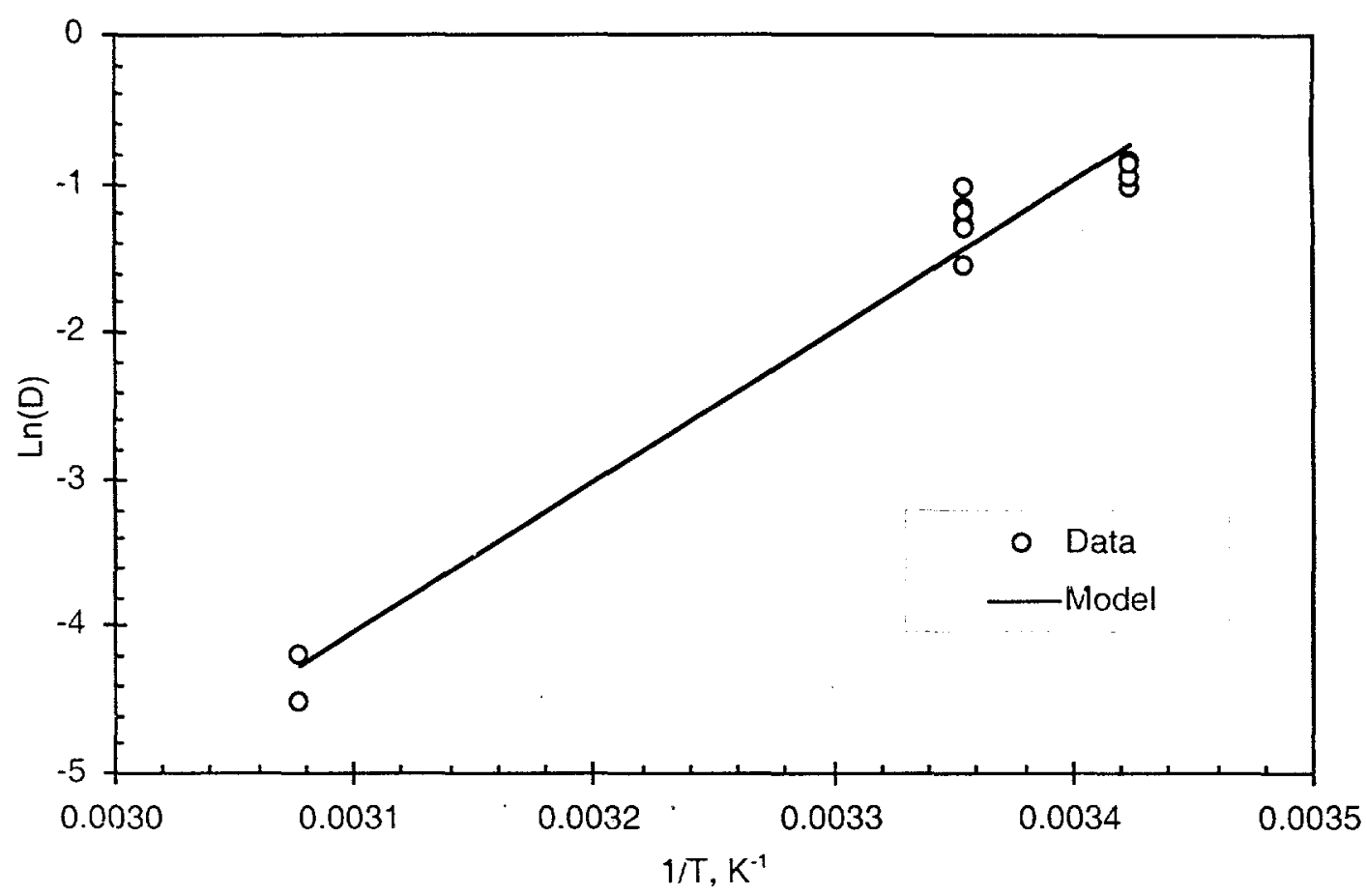

Fig. A-2. Effect of Temperature on $\mathrm{D}_{\mathrm{Cs}}$ for CSEX Solvent under Stripping Conditions of $0.0005 \mathrm{M} \mathrm{HNO}_{3}$ and $0.0001 \underline{\mathrm{M} \mathrm{CsNO}}_{3}$

Third, $\mathrm{D}_{\mathrm{Cs}}$ values measured when only tracer levels of ${ }^{137} \mathrm{Cs}\left(\sim 1 \times 10^{-7} \underline{\mathrm{M}}\right)$ are present are generally higher and more difficult to reproduce than when total cesium concentrations are $\geq 1 \times 10^{-}$ ${ }^{5} \mathrm{M}$. The mass balance for cesium was as good at tracer levels as at higher cesium concentrations. Thus, the inconsistency of tracer-level extraction results is probably due to minor constituents present in the solvent or the aqueous solutions or both. If this is the case, then the ORNL approach of adding natural cesium nitrate to the strip solution is certainly valid.

Fourth, also remarkable is the positive effect of trialkylamine on the stripping behavior of the solvent (compare stripping data in Appendix B, Tables B-12 through - 16 with those in Tables B-17 and -18). As is discussed in the next section, ANL stripping results have not all agreed with measurements made at $\mathrm{ORNL}$. The $\mathrm{D}_{\mathrm{Cs}}$ values for batch and countercurrent stripping after the solvent was contacted with the ANL-produced SRS-feed simulants were always in 0.2 to 0.3 , compared with measurements of 0.02 to 0.04 at ORNL. However, very low concentrations of triisooctylamine $\left(10^{-4} \underline{\mathrm{M}}\right)$ in the solvent drops the $\mathrm{D}_{\mathrm{Cs}}$ value in the strip section into the range from 0.02 to 0.04 under all conditions studied at ANL and ORNL. Two explanations can be put forward.

g. The first explanation originated at ORNL [BONNESEN]. Cesium nitrate is extracted into the organic solvent in two forms - (1) the more extractable form, where Cs-BoBCalix $6^{+}$and $\mathrm{NO}_{3}$ are dissociated in the solvent, and (2) the less extractable, undissociated $\mathrm{CsNO}_{3}-\mathrm{BoBCalixC6}$ form. The organic soluble trialkylamine $\left(\mathrm{R}_{3} \mathrm{~N}\right)$ forms the organic salt $\mathrm{R}_{3} \mathrm{NH}^{+} \mathrm{NO}_{3}{ }^{-}$when contacted by the aqueous scrub and strip solutions which contain nitric acid. The additional nitrate ion in the organic phase forces 
the association of the $\mathrm{Cs}-\mathrm{BoBCalixC} 6^{+}$and $\mathrm{NO}_{3}{ }^{-}$and, therefore, decreases cesium-ion partitioning to the organic solvent.

h. The second explanation is that more than one neutral cesium salt exists in the organic solvent. In this case, the counter anion to cesium would be less hydrophilic than nitrate and, therefore, more difficult to strip. This anion could be from an acidic organic impurity in the solvent or some species that is extracted with $\mathrm{Cs}^{+}$from the aqueous feed: In either case, adding a trialkylamine to the solvent provides an organic-soluble cation that bonds more strongly to the minor impurity than does $\mathrm{Cs}^{+}$. Cesium is then readily stripped as a nitrate salt.

In all likelihood, both mechanisms are significant. Adding small quantities of trialkylamine will (1) increase stripping efficiencies with fresh solvent and (2) negate stripping problems due to potential buildup of acidic degradation products and yet-unspecified extractable components of tank waste feeds. Trialkylamine addition should be considered in future testing and development activities for the alkaline-side CSEX process.

\section{RECONCILIATION OF ANI. AND ORNL DISTRIBUTION RATIOS}

The first multistage countercurrent demonstration of the alkaine-side CSEX process (test CS2) and the subsequent batch-contact experiments at ANL (see Appendix B here) showed the distribution ratio for ${ }^{137} \mathrm{Cs}$ to be approximately an order oî magnitude higher than expected based on the ORNL results [BONNESEN]. Between that time and the second multistage demonstration (tests CS18 and CS 19), both ANL and ORNL worked diligently to reconcile the differences. We found that the differences were not due to:

9. Contact with stainless steel

10. Contact with Teflon PFA

11. Contact with glass

12. Differences in experimental method

13. Differences in counting techniques

14. Differences in personnel making the measurements

15. Differences in location

16. Differences in water quality

17. Differences in composition of the strip solution

18. Differences in solvent composition

19. Differences in batches of the BoBCalixC6

20. Differences in batches of the CS-3 modifier

The differences in stripping performance were eventually attributed to the SRS feed simulants prepared at the two laboratories. The inorganic compositions are the same by chemical analysis, but the effect on cesium stripping is quite different. When ORNL personnel tested the feed simulants prepared at $A N L$, they measured the same high $D_{C s}$ values for cesium stripping that we saw at ANL. Two differences between the feed simulants prepared at ANL and those prepared at ORNL have been found. 
First is a difference in how the simulants were prepared. At ORNL, all preparation is done in small batches using small-scale equipment (e.g., test tubes) made of Teflon At ANL, solutions are prepared in large batches using glassware for eventual storage in high-density polyethylene bottles. Preparing highly alkaline solutions in Pyrex will cause some leaching of glass from the container. Although silicate additions did not affect cesium distribution in earlier ORNL experiments, the form of the leached species is not known at this time.

Second, a difference was discovered when ANL extracted both the ANL and ORNL feed simulants (SRS\#2) with deuterochlorobenzene (a solvent that should extract polar and non-polar organic compounds from a high-ionic-strength aqueous solution). The NMR (nuclear magnetic resonance) spectra revealed a signature in the deuterochlorobenzene from the ORNL simulant with a concentration of $\sim 0.01 \mathrm{M}$ hydrogen atoms. Researchers at ORNL felt this signature may be due to acetone used to rinse the beaker before their simulant was prepared. The NMR experts at ANL do not feel the chemical shift is consistent with the presence of acetone. However, even if acetone were present, because of its low concentration, it would probably not have affected the stripping of cesium from the CSEX solvent.

As discussed in the body of this report, further work at ORNL after tests CS18 and CS19 showed that the aqueous (DF) feed made at ANL contained two surfactants, undecyl and dodecyl sulfonic acids in their anionic form, in the 1 ppm range. One of these components, sodium dodecyisulforiate, was added to the aqueous (DF) feed at ORNL and found to cause the same stripping problems that were seen earlier with the aqueous (DF) feed prepared at ANL [MOYER]. With the completion of this work at ORNL, the discrepancies between the ANL ard ORNL strip data have been resolved.

\section{CONCLUSIONS}

In analyzing the $\mathrm{D}_{\mathrm{Cs}_{\mathrm{s}}}$ data measured at $\mathrm{ANL}$ and reported in Appendix $\mathrm{B}$, we found that ( 1 ) $\mathrm{D}_{\mathrm{Cs}}$ can be increased by increasing the concentration of nitrate or hydroxide anions, $(2) \mathrm{D}_{\mathrm{Cs}}$ is strongly dependent on temperature, (3) $\mathrm{D}_{\mathrm{Cs}}$, when measured at tracer levels, can be inconsistent, and (4) trialkylamines have a positive effect on the stripping of cesium. These observations were considered in the design of the second series of multistage tests (tests CS18 and CS19).

Reconciliation of the discrepancy in cesium stripping between ANL and ORNL was only partially completed in this work. Many differences were eliminated until the aqueous (DF) feed was identified as the source of the problem. Later work, which was done at ORNL, identified undecyl and dodecyl sulfonic acids, common surfactants in laboratory detergents, as the source of the problem. As noted in the body of this report, the addition of a trialkylamine will improve stripping performance and provide insurance against many potential problems such as trace levels of undecyl and dodecyl sulfonic acids in the feed. Work on the use of a trialkylamine as a component of the solvent is being continued at ORNL. 


\section{APPENDIX B \\ CESIUM DISTRIBUTION RATIOS MEASURED AT ANL}

This appendix contains the cesium distribution ratio $\left(\mathrm{D}_{\mathrm{Cs}}\right)$ data that were collected to $(1)$ support the flowsheet design for the alkaline-side CSEX process and (2) reconcile differences in $\mathrm{D}_{\mathrm{Cs}}$ values measured at $\mathrm{ANL}$ and ORNL. The data are discussed in Appendix $\mathrm{A}$. Note that all $\mathrm{D}_{\mathrm{Cs}}$ values were determined by measuring the amount of ${ }^{137} \mathrm{Cs}$ in each phase after equilibration of the two phases. To address the possibility of kinetics effects during equilibration, the two phases were contacted using vigorous vortexing for 10,15 , and $30 \mathrm{~s}$. It was found that equilibrium was essentially attained at $30 \mathrm{~s}$. All tests reported here were carried out with sufficient vortexing to insure equilibrium conditions. ORNL personnel also explored kinetic effects and found that they were not a problem [BONNESEN]. Extraction and stripping by vortex mixing were very fast so that $D_{C s}$ values were within $10 \%$ of equilibrium after $15 \mathrm{~s}$.

For these tests, three batches of solvent were prepared at ANL. The first batch of $1.6 \mathrm{~L}$ was prepared on July 17, 1998 for the first multistage test, CS2. The second batch of $1.2 \mathrm{~L}$ was prepared on August 19, 1998 for the single-stage stage efficiency tests. The third batch of 1:2 L was prepared on September 17, 1998 for the second and third multistage tests, CS18 and CS19. Most of the tests reported here used the solvent from the first batch. Where the solvent source is known, it is indicated. In all cases, the BoBCalixC6 was made by IBC Advanced Technoiogies, all the Cs-3 was made at ORNL, and all the Isopar ${ }^{B} \mathrm{~L}$ is from Exxon Corp.

Table B-1. Cesium Distribution Ratio between CSEX Solvent and $1 \underline{\mathrm{M}} \mathrm{NaNO}_{3}$

Solvent: $0.01 \underline{\mathrm{M} B o B C a l i x C 6}$ and $0.20 \mathrm{M} \mathrm{Cs}-3$ in Isopar ${ }^{\circledR 8} \mathrm{~L}$. This fresh solvent was taken from the solvent batch that was prepared for multistage test CS2.

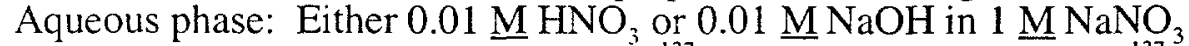

Cesium: Initially was present either as ${ }^{137} \mathrm{Cs}$ at the tracer level or as ${ }^{137} \mathrm{Cs}$ at the tracer level plus $0.001 \mathrm{M} \mathrm{CsNO}_{3}$ in the aqueous phase.

Temperature: $25^{\circ} \mathrm{C}$

Organic-to-aqueous volume ratio: $1 / 1$

Test vessel: Glass centrifuge tubes

\begin{tabular}{|c|c|c|c|c|c|}
\hline $\begin{array}{c}\text { Component in } \\
\text { Addition to } 1 \mathrm{M} \\
\mathrm{NaNO}_{3}\end{array}$ & $\begin{array}{c}\text { Direction of } \\
\text { Extraction }\end{array}$ & $\mathrm{D}_{\mathrm{Cs}}$ & $\begin{array}{c}\text { Mass Balance, } \\
\%\end{array}$ & $\mathrm{D}_{\mathrm{Cs}}$ & Mass Balance, \% \\
\cline { 3 - 6 } & forward & 4.1 & 99 & 5.0 & 99 \\
\hline $0.01 \mathrm{M} \mathrm{HNO}_{3}$ & reverse & 4.2 & 93 & 3.4 & 91 \\
\hline $0.01 \underline{\mathrm{M} \mathrm{NaOH}}$ & forward & 4.9 & 112 & 3.9 & 110 \\
\hline$"$ & reverse & 5.8 & 97 & 4.0 & 95 \\
\hline
\end{tabular}


Table B-2. Cesium Distribution Ratio between CSEX Solvent and Dilute Acid or Base

Solvent: $0.01 \underline{\mathrm{M}}$ BoBCalixC6 and $0.20 \underline{\mathrm{M} C s-3}$ in Isopar ${ }^{(B)} \mathrm{L}$. This fresh solvent was taken from the solvent batch that was prepared for multistage test CS2.

Aqueous phase: Either $0.001 \mathrm{M} \mathrm{HNO}_{3}$ or $0.001 \underline{\mathrm{MNaOH}}$

Cesium: Initially was either tracer level or $0.001 \underline{\mathrm{M}} \mathrm{CsNO}_{3}$ in the aqueous phase.

Temperature: $25^{\circ} \mathrm{C}$

Organic-to-aqueous volume ratio: $1 / 1$

Test vessel: Glass centrifuge tubes

\begin{tabular}{|c|c|c|c|c|c|}
\hline \multirow[b]{2}{*}{ Aquieous Phase } & \multirow[b]{2}{*}{$\begin{array}{c}\text { Direction of } \\
\text { Extraction }\end{array}$} & \multicolumn{2}{|c|}{ Tracer ${ }^{137} \mathrm{Cs}$} & \multicolumn{2}{|c|}{ Tracer ${ }^{137} \mathrm{Cs}+0.001 \mathrm{M} \mathrm{CsNO}_{3}$} \\
\hline & & $\mathrm{D}_{\mathrm{Cs}}$ & $\begin{array}{c}\text { Mass Balance, } \\
\%\end{array}$ & $\mathrm{D}_{\mathrm{Cs}}$ & $\begin{array}{c}\text { Mass Balance, } \\
\%\end{array}$ \\
\hline $0.001 \underline{\mathrm{MHNO}_{3}}$ & forward & 0.15 & 89 & 0.060 & 99 \\
\hline$"$ & reverse & 2.2 & 96 & 1.6 & 100 \\
\hline $0.001 \underline{\mathrm{M} \mathrm{NaOH}}$ & forward & 6.3 & 94 & 0.11 & 103 \\
\hline$"$ & reverse & 3.7 & 96 & 1.9 & 96 \\
\hline
\end{tabular}


Table B-3. Cesium Distribution Ratio between CSEX Solvent and $1 \underline{\mathrm{MNaNO}} \mathrm{Na}_{3}$ with $0.01 \underline{\mathrm{M}}$ $\mathrm{HNO}_{3}$

Solvent: $0.01 \underline{\mathrm{M} B o B C a l i x C 6}$ and $0.20 \mathrm{M} \mathrm{Cs}-3$ in Isopar ${ }^{\circledR} \mathrm{L}$. This fresh solvent was taken from the solvent batch that was prepared for multistage test CS2.

Aqueous phase: $1 \underline{\mathrm{M}} \mathrm{NaNO}_{3}$ with $0.01 \mathrm{M} \mathrm{HNO}_{3}$

Cesium: Except as noted, ${ }^{137} \mathrm{Cs}$ was initially present at the tracer level in the aqueous phase.

Temperature: $25^{\circ} \mathrm{C}$

Organic-to-aqueous volume ratio: $1 / 1$

Test vessel: Glass centrifuge tubes

\begin{tabular}{|c|c|c|}
\hline Contact & $\mathrm{D}_{\mathrm{Cs}}$ Value & Material Balance, \% \\
\hline DCs-1 $^{\mathrm{a}}$ & 4.5 & 101 \\
\hline$"$ & 4.1 & 99 \\
\hline$"$ & 4.3 & 92 \\
\hline$"$ & 4.6 & 100 \\
\hline$"$ & $5.0^{\mathrm{h}}$ & 99 \\
\hline DCs-2 & 4.5 & 94 \\
\hline$"$ & 4.2 & 93 \\
\hline$"$ & 4.1 & 92 \\
\hline$"$ & 4.7 & 103 \\
\hline$"$ & $3.4^{\mathrm{e}}$ & 91 \\
\hline DCs-3 & 4.1 & 101 \\
\hline DCs-4 $^{\mathrm{c}}$ & 3.9 & 100 \\
\hline
\end{tabular}

a. Contact DCs- 1 was between fresh solvent with fresh aqueous solution containing the ${ }^{137} \mathrm{Cs}$ tracer. After contact in DCs-1, the organic phase was divided into two parts.

b. This aqueous phase initially contained tracer levels of cesium plus $0.001 \mathrm{M} \mathrm{CsNO}_{3}$.

c. For contact DCs-2, one-half of the organic phase from the DCs- 1 contact was contacted with fresh aqueous solution with the same composition used in the initial contact but containing no ${ }^{137} \mathrm{Cs}$ tracer.

d. For contact DCs-3, the other half of the organic phase from the DCs- 1 contact was contacted with aqueous solution of the same composition as the other contacts but also containing ${ }^{137} \mathrm{Cs}$ tracer.

e. For contact DCs-4, the aqueous phase in DCs-1 was contacted with fresh solvent. Aqueous

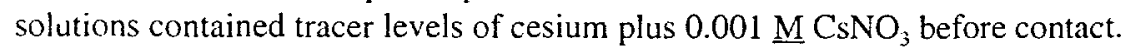


Table B-4. Cesium Distribution Ratio between CSEX Solvent and $1 \underline{\mathrm{MNaNO}} \mathrm{Na}_{3}$ with $0.01 \underline{\mathrm{M}}$ $\mathrm{NaOH}$

Solvent: $0.01 \mathrm{M}$ BoBCalixC6 and $0.20 \mathrm{M}$ Cs-3 in Isopar ${ }^{\circledR} \mathrm{L}$. This fresh solvent was taken from the solvent batch that was prepared for multistage test CS2.

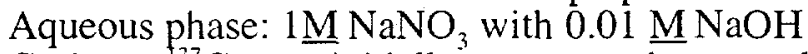

Cesium: ${ }^{37} \mathrm{Cs}$ was initially present at the tracer level in the aqueous phase.

Temperature: $25^{\circ} \mathrm{C}$

Organic-to-aqueous volume ratio: $1 / 1$

Test vessel: Glass centrifuge tubes

\begin{tabular}{|c|c|c|}
\hline Contact & $\mathrm{D}_{\mathrm{C} \text { V Value }}$ & Material Balance, $\%$ \\
\hline DCs-1 ${ }^{\mathrm{a}}$ & 4.7 & 99 \\
\hline$"$ & 4.9 & 112 \\
\hline$"$ & 5.5 & 89 \\
\hline$"$ & 5.7 & 94 \\
\hline DCs-2 & 5.2 & 105 \\
\hline$"$ & 5.8 & 97 \\
\hline$"$ & 5.4 & 107 \\
\hline$"$ & 6.0 & 108 \\
\hline DCs-3 & 5.2 & 104 \\
\hline DCs-4 & 5.1 & 99 \\
\hline
\end{tabular}

a. Contact DCs-1 was between fresh solvent with fresh aqueous solution containing the ${ }^{137} \mathrm{Cs}$ tracer. After contact in DCs-1, the organic phase was divided into two parts.

b. For contact DCs-2, one half of the organic phase from the DCs-1 contact was contacted with fresh aqueous solution with the same composition used in the initial contact but containing no ${ }^{137} \mathrm{Cs}$ tracer.

c. For contact DCs-3, the other half of the organic phase from the DCs- 1 contact was contacted with aqueous solution of the same composition as the other contacts but also containing ${ }^{137} \mathrm{Cs}$ tracer.

d. For contact DCs-4, the aqueous phase contacted in DCs- .1 was contacted with fresh solvent. 
Table B-5. Effect of Temperature on $D_{C s}$ between CSEX Solvent and Salt Solutions

Solvent: $0.01 \underline{\mathrm{M}}$ BoBCalixC6 and $0.20 \mathrm{MCs}-3$ in Isopar ${ }^{\mathrm{B}} \mathrm{L}$. This fresh solvent was taken from the solvent batch that was prepared for multistage test CS2.

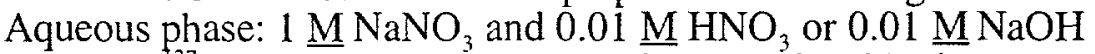

Cesium: ${ }^{137} \mathrm{Cs}$ was initially present at the tracer level in the aqueous phase.

Temperature: 25 or $50^{\circ} \mathrm{C}$

Organic-to-aqueous volume ratio: $1 / 1$

Test vessel: Glass centrifuge tubes

\begin{tabular}{|c|c|c|c|c|}
\hline \multirow[b]{2}{*}{ Temperature, ${ }^{\circ} \mathrm{C}$} & \multicolumn{2}{|c|}{$1 \underline{\mathrm{M} \mathrm{NaNO}}{ }_{3}+0.01 \underline{\mathrm{M} \mathrm{HNO}_{3}}$} & \multicolumn{2}{|c|}{$1 \underline{\mathrm{M} \mathrm{NaNO}_{3}}+0.01 \underline{\mathrm{M} \mathrm{NaOH}}$} \\
\hline & Forward $D_{\mathrm{Cs}}$ & Reverse $\mathrm{D}_{\mathrm{Cs}}$ & Forward $\mathrm{D}_{\mathrm{Cs}}$ & Reverse $\mathrm{D}_{\mathrm{Cs}}$ \\
\hline 25 & $4.4^{a}$ & $4.4^{\mathrm{b}}$ & $5.2^{\mathrm{c}}$ & $5.6^{d}$ \\
\hline 50 & 0.49 & 0.68 & 0.36 & 0.33 \\
\hline$"$ & 0.68 & 0.88 & 0.35 & 0.59 \\
\hline
\end{tabular}

a. Average value for DCs- 1 in Table B-3 (first four values).

b. Average value for DCs-2 in Table B-3 (first four values).

c. Average value for DCs- 1 in Table B-4 (last two values).

d. Average value for DCs-2 in Table B-4 (last two values).

Table B-6. Effect of Temperature on $\mathrm{D}_{\mathrm{Cs}}$ between CSEX Solvent and Dilute Acid or Base

Solvent: $0.01 \mathrm{M}$ BoBCalixC6 and $0.20 \mathrm{M}$ Cs-3 in Isopar ${ }^{\circledR} \mathrm{L}$. This fresh solvent taken from the solvent batch that was prepared for multistage test CS2.

Aqueous phase: $0.009 \mathrm{M} \mathrm{HNO}_{3}$ or $0.002 \mathrm{M} \mathrm{NaOH}$

Cesium: ${ }^{37} \mathrm{Cs}$ was initially present at the tracer level in the aqueous phase.

Temperature: 25 or $50^{\circ} \mathrm{C}$

Organic-to-aqueous volume ratio: $1 / 1$

Test vessel: Glass centrifuge tubes

\begin{tabular}{|c|c|c|c|c|c|}
\hline \multirow{2}{*}{ Aqueous Phase } & Temperature, ${ }^{\circ} \mathrm{C}$ & \multicolumn{2}{|c|}{ Forward $\mathrm{D}_{\mathrm{Cs}}$} & \multicolumn{2}{|c|}{ Reverse $\mathrm{D}_{\mathrm{Cs}}$} \\
\cline { 3 - 6 } & & 1 minute & 3 minutes & 1 minute & 3 minutes \\
\hline $0.009 \mathrm{M} \mathrm{HNO}_{3}$ & 25 & 0.29 & 0.28 & 1.4 & 1.1 \\
\hline$"$ & 50 & 0.40 & 0.09 & 0.43 & 0.21 \\
\hline $0.002 \mathrm{M} \mathrm{NaOH}$ & 25 & 21 & 16 & 24 & 22 \\
\hline$"$ & 50 & 2.0 & 1.3 & 2.2 & 1.4 \\
\hline
\end{tabular}




\section{Table B-7. Cesium Distribution Ratio for CSEX Solvent Used in Test CS2}

Solvent: $0.01 \mathrm{M}$ BoBCalixC6 and $0.20 \mathrm{M} \mathrm{Cs}-3$ in Isopar ${ }^{\circledR} \mathrm{L}$. This used solvent was taken from the organic effluent during multistage test CS2.

Aqueous phase: Various $\mathrm{HNO}_{3}$ concentrations as shown

Cesium: Initial $\mathrm{CsNO}_{3}$ concentrations were as shown for the forward extraction. In each forward extraction ${ }^{137} \mathrm{Cs}$ was present at the tracer level. Note that, for the back (reverse) extraction, no additional cesium was added. Instead, the aqueous phase had $\mathrm{HNO}_{3}$ alone at the concentration shown.

Temperature: $25^{\circ} \mathrm{C}$

Organic-to-aqueous volume ratio: $1 / 1$

Test vessel: Glass centrifuge tubes

\begin{tabular}{|c|c|c|c|c|c|c|}
\hline \multirow{2}{*}[\mathrm{HNO}_{3}]{,$\underline{\mathrm{M}}$} & \multicolumn{3}{|c|}{ Forward $\mathrm{D}_{\mathrm{Cs}}$} & \multicolumn{3}{c|}{ Reverse $\mathrm{D}_{\mathrm{Cs}}$} \\
\cline { 2 - 7 } & {$[\mathrm{Cs}]=$ tracer } & {$[\mathrm{Cs}]=10^{-6} \underline{\mathrm{M}}$} & {$[\mathrm{Cs}]=10^{-4} \underline{\mathrm{M}}$} & {$[\mathrm{Cs}]=$ tracer } & {$[\mathrm{Cs}]=10^{-6} \underline{\mathrm{M}}$} & {$[\mathrm{Cs}]=10^{-4} \underline{\mathrm{M}}$} \\
\hline 0.001 & 0.28 & - & - & 0.55 & - & - \\
\hline 0.00533 & 0.30 & 0.22 & 0.11 & 0.57 & 0.59 & 0.16 \\
\hline 0.0133 & 0.43 & 0.35 & 0.19 & 0.74 & 0.42 & 0.26 \\
\hline 0.0227 & 0.505 & 0.79 & 0.39 & 1.27 & 1.08 & 0.51 \\
\hline
\end{tabular}

Table B-8. Cesium Distribution Ratio for CSEX Solvent Used in Tests CS18 and CS19

Solvent: $0.01 \underline{\mathrm{M} B o B C a l i x C 6}$ and $0.20 \mathrm{M} \mathrm{Cs}-3$ in Isopar ${ }^{\circledR} \mathrm{L}$. This used solvent was taken from the organic effluent during multistage tests CS18 and CS19.

Aqueous phase: Various $\mathrm{HNO}_{3}$ concentrations as shown

Cesium: Initial $\mathrm{CsNO}_{3}$ concentrations were as shown for the forward extraction. In each forward extraction ${ }^{137} \mathrm{Cs}$ was present at the tracer level. Note that, for the back (reverse) extraction, no additional cesium was added. Instead, the aqueous phase had $\mathrm{HNO}_{3}$ alone at the concentration shown.

Temperature: $25^{\circ} \mathrm{C}$

Organic-to-aqueous volume ratio: $1 / 1$

Test vessel: Glass centrifuge tubes

\begin{tabular}{|c|c|c|c|c|c|c|}
\hline \multirow{2}{*}[\mathrm{HNO}_{3}]{,$\underline{\mathrm{M}}$} & \multicolumn{3}{|c|}{ Forward $\mathrm{D}_{\mathrm{Cs}}$} & \multicolumn{3}{c|}{ Reverse $\mathrm{D}_{\mathrm{Cs}}$} \\
\cline { 2 - 7 } & {$[\mathrm{Cs}]=$ tracer } & {$[\mathrm{Cs}]=10^{-6} \underline{\mathrm{M}}$} & {$[\mathrm{Cs}]=10^{-4} \underline{\mathrm{M}}$} & {$[\mathrm{Cs}]=$ tracer } & {$[\mathrm{Cs}]=10^{-6} \underline{\mathrm{M}}$} & {$[\mathrm{Cs}]=10^{-4} \underline{\mathrm{M}}$} \\
\hline 0.001 & 0.79 & 0.40 & 0.04 & 2.11 & 1.31 & 0.39 \\
\hline 0.00533 & 0.60 & 0.35 & 0.11 & 1.37 & 1.23 & 0.20 \\
\hline 0.0133 & 0.57 & 0.38 & 0.17 & 1.06 & 1.13 & 0.26 \\
\hline 0.0227 & 0.68 & 0.49 & 0.34 & 1.22 & 1.11 & 0.46 \\
\hline
\end{tabular}


Table B-9. Cesium Distribution Ratio for CSEX Solvent Prepared at ORNL

Solvent: $0.01 \underline{\mathrm{M}}$ BoBCalixC6 and $0.20 \underline{\mathrm{M} C s-3}$ in Isopar ${ }^{\mathrm{B}} \mathrm{L}$. This fresh solvent was prepared at ORNL.

Aqueous phase: Various $\mathrm{HNO}_{3}$ concentrations as shown

Cesium: ${ }^{37} \mathrm{Cs}$ was initially present at the tracer level in the aqueous phase.

Temperature: $25^{\circ} \mathrm{C}$

Organic-to-aqueous volume ratio: $1 / 1$

Test vessel: Glass centrifuge tubes

\begin{tabular}{|c|c|c|}
\hline$\left[\mathrm{HNO}_{3}\right]^{\alpha}, \underline{\mathrm{M}}$ & $\mathrm{D}_{\mathrm{Cs}}$ Value & Material Balance, \% \\
\hline 0.001 & 0.24 & 67 \\
\hline 0.00533 & 0.22 & 99 \\
\hline 0.0133 & 0.31 & 93 \\
\hline 0.0227 & 0.43 & 93 \\
\hline
\end{tabular}

a. Concentration of $\mathrm{HNO}_{3}$ before contact with the solvent.

Table B-10. Cesium Distribution Ratio for CSEX Solvent and $0.001 \mathrm{M} \mathrm{NaOH}$

Solvent: $0.01 \mathrm{MB}$ BoBCalixC6 and $0.20 \mathrm{M} \mathrm{Cs}-3$ in Isopar ${ }^{\circledR} \mathrm{L}$. This fresh solvent was taken from the solvent batch that was prepared for multistage test CS2.

Aqueous phase: $0.001 \mathrm{M} \mathrm{NaOH}$

Cesium: ${ }^{37} \mathrm{Cs}$ was initially present at the tracer level in the aqueosus phase.

Temperature: $25^{\circ} \mathrm{C}$

Organic-to-aqueous volume ratio: $1 / 1$

Test vessel: Glass centrifuge tubes

\begin{tabular}{|c|c|c|}
\hline Contact & $\mathrm{D}_{\mathrm{Cs}}$ Value & Material Balance, \% \\
\hline DCs-1 ${ }^{\mathrm{a}}$ & 13 & 95 \\
\hline DCs-2 & \\
\hline DCs-3 & 13 & 94 \\
\hline DCs $-4^{\mathrm{d}}$ & 16 & 97 \\
\hline
\end{tabular}

a. Contact DCs- 1 was between fresh solvent with fresh aqueous solution containing the ${ }^{137} \mathrm{Cs}$ tracer. After contact in DCs-1, the organic phase was divided into two parts.

b. For contact DCs-2, one-half of the organic phase from the DCs-l contact was contacted with fresh aqueous solution with the same composition used in the initial contact but containing no ${ }^{137} \mathrm{Cs}$ tracer.

c. For contact DCs-3, the other half of the organic phase from the DCs-1 contact was contacted with aqueous solution of the same composition as the other contacts but also containing ${ }^{137} \mathrm{Cs}$ tracer.

d. For contact DCs-4, the aqueous phase in DCs-1 was contacted with fresh solvent. 
Table B-11. Cesium Distribution Ratio for CSEX Solvent and 0.001 $\underline{\mathrm{M}} \mathrm{HNO}_{3}$

Solvent: $0.01 \underline{\mathrm{M}}$ BoBCalixC6 and $0.20 \underline{\mathrm{M}} \mathrm{Cs}-3$ in Isopar ${ }^{\mathbb{B}} \mathrm{L}$

Aqueous phase: $0.001 \mathrm{M} \mathrm{HNO}_{3}$

Cesium: ${ }^{{ }^{37} \mathrm{Cs}}$ was initially present at the tracer level in the aqueous phase.

Temperature: $25^{\circ} \mathrm{C}$

Organic-to-aqueous volume ratio: $1 / 1$

Test vessel: Glass centrifuge tubes

\begin{tabular}{|c|c|c|}
\hline Contact & $D_{C s}$ Value & Material Balance, \% \\
\hline${\text { DCs- }{ }^{\mathrm{a}}}^{\mathrm{a}}$ & 0.15 & 86 \\
\hline DCs- $^{\mathrm{b}}$ & 0.33 & 80 \\
\hline DCs-3 $^{\mathrm{c}}$ & 0.22 & 72 \\
\hline DCs-4 & 0.39 & 138 \\
\hline
\end{tabular}

a. Contact DCs-1 was between fresh solvent with fresh aqueous solution containing the ${ }^{137} \mathrm{Cs}$ tracer. After contact in DCs-1, the organic phase was divided into two parts.

b. For contact DCs-2, one-half of the organic phase from the DCs- 1 contact was contacted with fresh aqueous solution with the same composition used in the initial contact but containing no ${ }^{137} \mathrm{Cs}$ tracer.

c. For contact DCs-3, the other half of the organic phase from the DCs- 1 contact was contacted with aqueous solution of the same composition as the other contacts but also containing ${ }^{137} \mathrm{Cs}$ tracer.

d. For ccritact DCs -4 , the aqueous phase in DCs- 1 was contacted with fresh solvent. 
Table B-12. Cesium Distribution Ratio for Consecutive Contacts of Fresh Solvent at $19^{\circ} \mathrm{C}$

Solvent: $0.01 \mathrm{M}$ BoBCalixC6 and $0.20 \mathrm{M}$ Cs-3 in Isopar ${ }^{(1)} \mathrm{L}$. This solvent was from the batch prepared for Tests CS 18 and CS19.

Aqueous phase: As shown in table. The aqueous phase was fresh for each contact.

Cesium: ${ }^{1{ }^{37} \mathrm{Cs}}$ was added at the tracer level to the aqueous phase that was the feed for the extraction contacts.

Temperature: $19^{\circ} \mathrm{C}$

Organic-to-aqueous volume ratio: $1 / 1$

Test vessel: Glass centrifuge tubes

\begin{tabular}{|c|c|c|c|}
\hline \multirow[b]{2}{*}{ Extraction Feed ${ }^{2}$} & \multicolumn{3}{|c|}{$\mathrm{D}_{\mathrm{Cs}}$ Value } \\
\hline & $\mathrm{SRS} \# 2^{\mathrm{b}}$ & SRS\#4 & SRS\#4 \\
\hline Extaction-1 & 17 & 18 & 16 \\
\hline Extraction-2 & 14 & 16 & 17 \\
\hline $2 \underline{\mathrm{M}} \mathrm{NaOH}$ Scrub & 45 & 56 & \\
\hline $0.05 \mathrm{M} \mathrm{HNO}_{3}$ Scrub & 1.3 & 1.4 & 1.3 \\
\hline Strip- $1^{c}$ & 0.09 & 0.14 & 0.17 \\
\hline Strip-2 ${ }^{\mathrm{c}}$ & 0.24 & 0.38 & 0.43 \\
\hline Strip-3 $3^{c}$ & 0.28 & 0.42 & 0.36 \\
\hline
\end{tabular}

a. Feed simulanis for the extraction-section contacts were from batches prepared for either test CS2 (SRS\#2) or tests CS18 and CS19 (SRS\#4).

b. Note that, after tire second extraction, the solvent was first scrubbed with $2 \underline{\mathrm{M}} \mathrm{NaOH}$.

c. The strip solution was $0.0005 \underline{\mathrm{M}} \mathrm{HNO}_{3}$ and $0.0001 \underline{\mathrm{M}} \mathrm{CsNO}_{3}$. 
Table B-13. Cesium Distribution Ratio for Consecutive Contacts of Fresh Solvent at $25^{\circ} \mathrm{C}$ with $\mathrm{O} / \mathrm{A}$ Volume Ratio of 1.0

Solvent: $0.01 \mathrm{M}$ BoBCalixC6 and $0.20 \mathrm{M}$ Cs-3 in Isopar ${ }^{\circledR} \mathrm{L}$

Aqueous phase: As shown in table. The aqueous phase was fresh for each contact. The SRS\#2 feed simulant was from the batch prepared for test CS2.

Cesium: ${ }^{137} \mathrm{Cs}$ was added at the tracer level to the aqueous phase that was the feed for the three extraction contacts.

Temperature: $25^{\circ} \mathrm{C}$

Organic-to-aqueous volume ratio: $1 / 1$

Test vessel: Glass centrifuge tubes

\begin{tabular}{|c|c|c|}
\hline CONTACT & $D_{C s}$ Value & Material Balance, $\%$ \\
\hline \multicolumn{3}{|l|}{ Extraction (SRS\#2 Feed Simulant) } \\
\hline Forward \#1 & 8.5 & 89 \\
\hline Forward \#2 & 7.7 & 98 \\
\hline Forward \#3 & 7.7 & 103 \\
\hline \multicolumn{3}{|l|}{ Scrub $\left(0.05 \underline{\mathrm{M}} \mathrm{HNO}_{3}\right)$} \\
\hline Back\#1 & 0.49 & 102 \\
\hline Back 籼 & 0.70 & 117 \\
\hline \multicolumn{3}{|c|}{ Strip $\left(0.0005 \underline{\mathrm{M}} \mathrm{HNO}_{3}, 0.0001 \underline{\mathrm{M}} \mathrm{CsNO}_{3}\right)$} \\
\hline \multirow[t]{2}{*}{ 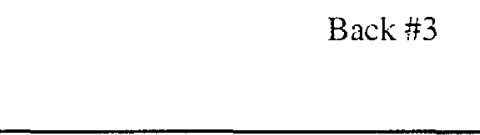 } & 0.14 & 94 \\
\hline & 0.17 & 92 \\
\hline Back \#4 & 0.28 & 140 \\
\hline Back \#5 & 0.21 & 90 \\
\hline Back \#6 & 0.19 & 77 \\
\hline Back \#7 & 0.15 & 94 \\
\hline
\end{tabular}


Table B-14. Cesium Distribution Ratio for Consecutive Contacts of Fresh Solvent at $25^{\circ} \mathrm{C}$ with Typical O/A Volume Ratios

Solvent: $0.01 \mathrm{M}$ BoBCalixC6 and $0.20 \underline{\mathrm{M}} \mathrm{Cs}-3$ in Isopar ${ }^{\circledR} \mathrm{L}$

Aqueous phase: As shown in table. The aqueous phase was fresh for each contact. The SRS\#2 feed simulant was from the batch prepared for test CS2.

Cesjum: ${ }^{137} \mathrm{Cs}$ was added at the tracer level to the aqueous phase that was the feed for the three extraction contacts.

Temperature: $25^{\circ} \mathrm{C}$

Organic-to-aqueous volume ratio: As shown in table

Test vessel: Glass centrifuge tubes

\begin{tabular}{|c|c|c|c|}
\hline CONTACT & O/A & $\mathrm{D}_{\mathrm{C}:}$ Value & Material Balance, $\%$ \\
\hline \multicolumn{4}{|c|}{ Extraction (SRS\#2 Feed Simulant) } \\
\hline Forward \#1 & 0.45 & 7.1 & 78 \\
\hline Forward \#2 & 1 & 6.6 & 96 \\
\hline Forward \#3 & 0.45 & 5.9 & 97 \\
\hline \multicolumn{4}{|l|}{ Scrub $\left(0.05 \underline{\mathrm{M}} \mathrm{HNO}_{3}\right)$} \\
\hline Back \#1 & 5 & 0.43 & 104 \\
\hline Back \#2 & 5 & 0.61 & 110 \\
\hline \multicolumn{4}{|c|}{ Strip $\left(0.0005 \underline{\mathrm{M}} \mathrm{HNO}_{3}+0.0001 \underline{\mathrm{M}} \mathrm{CsNO}_{3}\right)$} \\
\hline Back \#3 & 2.5 & 0.088 & 108 \\
\hline \multicolumn{4}{|l|}{ Strip $\left(0.005 \underline{\mathrm{M}} \mathrm{HNO}_{3}\right)$} \\
\hline Back \#4 & 2.5 & 0.44 & 105 \\
\hline Back \#5 & 2.5 & 0.83 & 107 \\
\hline Back \#6 & 2.5 & 1.09 & 106 \\
\hline Back \#7 & 2.5 & 0.99 & 94 \\
\hline \multicolumn{4}{|c|}{$\operatorname{Strip}\left(0.0005 \underline{\mathrm{M}} \mathrm{HNO}_{3}+0.0001 \underline{\mathrm{M}} \mathrm{CsNO}_{3}\right)$} \\
\hline Back \#8 & 2.5 & 0.39 & 96 \\
\hline
\end{tabular}


Table B-15. Cesium Distribution Ratio for Consecutive Contacts of Fresh Solvent at $25^{\circ} \mathrm{C}$ at $\mathrm{O} / \mathrm{A}=1.0$ Using Contact with Stainless Steel

Solvent: $0.01 \underline{\mathrm{M}}$ BoBCalixC6 and $0.20 \underline{\mathrm{M}} \mathrm{Cs}-3$ in Isopar ${ }^{\circledR} \mathrm{L}$

Aqueous phase: As shown in table. The aqueous phase was fresh for each contact. The SRS\#2 feed simulant was from the batch prepared for test CS2.

Cesium: ${ }^{137} \mathrm{Cs}$ was added at the tracer level to the aqueous phase that was the feed for the three extraction contacts.

Temperature: $25^{\circ} \mathrm{C}$

Organic-to-aqueous volume ratio: $1 / 1$

Test vessel: Glass centrifuge tubes with stainless steel washers in each tube

\begin{tabular}{|c|c|c|}
\hline Contact & $\mathrm{D}_{\mathrm{Cs}}$ Value & Material Balance, $\%$ \\
\hline \multicolumn{3}{|c|}{ Extraction (SRS\#2 Simulant Feed with Stainless Steel) } \\
\hline Forward \#1 & 9.1 & 97 \\
\hline Forward $\# 2$ & 9.6 & 124 \\
\hline Forward \#3 & 8.7 & 100 \\
\hline \multicolumn{3}{|c|}{ Scrub $\left(0.05 \underline{\mathrm{M}} \mathrm{HNO}_{3}\right.$ with Stainless Steel) } \\
\hline Back \#1 & 0.62 & 100 \\
\hline Back \#2 & 0.78 & 113 \\
\hline \multicolumn{3}{|c|}{ 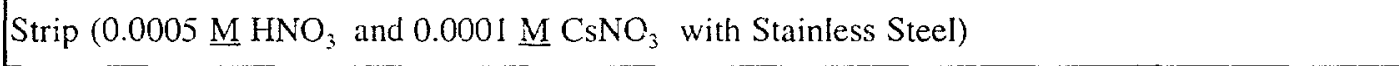 } \\
\hline Back \#3 & 0.14 & 96 \\
\hline Back \#4 & 0.31 & 98 \\
\hline Back \#5 & 0.27 & 118 \\
\hline
\end{tabular}


Table B-16. Cesium Distribution Ratio for Consecutive Contacts of Fresh Solvent at $25^{\circ} \mathrm{C}$ at $\mathrm{O} / \mathrm{A}=1.0$ Using Contact with Teflon PFA Tubing

Solvent: 0.01 M BoBCalix 6 and $0.20 \mathrm{M} \mathrm{Cs}-3$ in Isopar ${ }^{\mathrm{B}} \mathrm{L}$

Aqueous phase: As shown in table. The aqueous phase was fresh for each contact. The SRS\#2 feed simulant was from the batch prepared for test CS2.

Cesium: ${ }^{137} \mathrm{Cs}$ was added at the tracer level to the aqueous phase that was the feed for the three extraction contacts.

Temperature: $25^{\circ} \mathrm{C}$

Organic-to-aqueous volume ratio: $1 / 1$

Test vessel: Glass centrifuge tubes with sections of Teflon PFA tubing in each tube

\begin{tabular}{|c|c|c|}
\hline Contact & $\mathrm{D}_{\mathrm{Cs}}$ Value & Material Balance, $\%$ \\
\hline \multicolumn{3}{|c|}{ Extraction (SRS\#2 Simulant Feed with Teflon PFA) } \\
\hline Forward \#1 & 9.4 & 96 \\
\hline Forward \#2 & 9.6 & 124 \\
\hline Forward \#3 & 8.7 & 100 \\
\hline \multicolumn{3}{|c|}{ Scrub $\left(0.05 \underline{\mathrm{M}} \mathrm{HNO}_{3}\right.$ with Teflon PFA) } \\
\hline Back \#1 & 0.62 & 100 \\
\hline Back \#2 & 0.78 & 113 \\
\hline \multicolumn{3}{|c|}{ Strip $\left(0.0005 \underline{\mathrm{M}} \mathrm{HNO}_{3}, 0.0001 \underline{\mathrm{M}} \mathrm{CsNO}_{3}\right.$ with Teflon PFA) } \\
\hline Back \#1 & 0.13 & 96 \\
\hline Back \#2 & 0.30 & 96 \\
\hline Back \#3 & 0.36 & 99 \\
\hline
\end{tabular}


Table B-17. Cesium Distribution Ratio for Consecutive Contacts of Fresh Solvent at Selected Temperatures

Solvent: $0.01 \underline{\mathrm{M}}$ BoBCalixC6 and $0.20 \underline{\mathrm{M}} \mathrm{Cs}-3$ in Isopar ${ }^{\circ} \mathrm{L}$

Aqueous phase: As shown in table. The aqueous phase was fresh for each contact. The SRS\#4 feed simulant was from the batch prepared for tests CS18 and CS19.

Cesium: ${ }^{137} \mathrm{Cs}$ was added at the tracer level to the aqueous phase that was the feed for the one extraction contact.

Temperature: As shown in table

Organic-to-aqueous volume ratio: $1 / 1$

Test vessel: Glass centrifuge tubes

\begin{tabular}{|c|c|c|c|}
\hline Contact & Temperature, ${ }^{\circ} \mathrm{C}$ & $\mathrm{D}_{\mathrm{Cs}}$ Value & Material Balance, $\%$ \\
\hline \multicolumn{4}{|c|}{ Extraction (SRS\#4 Simulant Feed) } \\
\hline Forward \#1 & 9 & 26 & 87 \\
\hline \multicolumn{4}{|l|}{ Scrub $\left(0.05 \underline{\mathrm{M}} \mathrm{HNO}_{3}\right)$} \\
\hline Back\#1 & 9 & 4.3 & 103 \\
\hline \multicolumn{4}{|c|}{ Strip $\left(0.0005 \underline{\mathrm{M}} \mathrm{HNO}_{3}, 0.0001 \mathrm{M} \mathrm{CsNO}_{3}\right)$} \\
\hline Back \#2 & 52 & 0.021 & 113 \\
\hline Back \#3 & 52 & 0.015 & 94 \\
\hline Back \#4 & 52 & 0.011 & 89 \\
\hline
\end{tabular}


Table B-18. Cesium Distribution Ratio for Consecutive Contacts of Fresh Solvent with $0.001 \mathrm{M}$ Triisooctyl Amine

Solvent: $0.01 \underline{\mathrm{M}}$ BoBCalixC6, $0.20 \mathrm{M}$ Cs-3, and $0.001 \underline{\mathrm{M}}$ triisooctyl amine in Isopar ${ }^{\mathbb{Q}} \mathrm{L}$

Aqueous phase: As shown in table. The aqueous phase was fresh for each contact. The SRS\#4 feed simulant was from the batch prepared for tests CS18 and CS19.

Cesium: ${ }^{137} \mathrm{Cs}$ was added at the tracer level to the aqueous phase that was the feed for the one extraction contact.

Temperature: $25^{\circ} \mathrm{C}$

Organic-to-aqueous volume ratio: $1 / 1$

Test vessel: Glass centrifuge tubes

\begin{tabular}{|c|c|c|}
\hline Contact & $D_{C s}$ Value & Material Balance, $\%$ \\
\hline \multicolumn{3}{|c|}{ Extraction (SRS\#4 Simulant Feed) } \\
\hline Forward \#1 & 10.2 & 86 \\
\hline \multicolumn{3}{|l|}{ Scrub $\left(0.05 \underline{\mathrm{M}} \mathrm{HNO}_{3}\right)$} \\
\hline Back \#1 & 0.56 & 111 \\
\hline \multicolumn{3}{|c|}{ Strip $\left(0.0005 \underline{\mathrm{M} \mathrm{HNO}}, 0.0001 \underline{\mathrm{M}} \mathrm{CsNO}_{3}\right)$} \\
\hline Back \#2 & 0.032 & 113 \\
\hline Back \#3 & 0.026 & 92 \\
\hline Back \#4 & 0.022 & 89 \\
\hline
\end{tabular}


Table B-19. Cesium Distribution Ratio for Consecutive Contacts of Fresh Solvent with $0.0001 \underline{\mathrm{M}}$ Triisooctyl Amine

Solvent: $0.01 \underline{\mathrm{M}}$ BoBCalixC6, $0.20 \underline{\mathrm{M} \mathrm{Cs}}-3$, and $0.0001 \underline{\mathrm{M}}$ triisooctyl amine in Isopar ${ }^{\circledR} \mathrm{L}$ Aqueous phase: As shown in table. The aqueous phase was fresh for each contact. The SRS\#4 feed simulant was from the batch prepared for tests CS18 and CS19.

Cesium: ${ }^{137} \mathrm{Cs}$ was added at the tracer level to the aqueous phase that was the feed for the one extraction contact.

Temperature: $25^{\circ} \mathrm{C}$

Drganic-to-aqueous volume ratio: $1 / 1$

Test vessel: Glass centrifuge tubes

\begin{tabular}{|c|c|c|}
\hline Contact & $\mathrm{D}_{\mathrm{Cs}}$ Value & Mass Balance, \% \\
\hline Extraction (SRS\#4SimulantFeed) & 9.9 & 90 \\
\hline Forward \#1 & \multicolumn{3}{|l|}{} \\
\hline Scrub (0.05 $\underline{\mathrm{M} \text { HNO}}$ ) & 0.57 & 109 \\
\hline Back \#1 & & 114 \\
\hline Strip (0.0005 $\underline{\mathrm{M} \text { HNO}}, 0.0001 \underline{\mathrm{M} \mathrm{CsNO}}$ ) & 0.037 & 97 \\
\hline Back \#2 & 0.036 & 90 \\
\hline Back \#3 & 0.041 & \\
\hline Back \#4 & & \\
\hline
\end{tabular}


Table B-20. Effect of Temperature and Scrub Solution on $\mathrm{D}_{\mathrm{Cs}}$ for Extraction

Solvent: $0.01 \underline{\mathrm{M} B o B C a l i x C 6}$ and $0.20 \underline{\mathrm{M} C s-3}$ in Isopar ${ }^{\circledR} \mathrm{L}$. This fresh solvent was taken from the solvent batch that was prepared for multistage test CS2.

Aqueous phase: As shown in columns 3 and 4 of the table. The aqueous phase was fresh for each contact. The SRS\#2 feed simulant was from the batch prepared for test CS2.

Cesium: ${ }^{127} \mathrm{Cs}$ was added at the tracer level to the SRS\#2 feed simulant.

Temperature: $25^{\circ} \mathrm{C}$

Organic-to-aqueous volume ratio: As noted in table

Test vessel: Glass centrifuge tubes

\begin{tabular}{|c|c|c|c|c|}
\hline Temperature, ${ }^{\circ} \mathrm{C}$ & $\begin{array}{c}\text { Solvent Volume, } \\
\mathrm{mL}\end{array}$ & $\begin{array}{c}\text { SRS\#2 Volume, } \\
\mathrm{mL}\end{array}$ & $\begin{array}{c}\text { Scrub }\left(0.05 \mathrm{M} \mathrm{HNO}_{3}\right) \\
\text { Volume, } \mathrm{mL}\end{array}$ & $\mathrm{D}_{\mathrm{Cs}}$ Value \\
\hline 20 & 1.0 & 1.0 & - & 12.9 \\
\hline$"$ & $"$ & 0.91 & 0.09 & 12.8 \\
\hline$"$ & $"$ & 2.2 & - & 12.2 \\
\hline$"$ & $"$ & 2.0 & 0.2 & 13.3 \\
\hline 25 & $"$ & 1.0 & - & 9.8 \\
\hline$"$ & $"$ & 0.91 & 0.09 & 10.3 \\
\hline$"$ & $"$ & 2.2 & - & 9.4 \\
\hline$"$ & 2.0 & 0.2 & 9.6 \\
\hline
\end{tabular}




\section{APPENDIX C \\ SCALE-UP OF CENTRIFUGAL CONTACTORS}

\section{INTRODUCTION}

Centrifugal contactors are a new tool for carrying out solvent extraction in an efficient countercurrent stagewise manner with a minimum of liquid holdup in the system [BERNSTEIN1973B; LEONARD-1980; LEONARD-1988; LEONARD-1997; WEBSTER]. Existing data on centrifugal contactors were analyzed so that the results from small laboratory units with 2-cm-dia rotors can be scaled up accurately to plant-scale contactors with rotor diameters of 9,12 , and 25 $\mathrm{cm}$ and even Iarger. This work addresses both the stage efficiency and the hydraulic performance of the centrifugal contactor. The design and use of centrifugal contactors is made easier by the rule-of-thumb that each stage has essentially $100 \%$ stage efficiency whether it is used alone or in a multistage operation. A corollary rule-of-thumb is that each stage has the same hydraulic performance whether it is used alone or in a multistage operation.

The validity of the rule-of-thumb for stage efficiency is explored by looking at the results from our single-stage and multistage tests. Then the validity of the corollary rule-of-thumb for hydraulic performance is reviewed.

\section{STAGE EFFICIENCY}

A general rule-of-thumb is that a well-designed centrifugal contactor has essentially $100 \%$ extraction efficiency in each contactor stage. As the data summarized below show, this is the case as long as the fluid momentum (inertial forces) controls the liquid flow out of a contactor stage, between stages, and into the next stage. However, in small laboratory-scale centrifugal contactors, such as the 2-cm contactor, surface tension forces can be greater than the fluid momentum (inertial forces), and so, can control the liquid flow between stages. When this happens, the liquid enters the annular mixing zone of the contactor as discrete slugs of liquid. These slugs of liquid can have a volume that is on the same order of magnitude as that in the mixing zone of the 2-cm contactor. Thus, one liquid phase can pass through the mixing zone without contacting much liquid of the other phase and vice versa. As a result, even though the actual stage efficiency is close to $100 \%$, the apparent stage efficiency is significantly lower. This effect becomes more pronounced as the O/A flow ratio deviates from 1.0 , either up or down. As the flow ratio moves away from 1.0 at the same total flow rate, the flow rate of one phase must decrease. As its flow rate decreases, the interval of time between slugs increases, and this lowers the apparent stage efficiency further. A simple correlation of this effect on the stage efficiency in 2-cm contactors is the following:

$$
E_{a}=a-\left(b\left|\log _{10} R\right|\right)
$$

where $E_{a}$ is the fractional stage efficiency, $R$ is the $O / A$ flow ratio, and $a$ and $b$ are correlation coefficients obtained by a least-squares fit of Eq. C-1 to the data. This correlation is applied separately to $E_{\mathrm{a}}$ data for single-stage and multistage 2-cm tests. As noted below, the effect of 
surface tension on variations in interstage flow rate is reduced if the interstage liquid wets the interstage line. However, if either liquid phase exhibits slug flow in its interstage lines, the fact that the interstage flow of the other phase is smooth is almost irrelevant.

\section{Single Stage}

To determine the expected extraction efficiency in single-stage operation of the centrifugal contactor (2- to $25-\mathrm{cm}$ rotor diameter), the existing data were reviewed. The results, summarized in Table C-1, show that the stage efficiency is greater than $90 \%$ for most 2 - and $4-\mathrm{cm}$ units and is greater than $98 \%$ for all the larger units. For those cases where the stage efficiency drops below $90 \%$, the $\mathrm{O} / \mathrm{A}$ flow ratio appears to be enough above or below 1.0 so that one phase has a flow rate below 5 to $10 \mathrm{~mL} / \mathrm{min}$. This can be deduced by reading the various notes in Table C-1. At these low flow rates, as will be discussed next, there appears to be a problem that reduces the apparent stage efficiency, even though the actual stage efficiency remains high. Thus, for the higher flow rates in the larger single-stage centrifugal contactors, the stage efficiency is very close to $100 \%$.

Table C-1. Summary of Extraction Efficiency in Single-Stage Centrifugal Contactor Tests

\begin{tabular}{|c|c|c|c|c|c|c|c|}
\hline $\begin{array}{l}\text { Rotor } \\
\text { Dia., } \\
\mathrm{cm}\end{array}$ & $\begin{array}{l}\text { Nom. } \\
\text { Trruput, } \\
\text { L/min }\end{array}$ & $\begin{array}{c}\text { Type of } \\
\text { Operatior }\end{array}$ & $\begin{array}{l}\text { Component } \\
\text { Extracted or } \\
\text { Stripped }\end{array}$ & $\begin{array}{c}\text { O/A Flow } \\
\text { Ratio }\end{array}$ & $\begin{array}{c}\text { Stage Eff, } \\
\%\end{array}$ & Reference & Notes \\
\hline 2 & 0.044 & Extraction & $\mathrm{Tc}$ & $0.33-3.0$ & $100 \pm 2$ & LEONARD-1999B & $\mathrm{a}$ \\
\hline$"$ & $"$ & Scrub & $"$ & 2.0 & $100 \pm 8$ & $"$ & \\
\hline$"$ & $"$ & Strip & $"$ & 3.0 & $88 \pm 11$ & $"$ & \\
\hline$"$ & $"$ & Extraction & $\mathrm{Cs}$ & $0.17-1.0$ & $97 \pm 3$ & (This report) & $b$ \\
\hline$"$ & $"$ & Scrub & $"$ & 5.0 & $81 \pm 11$ & $"$ & \\
\hline$"$ & $"$ & Strip & $"$ & $0.33-3.0$ & $100 \pm 6$ & $"$ & $\mathrm{c}$ \\
\hline$"$ & $"$ & Extraction & $\mathrm{U}$ & $1.0-2.5$ & $94 \pm 4$ & LEONARD-1982 & $\mathrm{d}$ \\
\hline 4 & 0.6 & $"$ & $"$ & $0.5-2.5$ & $95 \pm 5$ & $"$ & \\
\hline$"$ & $"$ & $"$ & $\mathrm{Nd}$ & 0.01 & $88 \pm 10$ & LEONARD-1993 & \\
\hline$"$ & $"$ & $"$ & $"$ & 33 & $85 \pm 13$ & $"$ & \\
\hline 9 & 10 & $"$ & $\mathrm{U}$ & $0.2-1.0$ & $98 \pm 2$ & LEONARD-1981 & \\
\hline 12 & 20 & $"$ & $"$ & Not Avail. & $99 \pm 2$ & LEONARD-1982 & \\
\hline 25 & 120 & $"$ & $"$ & 1.0 & $100 \pm 2$ & BERNSTEIN-1973B & \\
\hline
\end{tabular}

\footnotetext{
a. $92 \% \pm 2 \%$ at $\mathrm{O} / \mathrm{A}=0.33$

b. $88 \% \pm 3 \%$ at $\mathrm{O} / \mathrm{A}=0.17$ for the first low $\mathrm{O} / \mathrm{A}$ case; $98 \% \pm 1 \%$ at $\mathrm{O} / \mathrm{A}=0.18$ for the second low $\mathrm{O} / \mathrm{A}$ case.

c. $88 \% \pm 9 \%$ at $\mathrm{O} / \mathrm{A}=0.33$.

d. Original 2-cm design at ANL.
}

For low flow rates (below 5 to $10 \mathrm{~mL} / \mathrm{min}$ ), a problem develops because the surface tension becomes a factor in the liquid flow. In this flow rate range, the liquid stops flowing continuously and starts emerging in drips. As with the continuous flow, the drips or slugs fall vertically into the annular mixing zone. Since the residence time in the mixing zone of the contactor is typically in the range from 1 to $5 \mathrm{~s}$, any dripping or slugging of liquid into the mixing 
zone will degrade the stage efficiency since some of the liquid that should have been there to extract the element has already passed through the mixing zone. While this phenomenon applies mainly to the 2-cm contactor, it also applies to the 4-cm contactor at very high (33) and low (0.01) O/A flow ratios, shown in Table C-1, where the flow rate of one phase or the other can fall below 5 to 10 $\mathrm{mL} / \mathrm{min}$. The problem does not apply at higher flow rates, where the momentum (inertial forces) of the liquid is much greater than the surface tension forces.

To determine the effect of low flow rate in single-stage 2-cm centrifugal contactors, experimental stage efficiencies for various $\mathrm{O} / \mathrm{A}$ flow ratios were collected and are listed in Table C2. A least-squares fit of these data using Eq. C-1 gives correlation coefficients of 1.0 for a and 0.15 for $b$, so that Eq. C-1 becomes

$$
\mathrm{E}_{\mathrm{a}}=1-\left(0.15\left|\log _{10} \mathrm{R}\right|\right)
$$

The data and the curve represented by Eq. C-2 are plotted in Fig. C-1. The results show that as the O/A flow ratio increases above or decreases below 1.0, the apparent stage efficiency decreases. This is most pronounced when the flow rate for one phase or the other falls below 5 to $10 \mathrm{~mL} / \mathrm{min}$. This suggests that the liquid with the low flow enters the stage as slugs of liquid and thus lowers îhe apparent (or overall) stage efficiency. As the stages used in these tests are made of stainit:s steel and not clear plastic, it was not possible to observe this slug flow. 
Table C-2. Effect of O/A Flow Ratio on Extraction Efficiency in Single-Stage 2-cm Contactors

\begin{tabular}{|c|c|c|c|c|c|c|}
\hline $\begin{array}{c}\text { O/A Flow } \\
\text { Ratio }\end{array}$ & $\begin{array}{l}\text { Total } \\
\text { Thruput, } \\
\mathrm{mL} / \mathrm{min}\end{array}$ & Type of Operation & $\begin{array}{c}\text { Component } \\
\text { Extracted or } \\
\text { Stripped }\end{array}$ & $\begin{array}{c}\text { Stage Eff., } \\
\%\end{array}$ & Reference & Notes \\
\hline 0.177 & 31.2 & Extraction & Cs & 97.7 & ('This report) & $\mathrm{a}, \mathrm{d}$ \\
\hline 0.180 & 39.4 & " & $"$ & 88.4 & " & $\mathrm{a}, \mathrm{d}$ \\
\hline 0.291 & 36.8 & $"$ & $\mathrm{Tc}$ & 91.6 & LIBERATORE & $\mathrm{a}, \mathrm{e}$ \\
\hline 0.327 & 35.0 & Strip & Cs & 87.9 & LEONARD-1998 & $b, d$ \\
\hline 0.357 & 38.6 & Extraction & $"$ & 99.4 & $"$ & $\mathrm{a}, \mathrm{d}$ \\
\hline 0.470 & 32.1 & " & $"$ & 99.4 & $"$ & $a, d$ \\
\hline 0.647 & 39.2 & $"$ & $"$ & 98.7 & $"$ & $\mathrm{a}, \mathrm{d}$ \\
\hline 0.68 & 35.4 & $"$ & $\mathrm{HNO}_{3}$ & 95 & LEONARD-1992 & $\mathrm{b}, \mathrm{f}$ \\
\hline 0.846 & 19.2 & $"$ & $\mathrm{Tc}$ & 101 & LIBERATORE & a. $\mathrm{c}, \mathrm{e}$ \\
\hline 0.883 & 40.1 & $"$ & $"$ & 101 & $"$ & $\mathrm{a}, \mathrm{c}, \mathrm{e}$ \\
\hline 0.927 & 39.5 & $"$ & $"$ & 99.4 & $"$ & $a, e$ \\
\hline 0.985 & 40.3 & $"$ & $"$ & 99.2 & 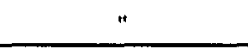 & $\mathrm{a}, \mathrm{e}$ \\
\hline 1.028 & 36.5 & Strip & $\mathrm{Cs}$ & 107.2 & (This report) & b, c, d \\
\hline 1.042 & 36.8 & $"$ & $"$ & 100.8 & " & $b, c, d$ \\
\hline 1.042 & 36.8 & $"$ & $"$ & 98.8 & $"$ & $b, d$ \\
\hline 1.056 & 38.6 & Extraction & $"$ & 99.5 & $"$ & $\mathrm{a}, \mathrm{d}$ \\
\hline 1.057 & 36.0 & Strip & $"$ & 99.8 & $"$ & b. d \\
\hline 1.083 & 10.0 & Extraction & $\mathrm{Tc}$ & 99.2 & LIBERATORE & : $\mathrm{i}, \mathrm{e}$ \\
\hline 1.950 & 29.5 & Scrub & $"$ & 108 & $n$ & a, c. e \\
\hline 1.990 & 29.9 & $"$ & $"$ & 92.8 & $"$ & $\mathrm{a}, \mathrm{e}$ \\
\hline 2.76 & 13.1 & Strip & $\mathrm{Cs}$ & 97.4 & (This report) & $b, d$ \\
\hline 2.92 & 42.3 & $"$ & $\mathrm{Tc}$ & 87.6 & LIBERATORE & $b, e$ \\
\hline 3.32 & 38.4 & " & $\mathrm{Cs}$ & 105.8 & (This report) & b. c, d \\
\hline 3.35 & 36.5 & Extraction & Tc & 99.6 & LIBERATORE & $\mathrm{a}, \mathrm{e}$ \\
\hline 5.85 & 22.3 & Scrub & $\mathrm{Cs}$ & 82.6 & (This report) & $b, d$ \\
\hline 6.10 & 11.8 & " & $"$ & 79.2 & $"$ & b. d \\
\hline
\end{tabular}

a. Alkaline-side operation.

b. Acid-side operation.

c. Not included in the correlation because stage efficiency cannot be greater than $100 \%$.

d. Part of a CSEX test which starts with alkaline-side Cs being extracted by a solvent consisting of $0.01 \mathrm{M}$

BoBCatix C6 and 0.20 M Cs-3 in Isopar L.

e. Part of a SRTALK test which starts with alkaline-side Tc being extracted by a solvent consisting of $0.04 \underline{\mathrm{M}} \mathrm{CE}$ and

$1.8 \mathrm{M}$ TBP in Isopar L.

f. Part of a TRUEX test which starts with acid-side Am being extracted by a solvent consisting of 0.2 M CMPO and 1.4

M TBP in nDD. 


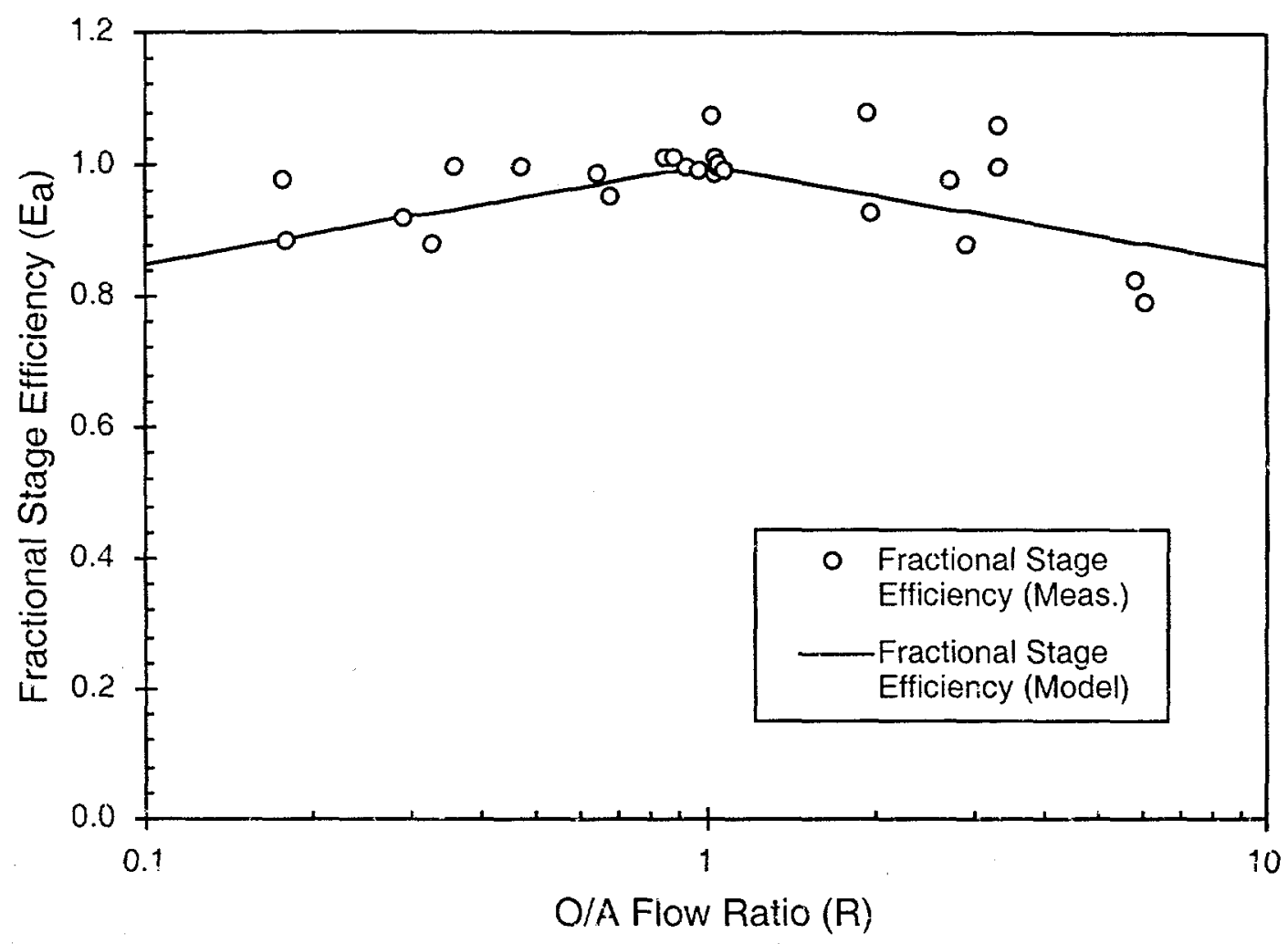

Fig. C-1. Correiation of Extraction Efficiency with O/A Flow Ratio in Single-Stage 2-crn Contactors

\section{Multistage}

To determine the expected extraction efficiency in multistage operation of the centrifugal contactor, the limited data available were reviewed. The results, summarized in Table $\mathrm{C}-3$, show that stage efficiency is greater than $90 \%$ for units that are $4-\mathrm{cm}$ and larger. For the 2-cm multistage contactor, stage efficiencies range between 60 and $91 \%$. For the multistage 2 -cm units, which have an effective slope in the interstage lines of only 10 to $15^{\circ}$, a problem with interstage flow occurs at flow rates up to 50 to $100 \mathrm{~mL} / \mathrm{min}$. As with single-stage $2-\mathrm{cm}$ contactor operation, this problem generally becomes worse as the O/A flow ratio moves away from 1.0, either above or below it. At these low flow rates, as will be discussed next, the problem reduces the apparent stage efficiency, even though the actual stage efficiency remains high. This interstage flow problem disappears at the larger flow rates used in larger multistage centrifugal contactors, and so, the extraction efficiency for multistage plant-scale centrifugal contactors should be very close to $100 \%$. This is indeed the case for the $4-$ and $25-\mathrm{cm}$ contactor results in Table C-3. 
Table C-3. Summary of Extraction Efficiency in Multistage Centrifugal Contactors

\begin{tabular}{|c|c|c|c|c|c|c|c|c|}
\hline $\begin{array}{c}\text { Rotor } \\
\text { Dia., cm }\end{array}$ & $\begin{array}{l}\text { Nom. } \\
\text { Thruput, } \\
\text { L/min }\end{array}$ & $\begin{array}{c}\text { Type of } \\
\text { Operation }\end{array}$ & $\begin{array}{c}\text { Component } \\
\text { Extracted or } \\
\text { Stripped }\end{array}$ & $\begin{array}{c}\text { O/A Flow } \\
\text { Ratio }\end{array}$ & $\begin{array}{l}\text { No. of } \\
\text { Stages }\end{array}$ & $\begin{array}{c}\text { Stage Eff., } \\
\%\end{array}$ & Ref. & Notes \\
\hline 2 & 0.04 & Extraction & $\mathrm{U}$ & 2.6 & 6 & $85 \pm 2$ & LEONARD- 1980 & $a \cdot b$ \\
\hline$"$ & " & Strip & $\bar{U}$ & 0.9 & 8 & $85 \pm 15$ & " & $a, b$ \\
\hline$"$ & $"$ & Extraction & $\mathrm{Sr}$ & 0.2 & 10 & 60 & LEONARD- 1997 & c \\
\hline$"$ & $"$ & $"$ & $\mathrm{Sr}$ & 1.0 & 10 & 91 & LAW-1997 & c \\
\hline$"$ & $"$ & $"$ & $\mathrm{Cs}$ & $0.3 \pm 0.1$ & 10 & $71 \pm 9$ & (This report) & $\mathrm{c}$ \\
\hline$"$ & $"$ & Strip & $\overline{C s}$ & $2.5 \pm 0.2$ & 11 & $69 \pm 1$ & " & $\mathrm{c}$ \\
\hline$"$ & $"$ & Extraction & $\mathrm{Sr}$ & 1.0 & 10 & $66 \pm 6$ & LAW-1999 & $\mathrm{c}$ \\
\hline " & $"$ & $"$ & $\mathrm{Tc}$ & 0.3 & 5 & 68 & LEONARD-1999B & c \\
\hline$"$ & $"$ & Strip & $\mathrm{Tc}$ & 0.3 & 4 & $88 \pm 4$ & 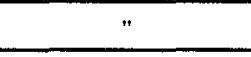 & $c$ \\
\hline 4 & 0.6 & Extraction & $\mathrm{U}$ & 0.5 & 4 & $91 \pm 1$ & LEONARD-1982 & d \\
\hline$"$ & $"$ & $"$ & $\underline{\mathrm{U}}$ & 0.5 & 4 & $100 \pm 1$ & - & $e$ \\
\hline 25 & 120 & Extraction & $\mathrm{U}$ & $2.5(\mathrm{f})$ & 10 & 100 & WEBSTER & $\mathrm{g}$ \\
\hline$"$ & $"$ & Strip & $\mathrm{U}$ & $1.0(f)$ & N.A. (h) & 95 & $"$ & $\mathrm{~g}$ \\
\hline
\end{tabular}

a. Stage efficiency is suspeci as $D(U)$ values were obtained from data correlation rather than measured

b. Origina! 2-cm dissign at ANL.

c. Revised 2-cm design at ANL.

d. Single-stage test done at the same time gave stage efficiency of $92 \% \pm 1 \%$.

e. Single-stage test done ai the same time gave stage efficiency of $98 \% \pm 1 \%$.

f. Not specified. This flow ratio is based on the Purex flowsheet in [SIDDALL].

g. Original $25-\mathrm{cm}$ centrifugal contactor design at SRS with paddle mixer under the rotor used in place of annular mixer around the rotor.

h. Not available. Would expect it to be $12 \pm 6$ contactor stages.

A flow problem develops in both single-stage and multistage $2-\mathrm{cm}$ contactor at low flow rates. However, because the effective slope of the interstage lines is only 10 to $15^{\circ}$ in the multistage tests, not liquid being pumped to a straight down $\left(90^{\circ}\right)$ slope as in the single-stage tests, the problem cccurs up to flow rates of 50 to $100 \mathrm{~mL} / \mathrm{min}$. At these low flow rates, the surface tension forces can be greater than the inertial forces. When this happens, the liquid emerges erratically from the exit port of one stage and flows through the interstage line as a slug. Since the interstage lines of the 2-cm contactor are made of translucent fluorocarbon tubing (Teflon PFA), which has an inside diameter of $5 / 16$ in. $(0.8 \mathrm{~cm})$, these liquid slugs can be seen fairly well. For example, at $32 \mathrm{~mL} / \mathrm{min}$, aqueous phase moves through the interstage lines of the 2-cm contactor in slugs, which have an average period of $10 \pm 9 \mathrm{~s}$. The period between consecutive slugs is 1 to 25 s. A rivulet of liquid follows a slug for up to several seconds. Then, surface tension forces collapse off the rivulet, and no further flow occurs until the next slug. As noted above, the residence time in the mixing zone of the contactor is typically in the range from 1 to $5 \mathrm{~s}$, so that any slugging of liquid between stages will degrade the stage efficiency. At higher flow rates in the 100 to $200 \mathrm{~mL} / \mathrm{min}$ range, the inertial forces override the surface tension forces, and the aqueous liquid 
flows smoothly from stage to stage. This can be seen clearly in a close-up video of liquid flowing through glass interstage lines of a 4-cm contactor [LEONARD-1985]. Note that the slugging of the interstage liquid in the $2-\mathrm{cm}$ contactor is less pronounced in the organic interstage lines since the organic phase wets the Teflon interstage line better. Overall, as seen in Table C-3, stage efficiency in multistage operation is degraded when interstage flow is low, as was the case in the 2cm contactor.

To quantify the effect of low flow rate on the operation of multistage 2 -cm centrifugal contactors, experimental stage efficiencies for various $\mathrm{O} / \mathrm{A}$ flow ratios were collected and are listed in Table C-4. A least-squares fit of these data using Eq. C-1 gives correlation coefficients of 0.80 for $a$ and 0.17 for $b$ :

$$
\mathrm{E}_{\mathrm{a}}=0.80-\left(0.17\left|\log _{10} \mathrm{R}\right|\right)
$$

A plot of the data and the curve represented by Eq. C-3 is given in Fig. C-2. As with the single-stage $2-\mathrm{cm}$ contactors, the results show a continuing decrease in the apparent stage efficiency as the $\mathrm{O} / \mathrm{A}$ flow ratio moves away from 1.0, This finding suggests that the observed liquid slugs lower the apparent (or overall) stage efficiency, and that this effect becomes more pronounced as the flow rate of either phase drops. The correlation given by Eq. C-3 can be used to estimate stage efficiency for 2 -cm tests when experimental data are not available. As shown by the data scatter in Fig. C-2, this estimate is a rough first approximation. Note that all the fractional stage cfficiencies for the 2-cm multistage tests lie between 0.60 and 0.91 . 
Table C-4. Effect of O/A Flow Ratio on Extraction Efficiency in Multistage 2-cm Contactors

\begin{tabular}{|c|c|c|c|c|c|c|c|}
\hline $\begin{array}{l}\text { OiA } \\
\text { Flow } \\
\text { Ratio }\end{array}$ & $\begin{array}{l}\text { Total } \\
\text { Thruput, } \\
\mathrm{mL} / \mathrm{min}\end{array}$ & $\begin{array}{l}\text { No. of } \\
\text { Stages }\end{array}$ & $\begin{array}{c}\text { Type of } \\
\text { Operation }\end{array}$ & $\begin{array}{c}\text { Component } \\
\text { Extracted or } \\
\text { Stripped }\end{array}$ & Stage Eff., \% & Reference & Notes \\
\hline 0.165 & 32.4 & 10 & Extraction & $\mathrm{Sr}$ & 60 & LEONARD-1997 & $b, d, f$ \\
\hline 0.195 & 31.9 & 10 & $"$ & $\mathrm{Cs}$ & 80 & (This report) & $\mathrm{a}, \mathrm{d}, \mathrm{g}$ \\
\hline 0.255 & 34.0 & 10 & $"$ & $"$ & 62 & $"$ & a, d, g \\
\hline 0.320 & 33.0 & 5 & $"$ & $\mathrm{Tc}$ & 68 & LEONARD-1999B & $a, d, h$ \\
\hline 0.332 & 39.3 & 4 & Strip & $"$ & $88.5 \pm 3.5$ & $"$ & $\mathrm{~b}, \mathrm{~d}, \mathrm{~h}$ \\
\hline 0.432 & 31.5 & 10 & Extraction & $\mathrm{Cs}$ & 71 & (This report) & $\mathrm{a}, \mathrm{d}, \mathrm{g}$ \\
\hline 0.87 & 84.2 & 8 & Strip & $\mathrm{U}$ & $85 \pm 15$ & LEONARD- 1980 & $b, c, e, i$ \\
\hline 1.00 & 15.2 & 10 & Extraction & $\mathrm{Sr}$ & $66 \pm 6$ & LAW-1999 & $\mathrm{b}, \mathrm{d}, \mathrm{k}$ \\
\hline 1.05 & 16.0 & 10 & Extraction & $\mathrm{Sr}_{\mathrm{r}}$ & 91 & LAW-1997 & $b, d, j$ \\
\hline 2.36 & 7.4 & 11 & Strip & $\mathrm{Cs}$ & 63 & (This report) & $\mathrm{b}, \mathrm{d}, \mathrm{g}$ \\
\hline 2.74 & 9.4 & 11 & $"$ & $"$ & 61 & $"$ & $\mathrm{~b}, \mathrm{~d}, \mathrm{~g}$ \\
\hline 2.63 & 97.4 & 6 & Extraction & $\mathrm{U}$ & $85 \pm 2$ & LEONARD-1980 & $b, c, e, i$ \\
\hline
\end{tabular}

a. Alkaline-side operation.

b. Acid-side operation.

c. Original 2-cm design at ANL.

d. Revised 2-cm design at ANL.

e. Stage efficiency is suspect as $D(U)$ values were obtairied from data correlation rather than measured.

f. Part of a SREX test which starts with acid-side S: being extracted by a solvent consisting of $0.10 \mathrm{M}$ CE in 1 -octanol.

g. Part of a CSEX test which starts with alkaline-side $\mathrm{C}$ s being extracted by a solvent consisting of $0.01 \underline{\mathrm{M}}$

BoBCalixC6 and $0.20 \mathrm{M} \mathrm{Cs-3}$ in isupar $\mathrm{L}$.

h. Part of a SRTALK test which starts witi alkaline-side Tc being extracted by a solvent consisting of $0.04 \underline{\mathrm{M}} \mathrm{CE}$ and 1.8 $\mathrm{M}$ TBP in Isopar $\mathrm{L}$

i. Part of a PUREX test which starts with acid-side U being extracted by a solvent consisting of $30 \%$ TBP in nDD.

j. Part c f a SREX test which starts with acid-side Sr being extracted by a solvent consisting of $0.15 \underline{\mathrm{M}} \mathrm{CE}$ and $1.2 \underline{\mathrm{M}}$

TBP in Isopar L. The aqueous feed was actual dissolved zirconium calcine from the Idaho National Engineering and

Environmental Laboratory (INEEL).

k. Part of a SREX test which starts with acid-side Sr being extracted by a solvent consisting of $0.15 \underline{\mathrm{M}} \mathrm{CE}$ and $1.5 \underline{\mathrm{M}}$

TBP in Isopar $L$. The aqueous feed was actual INEEL sodium-bearing waste. 


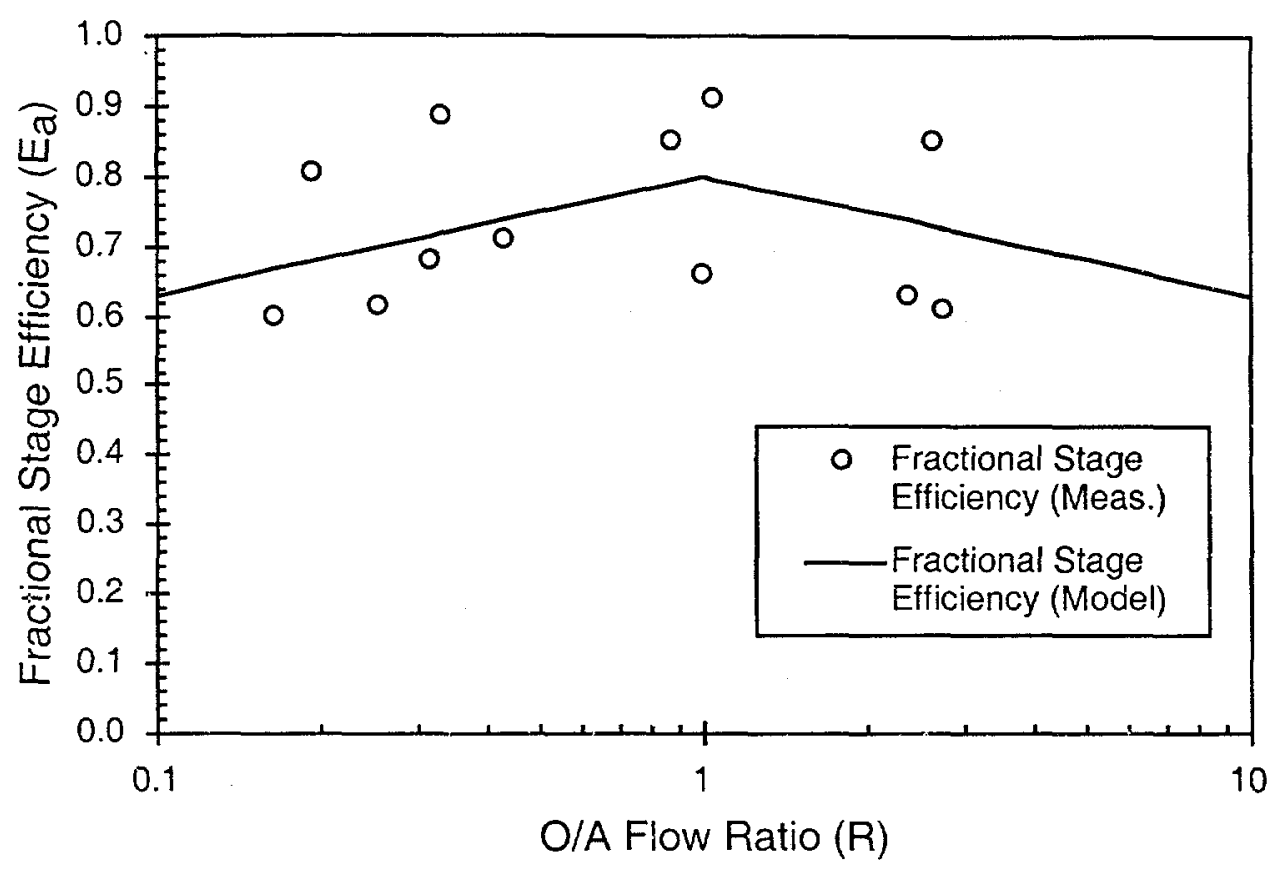

Fig. C-2. Correlation of Extraction Efficiency with O/A Flow Ratio in Multistage 2-cm Contactors

As noted for single-stage contactor operation, slug flow is nor a problem at high flow rates. Thus, in the 4-cm unit, where each flow is typically greater than $100 \mathrm{~mL} / \mathrm{min}$, the stage efficiencies for single-stage and muitistage tests are essentially identical (see Table C-3 and footnotes d and e there). Although there are only limited data for larger units, that is, the $25-\mathrm{cm}$ contactors in Table $\mathrm{C}-2$, the same behavior occurs in this case. Thus, if interstage flows for centrifugal contactors are above 100 to $200 \mathrm{~mL} / \mathrm{min}$, the rule-of-thumb (that each stage has essentially $100 \%$ stage efficiency whether it is used alone or is in a multistage operation) should apply.

\section{HYDRAULIC PERFORMANCE}

Good hydraulic performance of a contactor stage or stages occurs if the aqueous and organic phases are mixed well, flow into the rotor smoothly, flow out their respective stage exit ports with less than $1 \%$ other-phase carryover, and flow smoothly in the interstage lines between stages. As mentioned above, the 2-cm contactor has a problem because the flow rate in the interstage lines is low (below 100 to $200 \mathrm{~mL} / \mathrm{min}$ ) so that slug flow occurs, especially in the aqueous interstage lines. A second problem for the 2-cm contactor in the alkaline-side CSEX tests has been a resistance to phase inversion, that is, switching from aqueous-continuous to organiccontinuous operation (see the main body of this report). When this occurs, the dispersion in the mixing zone can no longer flow smoothly into the rotor. Instead, the dispersion backs up into the upper portion of the annular mixing zone and eventually overflows. This overflow liquid appears either at the liquid standpipe or at the lower (organic) exit port of the contactor stage. This phase inversion problem occurred only at high O/A flow ratios $(>1.0)$ for highly alkaline solutions such as the simulated tank waste feed. 
This phase-inversion problem had been seen earlier with the Purex process in the original 2-cm design at ANL [LEONARD-1980]. To avoid this problem with the Purex solvent, we initially went to a $4-\mathrm{cm}$ contactor. This solved the phase inversion problem. It was not a problem in the 9-, 12-, or 25-cm contactors either. The current $2-\mathrm{cm}$ contactor has a revised design that eliminated phase inversion problems with the Purex solvent by using a longer rotor and a smaller annular gap in the mixing zone [LEONARD-1997]. Based on our experience with the Purex solvent, we expect that the current phase inversion problem will also be limited to the $2-\mathrm{cm}$ contactor. When it did occur in a 2-cm contactor stage, turning off the rotor motor for $5 \mathrm{~s}$ (or as long as it takes for the rotor to stop) and then restarting it w'ould usually correct the problem. Nonetheless, this problem should not exist at all in larger units.

In general, if a single-stage contactor can operate at all $\mathrm{O} / \mathrm{A}$ flow ratios for the liquid pair found in each section of the solvent extraction process, it should have stable hydraulic performance that will not be degraded by process upsets. For the $4-\mathrm{cm}$ contactor tests, the hydraulic performance of the multistage unit was tested in addition to the stage efficiency. It was found that the hydraulic performance of the multistage unit was identical to that of a single-stage unit. Thus, it appears that the corollary rule-of-thumb (that each stage has the same hydraulic performance whether it is used alone or is in a multistage operation) is valid as long as the diameter of the centrifugal contactor rotor is $4 \mathrm{~cm}$ or larger.

\section{DISCUSSION}

Althougin the 4-cm unit works better than the $2-\mathrm{cm}$ unit, the latter is advantagecus for two reasons. First. the $2-\mathrm{cm}$ unit takes up less space than the $4-\mathrm{cm}$ unit. Second, and usually most important, the feed volumes required for the 2 -cm unit are 15 times less than those for the $4-\mathrm{cm}$ unit, that is, feed volumes or the order of 1 to $2 \mathrm{~L}$ are required for the $2-\mathrm{cm}$ unit instead of the 15 to $30 \mathrm{~L}$ required for the $4-\mathrm{cm}$ unit. In addition, because the 2 -cm contactor brings out mass transfer and hydraulic performance problems, a solvent extraction process that can run there should run easily in larger units.

Slug flow of the liquid in the interstage line occurs when the surface tension forces are greater than the inertial forces (momentum). Under such conditions, the continuous flow of liquid breaks up into discrete slugs. To predict when the slug flow will occur, the data were analyzed using the dimensionless Weber number $\left(\mathrm{N}_{\mathrm{we}_{\mathrm{c}}}\right)$, which is the ratio of the inertial force divided by the surface tension force. The Weber number for the interstage flow is given as

$$
N_{w_{e}}=V^{2} \cdot D \cdot \rho / \gamma
$$

where $\mathrm{V}$ is the average velocity of the flowing interstage liquid, $\mathrm{D}$ is the diameter of the flowing interstage stream or rivulet, $\rho$ is the density of the interstage liquid, and $\gamma$ is the surface tension of the interstage liquid. An estimate of the Weber number is given in Table C-5 for typical liquid flows in different sizes of centrifugal contactor. As this table shows, the Weber number is less than 1.0 for the $2-\mathrm{cm}$ contactor, where slug flow is observed in the interstage line, and greater than 
1.0 for typical 4-cm contactor (and larger units) flows, where continuous flow is observed in the interstage line.

Table C-5. Estimate of Weber Number for Interstage Flow in Various Centrifugal Contactors

\begin{tabular}{|l|c|c|c|c|c|}
\hline \multicolumn{1}{|c|}{ Rotor diameter, cm } & 2 & 4 & 4 & 10 & 25 \\
\hline Volumetric flow rate (each phase), mL/min & 20 & 100 & 300 & 6,000 & 60,000 \\
\hline Evaluation of flow rates & Normal & Low & Normal & Normal & Normal \\
\hline Surface tension for aqueous phase, dynes/cm & 70 & 70 & 70 & 70 & 70 \\
\hline Surface tension for organic phase, dynes/crm & 30 & 30 & 30 & 30 & 30 \\
\hline Diameter of interstage tube, in. & 0.313 & 0.438 & 0.438 & 0.875 & 2.63 \\
\hline Diameter of rivulet (estimated). in. & 012 & 0.15 & 0.18 & 0.33 & 1 \\
\hline Ratio of rivulet to tube diameter & 0.38 & 0.34 & 0.41 & 0.38 & 0.38 \\
\hline Height of aqueous-phase liquid drop between stages, in. & 1.063 & 1.75 & 1.75 & 4.25 & 8 \\
\hline Height of organic-phase liquid drop between stages, in. & 0.688 & 1.125 & 1.125 & 3 & 4.5 \\
\hline Density of aqueous phase. g/L. & 1.000 & 1.000 & 1,000 & 1.000 & 1.000 \\
\hline Density of organic phase, g/L & 800 & 800 & 800 & 800 & 800 \\
\hline Velocity of interstage rivulet, m/s & 0.046 & 0.146 & 0.30 & 1.81 & 1.97 \\
\hline Estimate of Weber rumber fcr aqueous phase & 0.091 & 1.16 & 6.1 & 390 & 1.410 \\
\hline Estimate of Weber number fur organic phase & 0.170 & 2.2 & 11.3 & 730 & 2.600 \\
\hline
\end{tabular}

The Weber number analysis of interstage flow gives a rule-of-thumb that can be used to estimate when slug flow will occur. It should be used with caution as it makes two important simplifications. The first simplification assumes that the liquid does not wet the wall of the interstage line. If the liquid does wet the interstage wall, the liquid flowing in the interstage line will not break up into slugs. Note that if the interstage flow for one phase is sluggish, it does not matter much if the flow of the other phase is smooth. However, if the slugging flow has the lower flow rate, one might expect both the data scatter and the decrease in the extraction efficiency to be greater. For the $2-\mathrm{cm}$ centrifugal contactor results discussed here, the aqueous phase does not wet the interstage tubes while the organic phase does. Thus, at high O/A flow ratios, one would expect the data scatter to be greater and the extraction efficiency to be lower. An examination of the data in Figs. C-1 and C-2 gives a hint of such a trend.

The second simplification of this Weber number analysis is the assumption that one is dealing with the liquid as it moves through the interstage line, not as it exits from the collector ring in the contactor stage into the interstage line. In small contactors, for example, the 2 -cm contactor, the inertial force (momentum) of the liquid thrown from the spinning rotor is dissipated in the collector ring. When this happens, gravity forces balance surface tension forces as the liquid leaves horizontally from the collector ring and enters the level tube that leads to the interstage line. When the mass of liquid accumulating in the collector ring is great enough, gravity forces overwhelm surface tension forces and a slug of liquid exits from the collector ring exit tube. In 
this way, even liquids that wet the wall of the interstage line can exhibit a form of slug flow. In larger contactors, if the flows are high enough $(>100 \mathrm{~mL} / \mathrm{min}$ ), the inertial force (momentum) of the liquid thrown from the spinning rotor is not dissipated in the collector ring. As a result, the fluid momentum carries the liquid out of the collector ring, through the level exit tube, into the interstage line, and onto the next contactor stage with smooth interstage flow. In this situation, gravity forces and surface tension forces can be neglected as too small to be important. Thus, in plant-scale centrifugal contactors, the momentum of the liquid as it is spun from the rotor will carry the liquid out of the collector ring, through the level exit tube, and through the sloped interstage line to the next stage in a smooth continuous flow. For this reason, the exit tube from the collector ring is attached tangentially to the ring so that the momentum of the liquid in the collector ring drives the liquid into the exit tube.

\section{CONCLUSIONS}

Based on this analysis of data on centrifugal contactor operation, properly designed larger plant-scale contactors with rotor diameters of $4,9,12$, and $25 \mathrm{~cm}$ should have stage efficiencies close to $100 \%$ for both single-stage and multistage units. In addition, the hydraulic performance of these contactors should also be excellent. Because the small throughput of the 2-cm contactor brings out problems with bcih mass transter (stage efficiencies of 60 to $90 \%$ in multistage units) and hydraulic performance (phase inversion problems in the mixing zone and intermittent flow ir: the interstage lines), any solvent extraction process that can be run there wil! run even better in larger units. 


\section{REFERENCES}

\section{BEBBINGTON}

W. P. Bebbington, "The Reprocessing of Nuclear Fuels," Sci. Am. 235 (6), 30-41 (1976).

BERNSTEIN-1973A

G. J. Bernstein, D. E. Grosvenor, J. F. Lenc, and N. M. Levitz, "A High-Capacity Annular Centrifugal Contactor," Nucl. Technol. 20, 200-202 (1973).

BERNSTEIN-1973B

G. J. Bernstein, D. E. Grosvenor, J. F. Lenc, and N. M. Levitz, Development and Performance of a High-Speed Annular Centrifugal Contactor, Argonne National Laboratory Report ANL-7969 (1973).

\section{BONNESEN}

P. V. Bonmesen, L. H. Delmau, T. J. Haverlock, and B. A. Moyer, Alkaline-Side Extraction of Cesium from Savannah River Tank Waste Using a Calixarene-Crown Ether Extractcint, Oak Ridge National Laboratory Report ORNL/TM-13704 (1998).

LAW-1997

I. D. Law, D. J. Wond, L. G. Olson, T. A. Todd, Demonstration of a SREX Flowsheet for the Partitioning of Stronitum and Lead from Actual ICPP Sodium-Bearing Waste, Idaho National Engineering and Environmental Laboratory Report INEEL/EXT-97-00832 (August 1997).

LAW-1999

J. D. Law, D. J. Wood, and T. A. Todd, Development of a SREX Flowsheet for the Separation of Strontium from Dissolved INEEL Zirconium Calcine, Idaho National Engineering and Environmental Laboratory Report INEEL/EXT-99-00001 (January 1999).

LEONARD-1980

R. A. Leonard, G. J. Bernstein, A. A. Ziegler, and R. H. Pelto, "Annular Centrifugal Contactors for Solvent Extraction," Sep. Sci. Technol. 15 (4), 925-943 (1980).

LEONARD-1981

R. A. Leonard, G. J. Bernstein, R. H. Pelto, and A. A. Ziegler, unpublished document, Argonne National Laboratory (July 1981).

LEONARD-1982

R. A. Leonard and M. J. Steindler, unpublished document, Argonne National Laboratory (June 1982).

LEONARD-1985

R. A. Leonard, "Annular Centrifugal Contactors for Solvent Extraction," Argonne National Laboratory movie/video no. 85-805-FTM-001 DUB (November 1985).

LEONARD-1988

R. A. Leonard, "Recent Advances in Centrifugal Contactor Design," Sep. Sci. Technol. 23 (12-13), 1473-1487 (1988).

LEONARD-1992

R. A. Leonard, D. B. Chamberlain, L. S. Chow, J. K. Basco, T. R. Johnson, F. C. Mrazek, M. O. Wasserman, and D. G. Wygmans, "Centrifugal Contactor Development," in M. J. Steindler et al., Nuclear Technology Programs Semiannual Progress Report, October 1989-March 1990, Argonne National Laboratory Report ANL-91/42, pp. 135-141 (1992). 
LEONARD-1993

R. A. Leonard, D. G. Wygmans, M. J. McElwee, M. O. Wasserman, and G. F. Vandegrift, "The Centrifugal Contactor as a Concentrator for Solvent Extraction Processes," Sep. Sci. Technol. 28 (1-3), 177-200 (1993).

LEONARD-1994

R. A. Leonard and M. C. Regalbuto, "A Spreadsheet Algorithm for Stagewise Solvent Extraction," Sol. Extr. and Ion Exch. 12 (5), 909-930 (1994).

LEONARD-1995

R. A. Leonard, "Solvent Characterization Using the Dispersion Number," Sep. Sci. Technol. 30 (7-9), 1103-1122 (1995).

LEONARD-1997

R. A. Leonard, D. B. Chamberlain, and C. Conner, "Centrifugal Contactors for

Laboratory-Scale Solvent Extraction Tests," Sep. Sci. Technol. 32 (1-4), 193-210 (1997).

LEONARD-1999A

R. A. Leonard, "Design Rules for Solvent Extraction," Sol. Extr. and Ion Exch., 17 (3), 597-612 (1999).

LEONARD-1999B

R. A. Leonard, C. Conner, M. W. Liberatore, P. V. Bonnesen, D. J. Presley, B. A. Moyer, and G. J. Lumetta, "Developing and Testing an Alkaline-side Solvent Extraction Process for Technetium Separation from Tank Waste," Sep. Sci. Technol. 34 (6-7), 1043-1068 (1999).

LIEERATORE

M. W. Liberatore, C. J. Conner, and R. A. Leonard, unpublished data, Argonne National Laboratory (August 1997).

MOYER

B. A. Moyer, Oak Ridge National Laboratory, private communication, February 11, 1999.

SIDDALI.

T. H. Siddall, III, " Solvent Extraction Processes based on Tri-n-butyl Phosphate," in Chemical Processing of Reactor Fuels, ed., J. F. Flagg, Academic Press, New York, pp. 199-248 (1961).

WEBSTER

D. S. Webster, A. S. Jennings, A. A. Kishbaugh, and H. K. Bethmann, "Performance of Centrifugal Mixer-Settler in the Reprocessing of Nuclear Fuel," in W. A. Rodger and D. E. Ferguson, editors, Recent Advances in Reprocessing of Irradiated Fuel, Nuclear Engineering--Part XX, American Institute of Chemical Engineers, New York, Chem. Eng. Prog. Symp. Ser., No. 94, Vol. 65, pp. $70-77$ (1969). 
Distribution for ANL-99/14

Internal:

S. B. Aase

M. L. Dietz

K. L. Nash

J. P. Ackerman (2)

R. E. Einziger

J. Sedlet

D. B. Chamberlain

J. E. Harmon

M. J. Steindler

Y. I. Chang

R. A. Leonard (10)

C. Conner

C. J. Mertz

G. F. Vandegrift

TIS Files

External:

DOE-OSTI (2)

ANL-E Library

ANL-W Library

Chemical Technology Division Review Committee Members:

H. U. Anderson, University of Missouri-Rolla, Rolla, MO

E. R. Beaver, Monsanto Company, St. Louis, MO

A. L. Bement, Purdue University, West Lafayette, IN

M. V. Koch, University of Washington, Seattle, WA

R. A. Osteryoung, North Carolina State University, Raleigh, NC

V. P. Roan, University of Florida, Palm Beach Gardens, FL

G. R. St. Pierre, Ohio State University, Columbus, OH

J. N. Appel, Lockheed Martin Corporation, Richland, WA

W. D. Bond, Oak Ridge National Laboratory, Oak Ridge, TN

P. V. Bonnesen, Oak Ridge National Laboratory, Oak Ridge, TN

J. T. Carter, Savannah River Technical Center, Aiken, SC

J. T. Case, USDOE, Idaho Falls, ID

P. Colton, Pacific Northwest National Laboratory, Richland, WA

L. H. Delmau, Oak Ridge National Laboratory, Oak Ridge, TN

M. Dinehart, Los Alamos National Laboratory, Los Alamos, NM

S. D. Fink, Savannah River Technical Center, Aiken, SC

J. G. H. Getting, Pacific Northwest National Laboratory, Richland, WA

A. P. Gouge, Savannah River Technical Center, Aiken, SC

V. Halter, Los Alamos National Laboratory, Los Alamos, NM

R. Herbst, Idaho National Engineering and Environmental Laboratory, Idaho Falls, ID

M. E. Hodges, Savannah River Technical Center, Aiken, SC

J. O. Honeymann, Lockheed Martin Corporation, Richland, WA

E. P. Horwitz, Eichrom Industries, Darien, IL

P. Hudson, Savannah River Technical Center, Aiken, SC

L. J. Jardine, Lawrence Livermore National Laboratory, Livermore, CA

R. T. Jubin, Oak Ridge National Laboratory, Oak Ridge, TN

D. E. Kurath, Pacific Northwest National Laboratory, Richland, WA

J. D. Law, Idaho National Engineering and Environmental Laboratory, Idaho Falls, ID

G. J. Lumetta, Pacific Northwest National Laboratory, Richland, WA

C. P. McGinnis, Oak Ridge National Laboratory, Oak Ridge, TN

B. A. Moyer, Oak Ridge National Laboratory, Oak Ridge, TN 
A. L. Olson, Idaho National Engineering and Environmental Laboratory, Idaho Falls, ID M. J. Palmer, Los Alamos National Laboratory, Los Alamos, NM

L. M. Papouchado, Savannah River Technical Center, Aiken, SC

R. A. Peterson, Savannah River Technical Center, Aiken, SC

G. Pfennigworth, Martin Marietta Energy Systems, Inc., Oak Ridge, TN

S. F. Piccolo, Savannah River Technical Center, Aiken, SC

K. E. Plummer, Oak Ridge National Laboratory, Oak Ridge, TN

B. M. Rapko, Pacific Northwest National Laboratory, Richland, WA

K. J. Reuter, Savannah River Technical Center, Aiken, SC

R. D. Rogers, University of Alabama, Tuscaloosa, AL

P. Rutland, Savannah River Technical Center, Aiken, SC

R. A. Sachleben, Oak Ridge National Laboratory, Oak Ridge, TN

W. Schulz, Albuquerque, NM

J. L. Swanson, Richland, WA

W. L. Tamosaitis, Savannah River Technical Center, Aiken, SC

I. R. Tasker, Universe Technologies, Frederick, MD

L. L. Tavlarides, Syracuse University, Syracuse, NY

D. W. Tedder, Georgia Institute of Technology, Atlanta, GA

M. Thompson, Savannah River Technical Center, Aiken, SC

T. A. Todd, Lockheed Martin International, Idaho Falls, ID

V. Van Brunt, University of South Carolina, Columbia, SC

J. Watson, Oak Ridge National Laboratory, Oak Ridge, TN

R. M. Wham, Oak Ridge National Laboratory, Oak Ridge, TN

D. J. Wood, Idaho National Engineering and Environmental Laboratory, Idaho Falls, ID 